\title{
ESSAYS ON APPLIED MACROECONOMICS AND MONETARY POLICY
}

A Dissertation

presented to

the Faculty of the Graduate School

at the University of Missouri-Columbia

\author{
In Partial Fulfillment \\ of the Requirements for the Degree \\ Doctor of Philosophy
}

by

SAROJ DHITAL

Dr. Joseph Haslag, Dissertation Supervisor

MAY 2019 
The undersigned, appointed by the dean of the Graduate School, have examined the dissertation entitled

\section{ESSAYS ON APPLIED MACROECONOMICS AND}

\section{MONETARY POLICY}

presented by Saroj Dhital, a candidate for the degree of doctor of philosophy, and hereby certify that, in their opinion, it is worthy of acceptance.

Professor Joe Haslag

Professor Chris Otrok

Professor Chao Gu

Professor Xuemin Yan 


\section{ACKNOWLEDGEMENTS}

This work would not have been possible without the support of the Department of Economics at the University of Missouri - Columbia. I am grateful to all of those with whom I have had the pleasure to work during various projects. Each of the members of my Dissertation Committee, Dr. Joe Haslag, Dr. Chris Otrok, Dr. Chao Gu and Dr. Xuemin Yan, has provided me extensive personal and professional guidance and taught me a great deal about both scientific research and life in general. I would especially like to thank Dr. Joe Haslag, the chairman of my committee. As my teacher and mentor, he has taught me more than I could ever give him credit for here. He has shown me, by his example, what a good researcher (and person) should be.

Nobody has been more important to me in the pursuit of this project than the members of my family. I would like to thank my parents, whose love and guidance are with me in whatever I pursue. They are the ultimate role models. I'd also like to thank my friends who provided love and support, and unending inspiration. 
TABLE OF CONTENTS

ACKNOWLEDGEMENTS.

ii

\section{LIST OF ILLUSTRATION}

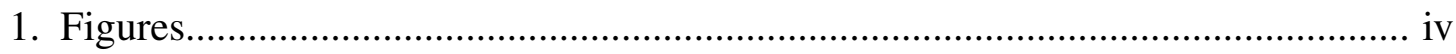

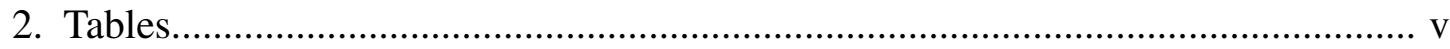

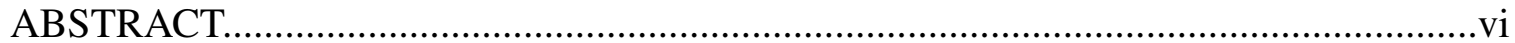

CHAPTER

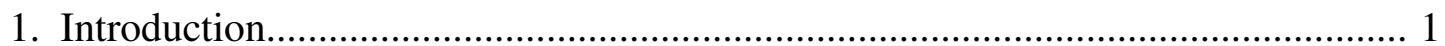

2. Global Financial Cycles and Macroeconomic Linkages.................................... 6

3. Decentralization and Regional Convergence: Evidence From Night-time Lights Data 51

4. Active and Passive Policy Regimes in Economies with Government Debt............ 88

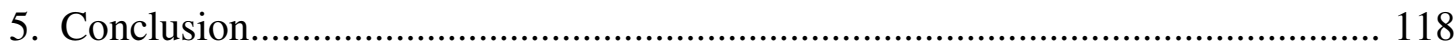

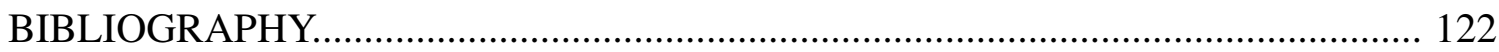

APPENDIX

1. List of Countries Used in Chapter 2 …....................................................... 131

2. List of Countries Used in Chapter 3........................................................ 132

VITA 


\section{LIST OF ILLUSTRATION}

Figure

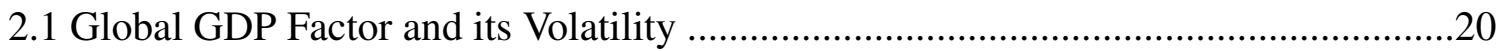

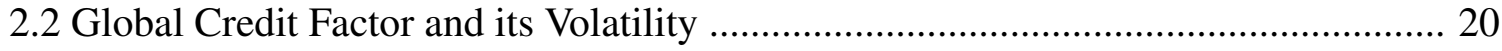

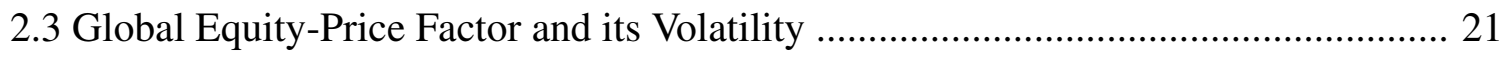

2.4 Global House-Price Factor and its Volatility ..................................................... 21

2.5 Impulse Response of Global GDP factor to Shock in Global Factors of Credit, Equity

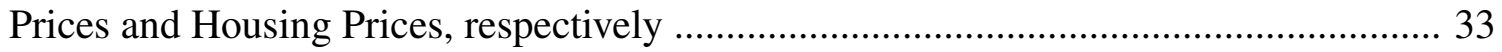

2.6 Impulse Response of Global Investment factor to Shock in Global Factors of Credit, Equity Prices and Housing Prices, respectively .................................................... 34

2.7 Impulse Response of Global Inflation factor to Shock in Global Factors of Credit, Equity Prices and Housing Prices, respectively ............................................................ 35

2.8 Impulse Response of the Global Macroeconomic Factors to the US Financial Shocks 37

2.9 Impulse Response of the Global Macroeconomic Factors to the UK Financial Shocks 38

2.10 Impulse Response of the Global Macroeconomic Factors to the German Financial

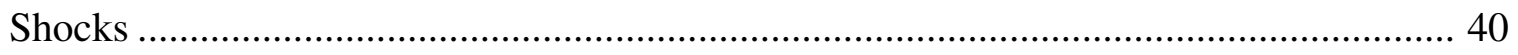

2.11 Volatility of the Estimated Financial Shocks ................................................... 43

2.12 Impulse Response of the Global GDP Factor to the Global Financial Shocks ........ 45

2.13 Effects of the US Financial Shocks on the US GDP Growth ................................ 47

2.14 Effects of the Global Financial Shocks on the Global GDP Factor ........................ 48

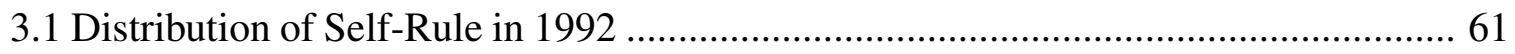

3.2 Within-Country Convergence from 1992 to 2010 around the World ......................... 65

3.3 Convergence Coefficients using Leave-one-out Estimators ................................. 81

4.1 Equilibrium under Monetary Regime ........................................................... 106 
4.2 Equilibrium under Monetary Regime ……………............................................ 108

4.3 Equilibrium under Fiscal Regime ...................................................................... 109

4.4 Equilibrium under Fiscal Regime ……………………................................... 111

4.5 Equilibrium under Fiscal Regime …………….............................................. 112

4.6 Equilibrium Under Fiscal Regime ………………….......................................... 113

4.7 Zero Lower Bounds Under Fiscal Regime ………………………………………... 113

4.8 Evolution of Money Growth Rate ………………........................................... 115

Table Page

2.1 Variance Decomposition of the Financial Variables due to Their Global Factors ...... 26 2.2 Variance Decomposition of the Financial Variables due to Joint Global Financial Factor

2.3 Variance Decomposition of the Financial Variables due to Their Global Factors: 20002013. 28

2.4 Variance Decomposition of the Macroeconomic Variables due to Their Global Factors 30

3.1 Countries with Biggest Change in Self-Rule ....................................................... 61

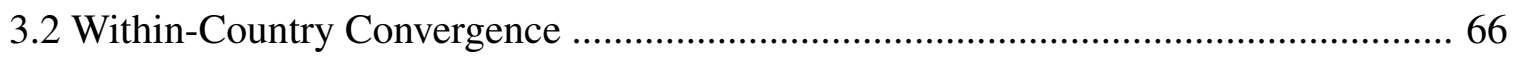

3.3 Decentralization and Within-Country Convergence .................................................... 69

3.4 Components of Decentralization and Within-Country Convergence ……………..... 72

3.5 Decentralization and Within-First-Subnational Region Convergence ........................ 74

3.6 Decentralization and Within-Country Convergence Towards Country Average ........ 77

3.7 Decentralization and Within-Country Convergence ................................................ 79

3.8 Additional Robustness Tests of Within-Country Convergence ……………….......... 83 


\begin{abstract}
The dissertation presents three essays in applied macroeconomics and monetary theory. First essay explores the existence of global financial cycles and examines the relationship between financial and macroeconomic sectors at a global scale. I find that there exist significant cycles in financial variables and the contribution of the financial shocks on global macroeconomic sector is significant and varying over time. Second essay examines the role of decentralization on regional convergence using night-time satellite lights data as proxy for regional economic activities. I find that the decentralization hinders regional convergence in the sample of developing countries. Third essay analyzes active and passive fiscal and monetary policy regime in the presence of long and short-maturity government debt. I utilize the advances made in money search model to analyze the policy regimes. I find that while there are some similarities between the regime, there are also significant differences. I also find that the results using money-search model can be different than using a reduced form models.
\end{abstract}




\section{Chapter 1}

\section{Introduction}

Many major macroeconomic events have occurred in the past two decades, including the Great Recession and the preceding global financial crisis. The financial crisis highlighted some of the shortcomings of the most prominent macroeconomic models. Some of the most prominent DSGE models failed to establish a link between financial and macroeconomic sectors. Financial intermediation was assumed to work efficiently. These limitations were brutally exposed by the financial crisis, as the crisis that initiated in the United States was swiftly spread across financial markets throughout the world, amplifying the global recession. In chapter 2, I attempt to address the issue and provide empirical evidence on the linkages between macroeconomic and financial sectors at a global scale.

In the aftermath of the financial crises, advanced economies saw an unprecedented rise in government debt. However, behavior of fiscal and monetary authorities during the crisis indicate a friction in policy making. Use of long-maturity government debts by both fiscal and monatery authorities were widely popular. Policy prescriptions of the most prominent models that study monetary policy appeared to be inadequate. Also, understanding the role and consequences of fiscal policies in a model where money is essential is largely missing. The observation warrants a study of fiscal and monetary policies ina setting where money 
is essential. I attempt to tackle the issue using in chapter 4.

Another major phenomenon that swept the globe in the past few decades was the decentralization reforms that saw delegation of fiscal and political powers to the local, or regional, governments. Decentralization has been at the center of institutional reforms not only in developed countries, but also in many developing and transition economies around the world. Primary stated objectives of decentralization reform is to improve economic growth and promote regional convergence. The theoretical prediction in the extant literature on whether decentralization promotes or hinders convergence is ambiguous. On the empirical front, quantifying the impact of decentralization from actual country experience has proved elusive due to lack of comparable data, especially in the developing countries. In chapter 3, I attempt to address the issue using satellite night-time lights data as proxy for regional economic activity.

This dissertation proposal consists of three essays in applied macroeconomics and monetary theory to address the concerns discussed above. First essay explores the existence of global financial cycles and examines the relationship between financial and macroeconomic sectors at a global scale. Second essay examines the role of decentralization on regional convergence using night-time satellite lights data as proxy for regional economic activities. Third essay analyzes the joint optimal fiscal and monetary policy when policy makers cannot commit to the future policies. I utilize the advances made in money search model to analyze the joint optimal policy.

Chapter 2 examines the time-varying linkages between the global financial and macroeconomic sectors. First, I examine the existence of global financial cycles. Second, I study if the financial sector is an important source of shocks for the global macroeconomic sector, and if there is time variation in the contribution of the financial shocks. I find evidence of quantitatively meaningful global cycles in credit and equity price. There is large degree of heterogeneity on the impact of the global factors across countries. The cycles are stronger 
in the years leading up to and following the crisis, including the house-price cycle. I do not find evidence of quantitatively meaningful joint global financial cycle encompassing all financial variables. I find that both the global and country-specific financial shocks matter in explaining fluctuations in the global cycles of macroeconomic variables. I also find evidence of time variation in the size and the transmission of the financial shocks, especially the equity-price and house-price shocks. There is evidence of increase in transmission of the financial shocks as well as increase in size of the shocks during financial crises, especially during the recent financial crisis. The contribution of the global and the US equity-price and house-price shocks increases significantly during the recent financial crisis.

Chapter 3 attempts to understand how decentralization reform affects regional convergence using a global sample of countries. Proponents of decentralization argue that it improves economic growth by increasing government efficiency and accountability, while critics argue that it increases regional inequality as limited state capacity and weaker endowments in poorer regions inhibit their growth. The empirical evidence is mixed and is based mostly on developed countries, due to lack of sub-national level data. This chapter aims to fill that gap by analyzing the impact of decentralization on regional convergence using sub-national level data from a global sample of developed and developing countries. Iconstruct a panel of sub-national dataset from 1992 to 2013 by using intensity of nighttime lights captured by U.S. Air Force satellites to proxy for local economic performance. I combine lights data with a new database of fiscal, political, and administrative decentralization derived from actual laws that are institutionalized and circumscribed. The use of night-time lights data allows me to cover a large number of developing countries in my sample, which was not possible before. The use of the new decentralization data provides a broader measure of decentralization as it allows us to study a wide range of fiscal, political and administrative authority of sub-national regions. I study within-country as well 
as within first sub-national level convergence and find that decentralization hinders convergence. The impacts are larger for developing countries.

In chapter 4, I study monetary and fiscal policies in a setting where money is essential, and with private financial intermediaries that facilitate liquidity transformation. In this setting, there's a role for currency and secured credit in the trade for consumption goods due to limited commitment and memory. Government bonds of short (one-period) and long (perpetuity) maturities are present as alternative store of value in the analysis. The government bonds of all maturities serve as pledgeable assets to acquire credit. I study two distinct policy regimes. First, I study a policy regime in which monetary authority actively changes money growth rate while fiscal authority passively adjusts nominal debt holding to keep money-to-debt ratio constant. Taxes adjust passively as well to balance the budget. Second, I study a regime in which fiscal authority actively changes nominal debt holdings and monetary authority passively adjusts money growth rate to keep the money-to-debt ratio constant. Studying different policy regimes allows me to study how different policy changes affect individuals' consumption opportunities differently, as well as difference in determination and evolution of inflation.

I find that the pledgeability of the long-maturity bond must be lower than that of the short-maturity bond and the collateral must be scarce, i. e., the value of aggregate collateral (government bonds) is insufficient to support efficient credit-backed trades. In both fiscal and monetary policy regimes, presence of long-maturity bonds provides unconventional policy tools where policy makers can implement policies that involve long-maturity bonds instead of one-period bonds. This is useful because it allows the policy makers to change term premium without affecting short-term interest rate. It is particularly useful when the policy makers are faced with zero lower bound on short-term interest rate. Policies that result in higher inflation, at a reasonable range, can be welfare improving in both regimes. The difference in two regimes is that the inflation evolves differently. Inflation 
evolves monotonously to policy changes in monetary policy regime, whereas it evolves non-monotonously in the fiscal policy regime. Also, the fiscal authority has an incentive to inflate when the initial level of debt is sufficiently high.

Results such as irrelevance of maturity structure for monetary policy away from zero lower bound reinforces the similar results in studies that use reduced form models. Results also reinforce the notion in fiscal theory of price level that fiscal policy can achieve desired inflation and output. Friedman rule result in Ramsey models and in studies of fiscal theory however is in contrast to the findings of the paper as moving away from Friedman rule is welfare improving when assets used as collaterals are scarce.

Chapter 5 concludes the proposal with a brief summary of the findings and the plan for completing the dissertation. 


\section{Chapter 2}

\section{Global Financial Cycles and}

\section{Macroeconomic Linkages}

\subsection{Introduction}

The Global Financial Crisis that preceded the Great Recession highlighted the linkage between the financial and macroeconomic sectors within and across economies. The most prominent macroeconomic models failed to predict the intensity of the following recession as these models failed to sufficiently establish a link between financial and macroeconomic sectors. Two major identified shortcomings of the models are the failure to sufficiently model financial sector and a possible time-varying relationship between the sectors. ${ }^{1}$ These limitations were brutally exposed by the crisis as the models largely failed to predict the degree of the crisis and the ensuing recession. The crisis that initiated in the United States was swiftly spread across global financial markets, amplifying the global recession. More-

\footnotetext{
${ }^{1}$ The sentiment was expressed by the Vice Chairman of the Federal Reserve Donald Kohn at a Federal Reserve conference in 2009 where he stated: "The various mechanisms that have tended to amplify asset price movements and feedbacks among those movements, credit supply, and economic activity were not well captured by the models used at most central banks." He also identified the need for models to take nonlinearities and tail events into much better account.
} 
over, there was substantial heterogeneity across economies in the effect of the crisis and the ensuing recession, as the level of contraction, timing and duration varied across countries. These observations warrant an analysis to understand global interaction between financial and macroeconomic sectors that account for possible time-varying relationship, especially with rising trade and financial flow between countries.

In this paper, I provide empirical evidence on the time-varying linkage between macroeconomic and financial sectors at a global scale. ${ }^{2}$ Using a setting that addresses time variation and heterogeneity, I ask the following questions. Are there global cycles in financial variables similar to the ones that have been documented for macroeconomic aggregates? ${ }^{3}$ Is the financial sector, both global and country-specific, an important source of shocks for the global macroeconomic sector? If so, are the contributions of the financial shocks varying over time? Is the transmission of the financial shocks, or the size of the shocks, or both, varying over time? Are the effect of the financial shocks different during financial crises, especially the recent financial crisis, compared with during normal times? Can the heterogeneity in the effect of the financial shocks across countries be explained?

In order to address the questions, I begin by examining the existence of global financial cycles and provide empirical characterization of the cycles using a time-varying parameter dynamic factor model (TVP-DFM). I study cycles of credit growth, equity-price growth and house-price growth, as well as a joint financial cycle that encompasses all three financial variables. Use of DFM to characterize financial and macroeconomic cycles is present in the literature. ${ }^{4}$ In order to capture and study changes in comovements in underlying variables across countries, I allow both factors and factor loadings to change over time. I

\footnotetext{
${ }^{2}$ Global scale here refers to the sample of 17 developed countries.

${ }^{3} \mathrm{~A}$ global cycle in a variable is characterized by the degree of comovement or synchronization in the underlying variable across countries.

${ }^{4}$ For financial cycles, see Stock and Watson (2011, 2016, 2005); Jörg and Sandra (2016); Hirata et al. (2012); Miranda-Agrippino and Rey (2015). For macroeconomic cycles, see Kose et al. (2003, 2008); Crucini et al. (2011). However, the use time-varying parameters and shock volatilities to study global cycles in financial variables is missing in the literature.
} 
also allow shock volatilities to change over time to capture and study changes in common components' (global factors') volatility over time. ${ }^{5}$

Next, I study whether the financial sector is an important source of shocks for the global macroeconomic sector. More specifically, I analyze whether shocks in the global, and country-specific, financial sector contribute to the fluctuations in the global macroeconomic sector. ${ }^{6}$ Then, I examine if there is time variation in the contribution of the financial shocks, especially during various financial crises. There are various reasons to suspect the response of macroeconomic variables to changes in financial conditions are changing over time. Growing prominence of the financial sectors and inter-linkages across countries, financial innovations, globalization, financial regulation, monetary policy changes and major political events such as formation of the European Union likely alter the response of macroeconomic sector to financial shocks. For instance, the role of the market for sub-prime mortgages in the Great Recession provides reason to believe that there is an increased importance of financial sector in explaining macroeconomic fluctuations. ${ }^{7}$ Studying time-varying contributions of the financial shocks also help understand how the financial crisis periods are different that normal times, and how each financial crises differs from the others. It also helps uncover possible non-linearities present in the data. Despite such concerns, only a few papers employ time-varying parameter models. ${ }^{8}$

In order to identify underlying sources of time variation, I study time variation in both the transmission of the shocks to the global macroeconomic sector and the size of

\footnotetext{
${ }^{5}$ The common component, or global factor, refers to shared information in the underlying variable across countries.

${ }^{6} \mathrm{Ha}$ et al. (2017) find no evidence of spillover from macroeconomic sector to the financial sector.

${ }^{7}$ Hatzius et al. (2010) and Prieto et al. (2016) discuss reasons for potential time variation in linkage between financial and macroeconomic variables.

${ }^{8}$ Abbate et al. (2016); Prieto et al. (2016); Kaufmann and Valderrama (2010); Davig et al. (2010); Guerrieri and Iacoviello (2017); Ciccarelli et al. (2012); Hubrich and Tetlow (2015); Nason and Tallman (2015); Gambetti and Musso (2017). See Prieto et al. (2016) for a detailed list of papers that employ time-varying parameters, methods employed, and the findings of the papers. Of these studies, onlyCiccarelli et al. (2012); Eickmeier et al. (2011); Gambetti and Musso (2017); Prieto et al. (2016) allow parameters to evolve smoothly over time.
} 
the shocks. I use time-varying parameter factor-augmented vector autoregression (TVPFAVAR) model with stochastic volatility to study the effect of the financial shocks. I allow continuous changes in autoregressive coefficients to capture both gradual and long-lasting changes in macro-financial linkages, which arises due to deep structural changes, as well as asymmetries over the business or the financial cycle related to financial frictions. I also allow changes in shock volatilities to capture and study changes in the shock sizes and simultaneous relations among the variables. I analyze impulse responses to the shocks of the same size to isolate changes in the transmission of the shocks from changes in the size of the shocks.

My main findings are as follows. First, I find evidence of quantitatively meaningful global cycles in credit and equity price. Roughly one-third of the variation in credit growth is attributable to the global factor of the credit cycle, roughly one-half of the variation in equity-price growth is attributable to the global factor of the equity-price cycle on average. The house-price growths are mostly attributable to idiosyncratic components over the sample period of 1970 to $2013 .{ }^{9}$ There is large degree of heterogeneity on the share of variation attributable to the global factors across countries, so a shock to a global factor (a global shock) would affect different countries differently. This is consistent with the experience of the Great Recession. The effect of the crisis showed substantial heterogeneity across countries, as the level of contraction, timing and duration varied across countries. I do not find evidence of a quantitatively meaningful joint global financial cycle that explains fluctuations in all three financial variables over the sample period.

Second, the cycles are stronger in the years leading up to and following the recent financial crisis, meaning that the comovements between financial sectors across countries are larger in those years compared to the historical comovements. Almost one-half of the variation in the credit and house-price growth is attributable to the respective global factors.

\footnotetext{
${ }^{9}$ The idiosyncratic components could be country specific, region specific or variable specific.
} 
Almost two-thirds of the variation in the equity-price growth is attributable to the global equity-price factor on average. The finding implies a growing inter-relationship between the financial sector in the sample of developed countries.

Third, both global shocks and shocks originating in a major country contribute to the fluctuations in the global cycles of macroeconomic variables. The equity-price shocks generate quantitatively larger responses than the credit and house-price shocks, but are less persistent. The global and US house-price shocks show growing marginal effect after the turn of the century, which is accompanied by the aforementioned increase in the size of the global house-price cycle.

Fourth, there is evidence of time variation in the size and transmission of the financial shocks, especially the equity-price and house-price shocks. I find evidence of an increase in transmission of the financial shocks as well as an increase in size of the shocks during various financial crises, especially during the recent financial crisis. During the recent financial crisis, the contribution of the global and the US house-price shocks increase significantly. The combination of the magnitude of increase in the size as well as the marginal effect of the house-price shocks is unprecedented, and could explain the slow recovery from the Great Recession.

There is a large body of literature that studies interactions between the macroeconomic and the financial sector. ${ }^{10}$ Shocks originating in the financial sector can result in more pronounced movements in asset prices and macroeconomic fluctuations. This can lead to international spillovers through cross-border linkages. Theoretical studies that model financial sector explicitly find a significant impact of changes in the financial sector on macroeconomic variables. ${ }^{11}$ Empirical studies in the literature often focus on transmission of lo-

\footnotetext{
${ }^{10}$ Claessens and Kose (2017) present survey of the literature.

${ }^{11}$ See Bernanke et al. (1999); Carlstrom and Fuerst (1997); Kiyotaki and Moore (1997); Geanakoplos (2010); Adrian et al. (2013). The models implement an amplification mechanism (or financial accelerator) that affects an entity's ability to access external financing. More specifically, changes in asset prices lead to changes in the entity's net worth, affecting their borrowing and investing ability. This phenomenon, in turn,
} 
cal shocks internationally or in the context of a country, ignoring potential effects across countries. ${ }^{12}$ Analysis on global macro-financial linkages is in its early stages. ${ }^{13}$ However, study of time-varying relationship between the global financial and macroeconomic sector is missing in the literature.

This paper contributes to various strands of the literature. First, this paper contributes to the literature of the financial cycle by providing a quantitative characterization of the cycles in different financial variables using a time-varying parameter model. To my knowledge, this is the first paper that uses a time-varying parameter model to quantify global cycles in multiple financial variables. Second, this paper contributes to the nascent literature of global macro-financial linkages. To my knowledge, this is the first paper to study timevarying global macro-financial linkages. It also contributes to the literature of international transmission of the financial shocks originating in a country. A common finding in the literature is that the time-variation in the contribution of the financial shocks on the GDP growth can mostly be attributed to change in the size of the shocks. Results on whether the transmission of the financial shocks varies over time are mixed. I study global transmission of the financial shocks originating in the US, the UK and Germany to identify the source of time-variation in the contribution of the shocks. Third, the paper can produce the heterogeneous effects of the financial shocks across countries. To my knowledge, this is the first paper to do so.

The rest of the paper is organized as follows. Section 2 presents the dataset used in the analysis and their sources. Section 3 presents the empirical methodology employed.

can intensify asset price fluctuations, and hence, macroeconomic fluctuations.

${ }^{12}$ See Cesa-Bianchi (2013); Cesa-Bianchi et al. (2015); Ciccarelli et al. (2012); Gambetti and Musso (2017); Eickmeier and $\mathrm{Ng}$ (2011) for international transmission of the financial shocks and Hubrich and Tetlow (2015); Nason and Tallman (2015); Prieto et al. (2016); Claessens et al. (2009, 2010, 2012); Borio (2014); Jordà et al. (2017) for country-specific analysis.

${ }^{13}$ For empirical research on macro-financial spillovers, see Helbling et al. (2011); Eickmeier and Ng (2011); Ha et al. (2017) They document that global shocks in financial variables are influential in driving macroeconomic fluctuations. Ciccarelli et al. (2012) find that the common components of both financial and macroeconomic variables play important role in explaining cross-border spillovers. 
Section 4 presents the main findings of the paper. First, I present the findings on the existence and the significance of global cycles of financial variables. Second, I present findings on the time-varying global macro-financial linkages. Section 5 tests the robustness of the results in section 4 . Section 6 concludes the paper with a summary of the main findings.

\subsection{Data}

I use the sample period of 1970 to 2013 (1960-1969 is used as training sample) to estimate the model. The sample period covers several financial crises, 'Bank Capital Squeeze' (1973-75), 'Least Developed Countries Debt Crisis' (1982-84), 'Savings and Loan Crisis' (1988-91), as defined in Lopez-Salido and Nelson (2010), stock market crash of 2000s and the Global Financial Crisis (2008-09).

I use a model that combines financial variables with macroeconomic variables. All time series are obtained from Schularick-Taylor's macrohistory database (Jordà et al. (2017)) $)^{14}$. I use annual data for 17 countries. The choice of frequency and number of countries are driven by data availability. Financial variables comprises log differenced real credit, real equity prices and real housing prices. Credit is defined as total loans to non-financial private sector. The financial variables used cover the most relevant features of the financial sector. These variables feature prominently in DSGE models that include financial frictions. House and asset prices capture the financial wealth whose movement can affect fluctuations in macroeconomic sector through wealth effects. Inclusion of credit stems from the fact that it indicates external financing for the private sector. Shrinkage in credit is usually associated with financial stress in the DSGE models. Macroeconomic variables comprises log differenced real GDP per capita, real investment per capita, and inflation rate. Real variables are constructed from nominal variables using local price indexes.

\footnotetext{
${ }^{14}$ dataset is found in http://www.macrohistory.net/data/
} 


\subsection{Empirical Methodology}

\subsubsection{Time-varying Parameter Dynamic Factor Model and Factor Aug- mented VAR}

First, I use a time-varying parameter dynamic factor model (TVP-DFM) with stochastic volatility to estimate the global factors of each financial and macroeconomic variables. I also estimate the global factor using all three financial variables to study if there exists a joint global financial cycle that encompasses all financial variables. This class of model is useful in identifying a few factors that explain fluctuations in large multi-dimensional data. I employ one factor model, so regional or country factors are not estimated. The estimated factors are interpreted as the global factors that help quantify the global cycle of the underlying variables. I use the variance decomposition method to quantify the contribution of the estimated global factors to the variance of the underlying variables for each countries. let $X_{t}$ be $n \times 1$ vector whose global factor I are interested in, then the TVP-DFM is of the form,

$$
x_{t}=\lambda_{t} F_{t}+u_{t}
$$

where $x_{t}$ is the growth rate of variable $X, \lambda_{t}$ is the factor loading, $F_{t}$ is the latent factor. $u_{t}$ is gaussian disturbance with mean zero and time-varying heteroskedastic covariance $V_{t}$. Adopting common identification assumption in the DFM literature, I assume that the first element of $\lambda_{t}$ is 1 and $V_{t}$ is diagonal, so $u_{t}$ are idiosyncratic shocks and $F_{t}$ contains information that are common to all time series in $X$. I use one variable at a time to estimate the global factors of the underlying variables. ${ }^{15}$

Once the global factors of macroeconomic and financial variables are estimated, I use them as proxy for global macroeconomic and financial variables to study the linkage be-

\footnotetext{
${ }^{15}$ Except when estimating the global factor of all financial variables.
} 
tween them using time-varying parameter factor augmented VAR (TVP-FAVAR). I use one financial variable at a time to study the effect of a shock to the global factor of the financial variable on the global macroeconomic factors. Let $y_{t}$ be the macroeconomic factors and $f_{t}$ be the factor of the financial variable of interest, estimated using the TVP-DFM above. TVP-FAVAR is then given by,

$$
\left(\begin{array}{c}
y_{t} \\
f_{t}
\end{array}\right)=c_{t}+B_{t, 1}\left(\begin{array}{c}
y_{t-1} \\
f_{t-1}
\end{array}\right)+\ldots+B_{t, p}\left(\begin{array}{c}
y_{t-p} \\
f_{t-p}
\end{array}\right)+e_{t}
$$

where $c_{t}$ is the intercept and $\left(B_{t, 1}, \ldots, B_{t, p}\right)$ are the VAR coefficients. $e_{t}$ is gaussian disturbance with mean zero and time-varying heteroskedastic covariance $Q_{t}$. I allow both factor loadings and VAR coefficients to vary every period, hence the model is quite flexible. Let $\beta_{t}=\left(c_{t}^{\prime}, \operatorname{vec}\left(B_{t, 1}^{\prime}, \ldots, \operatorname{vec}\left(B_{t, p}^{\prime}\right)\right)\right.$, then the time-varying parameters evolve as multivariate random walks of the form,

$$
\begin{aligned}
& \lambda_{t}=\lambda_{t-1}+\nu_{t} \\
& \beta_{t}=\beta_{t-1}+\eta_{t}
\end{aligned}
$$

where $\nu_{t}$ and $\eta_{t}$ are gaussian disturbances with mean zero and covariances $W_{t}$ and $R_{t}$ respectively. All error terms are uncorrelated over time and with each other, hence have the following structure.

$$
\left(\begin{array}{l}
u_{t} \\
e_{t} \\
\nu_{t} \\
\eta_{t}
\end{array}\right) \sim N\left(0,\left(\begin{array}{cccc}
V_{t} & 0 & 0 & 0 \\
0 & Q_{t} & 0 & 0 \\
0 & 0 & W_{t} & 0 \\
0 & 0 & 0 & R_{t}
\end{array}\right)\right)
$$

This model allows me to study dynamic interaction between the global financial and macroeconomic factors. I replace the global financial factors with financial variables of a country to study the effect of shocks to the country's financial variables on the global 
macroeconomic factors.

\subsubsection{Estimation}

I Estimate the model described by equations 2.1, 2.2 and 2.3 following the procedure used by Koop and Korobilis (2014) which uses two-step algorithm that greatly reduces computational time compared to typical estimation method used in the literature that uses the Markov Chain Monte Carlo (MCMC) approach ${ }^{16}$. The method I use combines variance discounting approach with the kalman filter recursion to estimate the posterior of the factors $f_{t}$ and time varying parameters $\theta_{t}=\left(\lambda_{t}, \beta_{t}\right)$. Use of typical kalman filter is not feasible in this setup as long as both $f_{t}$ and $\lambda_{t}$ are unobserved in the measurement equation. The approach uses a dual, conditionally linear filtering/smoothing algorithm to estimate the unobserved state $f_{t}$ and the parameters $\theta_{t}$. The dual approach first updates the parameters $\theta_{t}$ given the estimate of $f_{t}$, and subsequently updates the factors $f_{t}$ given $\theta_{t}$. Such an approach allows the use of two different linear kalman filters (or smoothers). Thus, this approach greatly reduces computational burden.

To estimate stochastic volatilities $\left(V_{t}, Q_{t}, W_{t}, R_{t}\right)$, the approach uses simulation free matrix discounting method as in Quintana and West (1988) ${ }^{17}$. For $V_{t}$ and $Q_{t}$, exponentially weighted moving average (EWMA) with decay factor $\kappa_{1}$ and $\kappa_{2}$ is used ${ }^{18}$. For $W_{t}$ and $R_{t}$, forgetting factor methods described in Koop and Korobilis (2014) is used, which depend on forgetting factors $\kappa_{3}$ and $\kappa_{4}$, respectively. Decay factor approach implies that an effective window of $\frac{\kappa_{1}}{2}-1$ observations is used to estimate $V_{t}$ and an effective window of $\frac{\kappa_{2}}{2}-1$ observations is used to estimate $Q_{t}$. Forgetting factor approach implies that an effective window of $\frac{1}{1-\kappa_{3}}\left(\frac{1}{1-\kappa_{4}}\right)$ observations is used to estimate $W_{t}\left(R_{t}\right)$. Lower values of decay

\footnotetext{
${ }^{16}$ The MCMC method samples from nonlinear and multivariate joint posterior density that are computationally expensive. See Primiceri (2005); Del Negro and Otrok (2008) for example.

${ }^{17}$ see Quintana and West (1988) or Koop and Korobilis (2014) for technical details.

${ }^{18}$ Such recursive estimators are computationally trivial. Moreover, it is an accurate approximation to an integrated GARCH model which is in line with Primiceri (2005); Cogley and Sargent (2005).
} 
or forgetting factors means that more recent observation, and its squared residual, are given higher weights in estimation of $V_{t}$ and $Q_{t}$. Forgetting and decay factors can be chosen based on expected time variation in the parameters, hence similar to choosing a prior in spirit. $\kappa_{1}=\kappa_{2}=1$ implies that $V_{t}$ and $Q_{t}$ are constant. $\kappa_{3}=\kappa_{4}=1$ implies that $W_{t}$ and $R_{t}$ are zero, which implies $\lambda_{t}$ and $\beta_{t}$ are constant. The following steps summarizes the estimation method.

- initialize parameters $\lambda_{0}, \beta_{0}, f_{0}, V_{0}, Q_{0}$

- obtain principle components estimate of factors $\left(\tilde{f}_{t}\right)$

- estimate parameters $\theta_{t}$ given $\tilde{f}_{t}$

- estimate $V_{t}, Q_{t}, W_{t}, R_{t}$ using variance discounting approach

- estimate $\theta_{t}$ using Kalman filter smoother (KFS) given $\left(V_{t}, Q_{t}, W_{t}, R_{t}\right)$

- estimate the factors $f_{t}$ given $\theta_{t}$ using KFS

\subsubsection{Shock Identification}

In order to identify the financial shocks, I conduct a cholesky decomposition of covariance matrix of reduced form VAR residuals. I specify the following ordering: GDP growth, Investment growth and Inflation, followed by a financial variable. I use one financial variable at a time to study the effect of the financial shock on the macroeconomic variables. ${ }^{19}$ The underlying assumption in such ordering is that the macroeconomic variables react to financial shocks with a delay, as wealth effects and effects involving financial intermediation may take time to materialize, whereas financial variables react instantaneously to macroeconomic shocks. This is a standard practice in macroeconomics as macroeconomic

\footnotetext{
${ }^{19}$ Including multiple financial variables can be problematic as proper ordering is not obvious.
} 
variables are slow moving compared to financial variables, which are sensitive to macroeconomic shocks.

\subsection{Findings}

\subsubsection{Time-varying Factors and Volatilities}

Figures 2.1, 2.2, 2.3 and 2.4 illustrate the estimated global factors and their volatilities for GDP, credit, equity prices and housing prices respectively from 1970 to 2013 . The blue curve is the estimated factor using TVP-DFM and the green curve is the estimated factor using the standard constant-parameter dynamic factor model. ${ }^{20}$ For the GDP and the equity-price factors, the estimates using two methods are almost identical. For the credit and the house prices, the factors are similar on the middle of a cycle, but are quite different near the peak and the trough. This implies that the time-varying parameter model could show different effects of the shocks in the variables during the peak than using a constantparameter model.

The estimated factors do a decent job of capturing the major economic events in the past few decades. In figure 2.1, the global GDP factor captures the downturn in the economy in the mid 1970s, early 1980s, late 1980s-early 1990s and early 2000s. Early 2000s recession is followed by boom phase until big crash during the Great Recession. The boom phases are associated with a rise in the estimated factor and the bust phases are associated with a decline.

The financial factors likewise capture the historical financial events well based on the figures 2.2, 2.3 and 2.4. All three financial factors decline during the bank capital squeeze of 1973-75. Similarly, the factors predict the financial crises of early 1980s and late 1980searly 1990s. There is a boom in the financial factors from early 1980s until late 1980s. This

\footnotetext{
${ }^{20}$ For constant-parameter model, set paramters in $\theta$ constant.
} 
boom is followed by the crash in early 1990s, where all three financial factors and the GDP factor decline. The observations roughly coincide with the 1990 oil price shock, the end of the cold war and the savings and loan crisis.

Based on figures 2.2 and 2.4, the housing and credit factors can account for the huge surge in the house-price growth and the credit growth in the 1980s. Various tax cuts allowed generous depreciation of housing assets and deregulation of savings and loan industry allowed expanded investment in mortgages during the time. Combined with the economic recovery and increased appetite for real estate, the housing and the credit bubbles were observed. Later, both house prices and credit declined during the early 1990s crisis. The findings are consistent with the observations. Based on figure 2.2, the magnitude of the decline in the credit factor was the largest during the crisis, which is consistent with the actual credit shrinkage that occurred during the crisis. Thanks to increased financial innovations and deregulation of the financial sector, the global economy experienced another boom period in the 1990s.

Figures 2.1, 2.2, 2.3 and 2.4 show that all the factors declined during the recession in early 2000s, although the decline in the equity-price factor is comparatively larger and the decline in the house-price factor is comparatively smaller. This is consistent with the actual experience of the crisis that saw huge crash in the stock market. This decline is followed by a recovery and boom period before declining sharply during the Global Financial Crisis. With continued innovation and deregulation of financial sector after the early 2000s recession, along with central banks keeping interest rates low, the financial sector, especially the housing and the credit, experienced another huge expansion. The factors declined sharply during the Global Financial Crisis with a comparatively larger decline in the equity-price and the house-price factors.

Volatilities of the factors behave mostly as expected. Figure 2.1 shows that the volatility of the GDP factor increased sharply in the early to mid 1970s and then followed by steady 
decline until the Great Recession. This period is famously known as the Great Moderation. The volatility increases sharply during the Great Recession. Hence, the volatility of the GDP factor captures the historical volatility well. Based on the findings, the beginning of the Great Recession (2007) marked the end of the Great Moderation.

Figures 2.2, 2.3 and 2.4 show that the volatility of the financial factors increase during financial crises. ${ }^{21}$ Figure 2.4 shows that the two biggest increases in the house-price volatility are during the 1990s crisis and the recent crisis, coinciding with the two biggest housing busts since the 1970s. These findings imply that the size of the shocks in global factors (global shocks) are changing over time, with bigger shocks during the crisis periods. $^{22}$

The findings show that the estimated factors predict the historical events well, and hence, serve as a validation of the model. Moreover, they show that allowing time variation in parameters and volatility could potentially provide different answers than constantparameter model during the crisis periods (peaks). Hence, I use the model to analyze the main queries of the paper.

\footnotetext{
${ }^{21}$ Note that these are yearly observations, so the volatility at a high frequency is not captured.

${ }^{22}$ Note that the system does not include the macroeconomic variables or factors. I study time-varying shock volatilities in model with macroeoconomic factors later in the paper.
} 

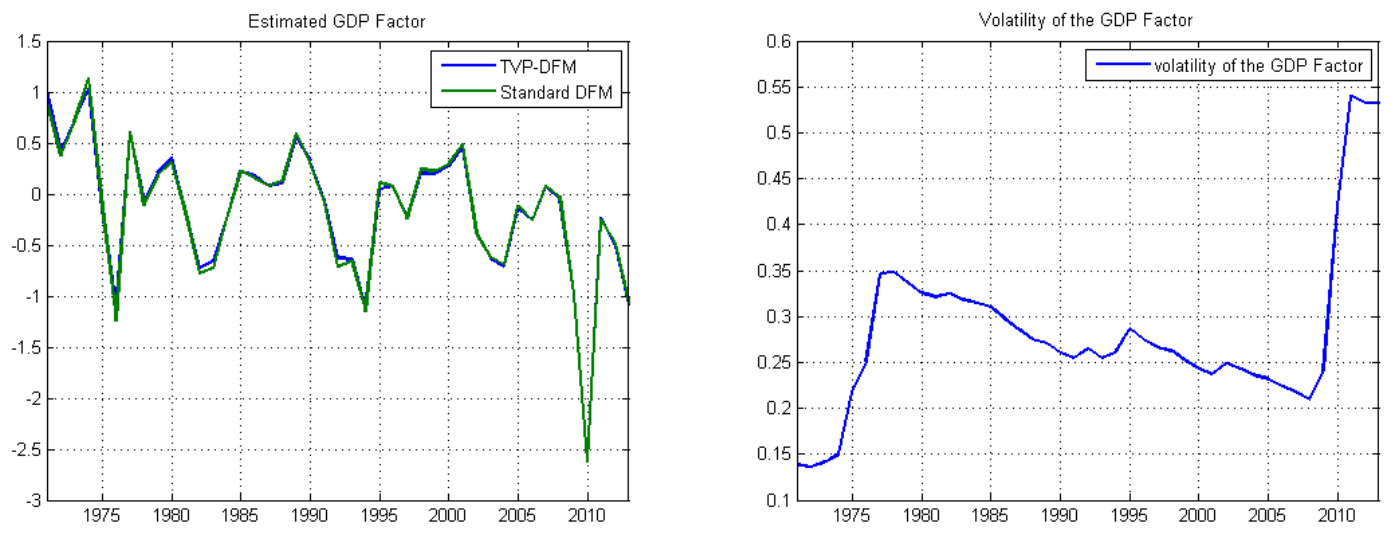

Figure 2.1: Global GDP Factor and its Volatility

Figure on the left panel illustrates the estimated global GDP factor and the figure on the right panel illustrates the volatility of the factor.

The variable on the vertical axis is the estimated factor for figure on the left panel and the factor volatility for the figure on the right panel. The variable on the horizontal axis is year. The blue curve is the estimated factor using TVP-DFM and the green curve is the estimated factor using standard constant parameters dynamic factor model.
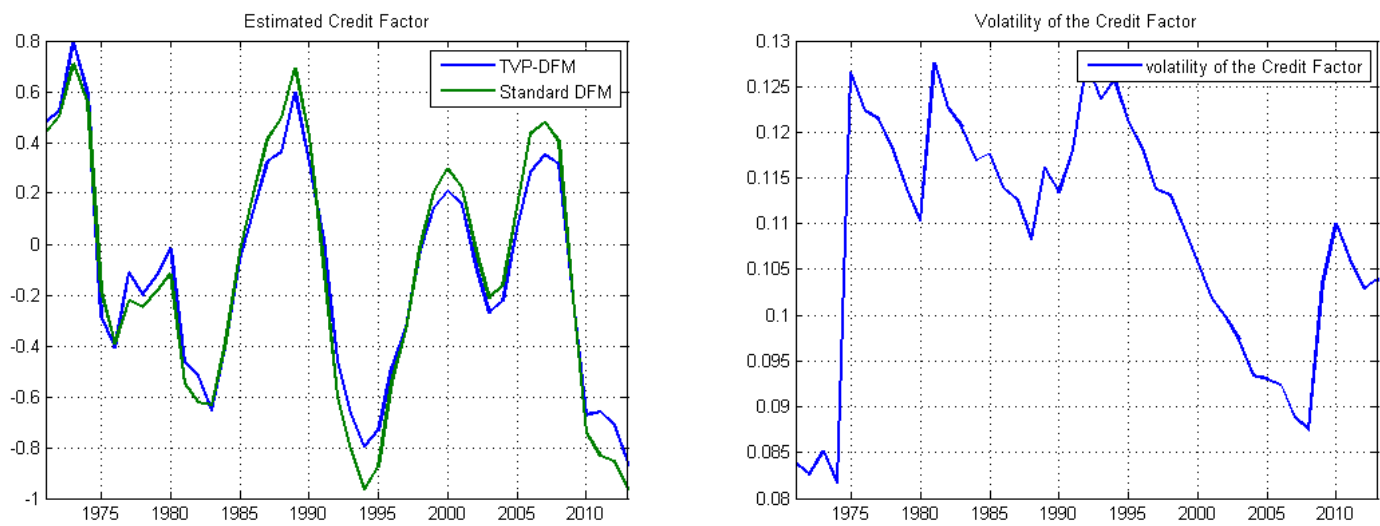

Figure 2.2: Global Credit Factor and its Volatility

Figure on the left panel illustrates the estimated global credit factor and the figure on the right panel illustrates the volatility of the factor. The variable on the vertical axis is the estimated factor for figure on the left panel and the factor volatility for the figure on the right panel. The variable on the horizontal axis is year. The blue curve is the estimated factor using TVP-DFM and the green curve is the estimated factor using standard constant parameters dynamic factor model. 

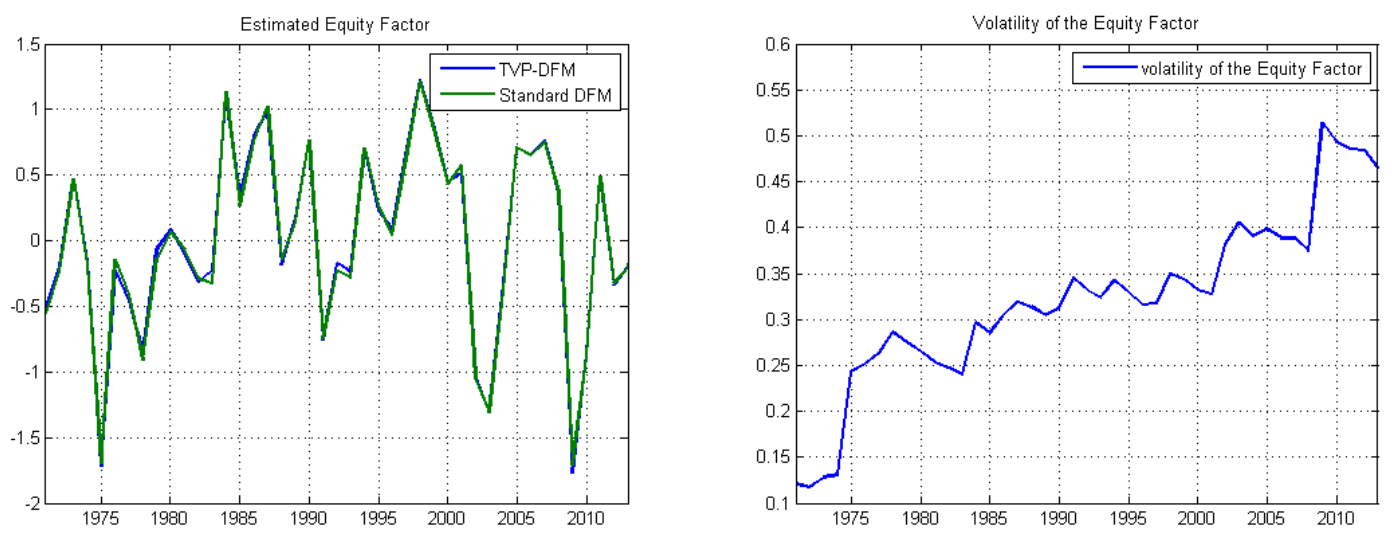

Figure 2.3: Global Equity-Price Factor and its Volatility

Figure on the left panel illustrates the estimated global equity-price factor and the figure on the right panel illustrates the volatility of the factor. The variable on the vertical axis is the estimated factor for figure on the left panel and the factor volatility for the figure on the right panel. The variable on the horizontal axis is year. The blue curve is the estimated factor using TVP-DFM and the green curve is the estimated factor using standard constant parameters dynamic factor model.
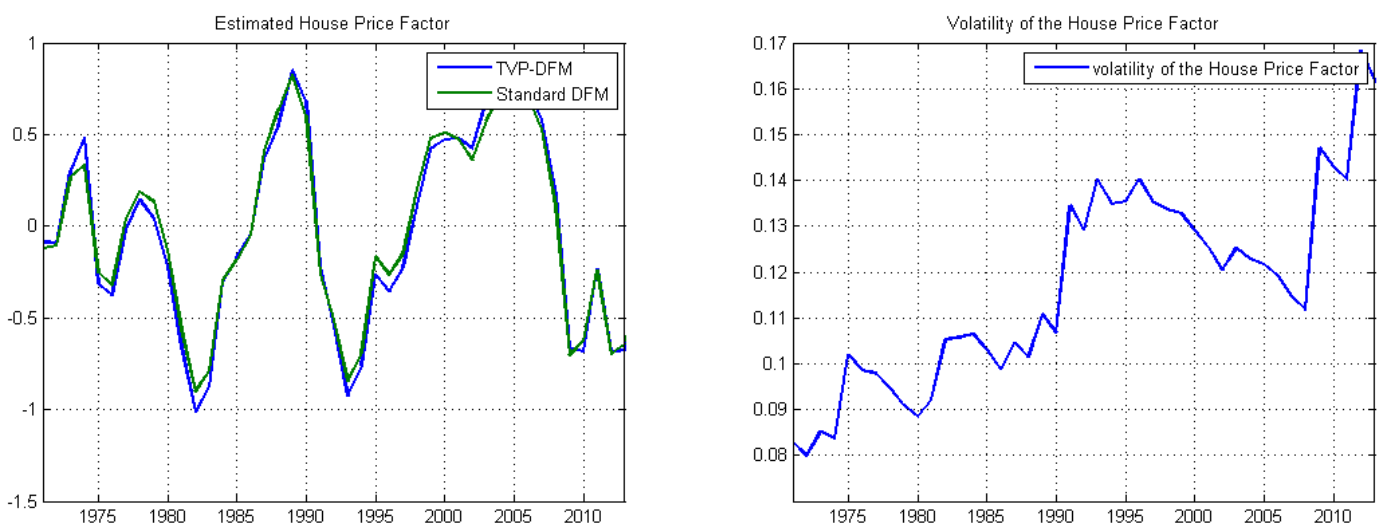

Figure 2.4: Global House-Price Factor and its Volatility

Figure on the left panel illustrates the estimated global house-price factor and the figure on the right panel illustrates the volatility of the factor. The variable on the vertical axis is the estimated factor for figure on the left panel and the factor volatility for the figure on the right panel. The variable on the horizontal axis is year. The blue curve is the estimated factor using TVP-DFM and the green curve is the estimated factor using standard constant parameters dynamic factor model. 


\subsubsection{Variance Decomposition}

Understanding the importance of the global factors in the evolution of the underlying variables is crucial from a policy perspective. If they are not quantitatively important, then I should not be too concerned about the global cycles. In order to study quantitative importance of the global factors, I compute the variance decomposition to quantify the fraction of variance of each financial variables that can be attributed to the global factor for each countries.

Table 2.1 shows the variance decompositions of financial variables attributable to the global factors. Columns 1-3 report results from analysis using the model with time-varying parameters and columns 4-6 are from the analysis using the model with constant parameters. The first and fourth columns report the share of variance of the credit growth for individual countries attributable to the global credit factors. Likewise, second, third, fifth and sixth columns report share of variance of the equity-price and the house-price growth for each countries attributable to the global factors of the equity price and the house price respectively. All entries are in percentages. In the analysis using the time-varying parameter model, the global credit factor explains about one-third of the variation in credit growth on average. This implies that there exist a global cycle in credit that accounts for about one-third of variation in the credit growth on average for the sample of 17 countries. This is comparable to the results found by Hirata et al. (2012); Kose et al. (2012) but significantly larger than that found by Ha et al. (2017) who only find 2 to 4 percent contribution of the global factor. The remaining variance is attributable to idiosyncratic components, which could include regional, country-specific or variable-specific components.

There is significant heterogeneity in the share of variance attributable to the global factors. The global factor dominates the credit growth in Canada, Belgium, Germany and Italy, accounting for more than 50 percent of the variation in credit growth. The global factor is less important for Australia, UK, Norway, Sweden, Finland and Portugal, accounting for 
less than 20 percent of the variation. Hence, a global credit shock, represented by a shock in the global credit factor, has different effects in the credit growth of different countries.

Equity-price growth has a more pronounced global component than the credit or the house prices. The global equity-price factor explains almost one-half of the variation in equity-price growth on average, as indicated by column 2. It dominates the equity-price growth of 7 countries. Only Portugal has less than 20 percent variation in equity-price growth attributable to the global factor. The average share of variance attributable to the global equity-price factor that I find is smaller than the studies that use constant parameter models (Ha et al. (2017); Hirata et al. (2012); Kose et al. (2012)) who account for about 60 percent variation attributable to the global factor. Miranda-Agrippino and Rey (2015) find that 66 percent of the variation in returns of risky assets is attributable to the global factor.

Movements in house prices appear to be mostly driven by idiosyncratic components as the global house-price factor explains only 20 percent of the variation in the house-price growth on average. The global house-price factor is meaningful only for a few countries which includes the UK, Belgium, Denmark, France, Sweden and Spain. The result is comparable to the studies that use constant-parameter models (Ha et al. (2017); Hirata et al. (2012)).

Variance decomposition analysis using the constant-parameter model (columns 3-6) yields similar results. There are few discrepancies for some countries in the analysis, such as contribution of the global house-price factor on the US house-price growth for instance, but overall, the constant-parameter analysis is consistent with the findings from the timevarying parameter analysis. In a sense, the constant-parameter analysis serves as a robustness test for the time-varying parameter analysis.

In summary, there are quantitatively significant global cycles in equity price and credit in the sample of 17 countries. ${ }^{23}$ The global equity-price cycle is quantitatively larger than

\footnotetext{
${ }^{23}$ Recent studies document significant cross-country comovements in individual financial variables. See
} 
the cycles of other two financial variables. Historically, the movements in house prices appear to be predominantly determined by regional or country specific components. ${ }^{24}$

Table 2.2 shows the variance decompositions of financial variables attributable to the joint global financial factor. This factor is determined by including all financial variables in the TVP-DFM to estimate a factor. On average, the joint global financial factor explains only about 28 percent of the variation in credit growth, 26 percent of the variation in equityprice growth and about 16 percent of the variation in house-price growth. Hence, it does not appear that there is a financial cycle that explains fluctuations in all three financial variables jointly. The constant-parameter analysis supports the conclusion. Ha et al. (2017) finds similar non-existence of a single financial cycle that encompasses all financial variables.

Table 2.3 reproduces the variance decompositions of the financial variables attributable to their global factors for the sample period starting at 2000. The exercise helps us understand whether the comovement in the financial variables across countries has increased or decreased during the recent periods. With the recent financial crisis being a major event in the global economy, it is useful to understand whether the global financial cycles preceding the crisis have become larger or smaller. The table shows that the global factors of all three financial variables explain a much larger share of the variation in growth of the underlying variables on average. The global credit and house-price factors explain almost one-half of the variation in the underlying variables on average, and the global equity-price factor explains almost two-thirds of the variation on average in equity-price growth. The constant-parameter model yields an even larger contribution of the equity-price factor. The numbers are comparable to that of the existing literature. These findings indicate a significant increase in the size of the global cycles of the variables after 2000, including the house-price cycle which is now quantitatively meaningful. Hirata et al. (2012) also finds

Claessens et al. (2012); Hirata et al. (2012). Results from this paper are in line with their findings.

${ }^{24}$ There could be more cross-country comovements of the financial variables at the higher frequency, especially in response to unanticipated policy shocks, news shocks and disruptions in financial market. 
significant increase in the size of the global cycles in house prices and equity prices post globalization $^{25}$.

The findings support the perceived increase in the prominence of financial sector around the world, especially the housing sector. It also supports the notion that the inter-linkages of financial sectors across countries are larger during the recent decades. Increase in comovement (or synchronization) of house prices across countries is comparatively more significant. One possible explanation for such significant increase in the magnitude of the global house-price cycle is as follows. In the USA, the housing sector started to expand around mid-80s due to various policies favoring ownership of homes. Credit market expansion and improved efficiency of financial markets helped in that regard too. Developed countries around the world started following the US's lead to promote ownership of homes. Together with increased inter-relationship of financial sectors around the world, house prices became more synchronized.

Since I aim to understand the impact of financial shocks on the global macroeconomic sector, it is useful to illustrate similar variance decomposition analysis for macroeconomic variables. Variance decompositions of the GDP, investment and inflation attributable to the global factors in the underlying variables are reported in Table 2.4. The table shows that there is significant comovements in the macroeconomic variables among the 17 countries. The global GDP factor explains more than one-half of the variation in the GDP growth, whereas the global investment factor explains more that one-third of the variation in investment growth on average. Variance decomposition of inflation shows that fluctuation in prices are highly synchronized in the sample of 17 countries. The findings are similar to those of the papers using constant-parameter models in the literature. ${ }^{26}$

Similar to that of the financial variables, there is significant heterogeneity in the share

\footnotetext{
${ }^{25}$ Claessens and Kose (2017) similarly find increased comovement of financial variables over time.

${ }^{26}$ Crucini et al. (2011) find similar results for GDP and investment. The magnitudes are slightly higher in this paper than in Crucini et al. (2011).
} 
Table 2.1: Variance Decomposition of the Financial Variables due to Their Global Factors

\begin{tabular}{|c|c|c|c|c|c|c|}
\hline \multirow[b]{2}{*}{ Countries } & \multicolumn{3}{|c|}{ Time-Varying Parameters } & \multicolumn{3}{|c|}{ Constant Parameters } \\
\hline & Credit & Equity Prices & House Prices & Credit & Equity Prices & House Prices \\
\hline USA & 33 & 54 & 12 & 35 & 42 & 39 \\
\hline Canada & 58 & 50 & 1 & 28 & 49 & 1 \\
\hline Japan & 44 & 41 & 6 & 27 & 38 & 0 \\
\hline Australia & 0 & 37 & 17 & 14 & 38 & 19 \\
\hline UK & 5 & 26 & 43 & 32 & 28 & 45 \\
\hline Belgium & 56 & 61 & 37 & 38 & 61 & 26 \\
\hline Denmark & 38 & 32 & 37 & 49 & 35 & 21 \\
\hline France & 41 & 59 & 50 & 42 & 63 & 35 \\
\hline Germany & 53 & 38 & 1 & 29 & 38 & 2 \\
\hline Italy & 58 & 47 & 1 & 45 & 50 & 5 \\
\hline Netherlands & 33 & 69 & 15 & 33 & 70 & 16 \\
\hline Norway & 1 & 32 & 1 & 7 & 36 & 4 \\
\hline Sweden & 17 & 50 & 40 & 40 & 56 & 48 \\
\hline Switzerland & 33 & 69 & 16 & 14 & 51 & 9 \\
\hline Finland & 18 & 29 & 24 & 33 & 40 & 24 \\
\hline Spain & 40 & 25 & 40 & 51 & 38 & 48 \\
\hline Portugal & 10 & 6 & 1 & 14 & 21 & 12 \\
\hline Average & 32 & 43 & 20 & 31 & 44 & 21 \\
\hline
\end{tabular}

Notes: The entries are the percentage of the variation attributable to the global factor. Columns 1-3 report results from analysis using the model with time-varying parameters and columns 4-6 report results from analysis using the model with constant parameters. Columns 1 and 4 report the variation in credit growth for individual countries attributable to the global credit factor, columns 2 and 5 report the variation in equity-price growth for individual countries attributable to the global equity-price factor and column 3 and 6 report the variation in house-price growth for individual countries attributable to the global house-price factor. 
Table 2.2: Variance Decomposition of the Financial Variables due to Joint Global Financial Factor

\begin{tabular}{|c|c|c|c|c|c|c|}
\hline \multirow[b]{2}{*}{ Countries } & \multicolumn{3}{|c|}{ Time-Varying Parameters } & \multicolumn{3}{|c|}{ Constant Parameters } \\
\hline & Credit & Equity Prices & House Prices & Credit & Equity Prices & House Prices \\
\hline USA & 41 & 22 & 6 & 32 & 18 & 24 \\
\hline Canada & 79 & 47 & 0 & 3 & 41 & 0 \\
\hline Japan & 22 & 34 & 75 & 10 & 40 & 3 \\
\hline Australia & 3 & 20 & 2 & 14 & 21 & 5 \\
\hline UK & 14 & 5 & 33 & 23 & 10 & 39 \\
\hline Belgium & 48 & 40 & 4 & 9 & 46 & 4 \\
\hline Denmark & 45 & 16 & 43 & 39 & 23 & 34 \\
\hline France & 18 & 42 & 22 & 8 & 50 & 12 \\
\hline Germany & 34 & 8 & 1 & 5 & 15 & 1 \\
\hline Italy & 29 & 26 & 26 & 13 & 34 & 34 \\
\hline Netherlands & 23 & 35 & 10 & 11 & 42 & 6 \\
\hline Norway & 3 & 19 & 3 & 16 & 28 & 9 \\
\hline Sweden & 9 & 22 & 11 & 11 & 35 & 21 \\
\hline Switzerland & 46 & 31 & 15 & 5 & 25 & 1 \\
\hline Finland & 14 & 26 & 10 & 13 & 37 & 23 \\
\hline Spain & 31 & 38 & 4 & 24 & 47 & 17 \\
\hline Portugal & 13 & 13 & 0 & 12 & 23 & 13 \\
\hline Average & 28 & 26 & 16 & 15 & 31 & 14 \\
\hline
\end{tabular}

Notes: The entries are the percentage of the variation attributable to the joint global financial factor. Columns 1 , 2 and 3 report the variation in credit growth, equity-price growth and house-price growth for individual countries attributable to the global financial factor obtained from the model with time-varying parameters, and columns 4 , 5 and 6 report the variation in credit growth, equity-price growth and house-price growth for individual countries attributable to the global financial factor obtained from the model with constant parameters. 
Table 2.3: Variance Decomposition of the Financial Variables due to Their Global Factors: 2000-2013

\begin{tabular}{|c|c|c|c|c|c|c|}
\hline \multirow[b]{2}{*}{ Countries } & \multicolumn{3}{|c|}{ Time-Varying Parameters } & \multicolumn{3}{|c|}{ Constant Parameters } \\
\hline & Credit & Equity Prices & House Prices & Credit & Equity Prices & House Prices \\
\hline USA & 49 & 19 & 63 & 47 & 48 & 52 \\
\hline Canada & 17 & 79 & 0 & 4 & 75 & 47 \\
\hline Japan & 26 & 76 & 33 & 5 & 0.84 & 41 \\
\hline Australia & 25 & 25 & 24 & 63 & 42 & 22 \\
\hline UK & 68 & 44 & 72 & 69 & 55 & 56 \\
\hline Belgium & 10 & 56 & 45 & 32 & 81 & 76 \\
\hline Denmark & 92 & 79 & 55 & 93 & 85 & 71 \\
\hline France & 55 & 85 & 82 & 58 & 92 & 81 \\
\hline Germany & 43 & 37 & 41 & 4 & 54 & 50 \\
\hline Italy & 67 & 52 & 19 & 68 & 55 & 11 \\
\hline Netherlands & 64 & 71 & 67 & 41 & 76 & 53 \\
\hline Norway & 50 & 76 & 39 & 66 & 82 & 35 \\
\hline Sweden & 29 & 87 & 82 & 57 & 93 & 81 \\
\hline Switzerland & 6 & 84 & 40 & 1 & 90 & 25 \\
\hline Finland & 53 & 95 & 51 & 82 & 77 & 56 \\
\hline Spain & 89 & 76 & 70 & 87 & 81 & 77 \\
\hline Portugal & 80 & 81 & 34 & 64 & 85 & 21 \\
\hline Average & 48 & 66 & 48 & 49 & 74 & 50 \\
\hline
\end{tabular}

Notes: Notes: The entries are the percentage of the variation attributable to the global factor. Columns 1-3 report results from analysis using the model with time-varying parameters and columns 4-6 report results from analysis using the model with constant parameters. Columns 1 and 4 report the variation in credit growth for individual countries attributable to the global credit factor, columns 2 and 5 report the variation in equity-price growth for individual countries attributable to the global equity-price factor and column 3 and 6 report the variation in houseprice growth for individual countries attributable to the global house-price factor. 
of variance attributable to the global macroeconomic factors. The heterogeneity tells us how a change in a global factor changes an individual country's underlying macroeconomic variable. The findings on such heterogeneity is useful to explain the observed heterogeneity during the recent financial crisis. For instance, a change in the global GDP factor changes the GDP of the UK much more than that of the US and hence, any shocks that affect the global GDP factor impact the UK more that they impact the US.

\subsubsection{Time-varying Effects of the Financial Shocks}

In this section, I study the time-varying effects of the financial shocks on the global macroeconomic sector. I analyze the impulse responses of the global macroeconomic factors to the financial shocks in order to study time variation in transmission of the shocks. Moreover, I analyze the shock volatilities to study the time variation in size of the shocks.

\section{Responses to the Global Financial Shocks}

First, I study the effects of shocks in the global factors of the financial variables (global shocks) on the global macroeconomic factors. The impulse responses are constructed such that the initial shocks are of the same size, one standard deviation. This helps isolate changes in transmission of the shocks from changes in their size. Figures 2.5, 2.6 and 2.7 plot the impulse responses of the global factors of GDP, investment and inflation to the negative global financial shocks respectively. The first column plots the median impulse responses to the shocks estimated for each time periods over the horizon of 18 years. Second, third and fourth column plot responses to the shocks at various representative years (1985, 2005 and 2008 respectively). This helps identify possible time variation in the transmission over the years and also possible variation during the crises compared to normal times.

The global macroeconomic factors decline in response to all three shocks. Equity-price shocks generate the largest responses from the macroeconomic factors compared to the 
Table 2.4: Variance Decomposition of the Macroeconomic Variables due to Their Global Factors

\begin{tabular}{|c|c|c|c|c|c|c|}
\hline \multirow[b]{2}{*}{ Countries } & \multicolumn{3}{|c|}{ Time-Varying Parameters } & \multicolumn{3}{|c|}{ Constant Parameters } \\
\hline & GDP & Investment & Inflation & GDP & Investment & Inflation \\
\hline USA & 20 & 4 & 77 & 43 & 16 & 72 \\
\hline Canada & 36 & 2 & 83 & 53 & 19 & 84 \\
\hline Japan & 76 & 55 & 38 & 53 & 44 & 60 \\
\hline Australia & 11 & 3 & 77 & 18 & 7 & 74 \\
\hline UK & 75 & 50 & 92 & 46 & 54 & 84 \\
\hline Belgium & 64 & 40 & 82 & 75 & 54 & 84 \\
\hline Denmark & 81 & 74 & 86 & 55 & 30 & 82 \\
\hline France & 55 & 85 & 82 & 79 & 74 & 90 \\
\hline Germany & 52 & 27 & 69 & 58 & 26 & 63 \\
\hline Italy & 72 & 49 & 85 & 69 & 55 & 87 \\
\hline Netherlands & 47 & 29 & 61 & 64 & 37 & 59 \\
\hline Norway & 28 & 1 & 73 & 28 & 3 & 73 \\
\hline Sweden & 54 & 37 & 72 & 56 & 51 & 79 \\
\hline Switzerland & 51 & 40 & 60 & 52 & 36 & 51 \\
\hline Finland & 42 & 12 & 84 & 56 & 22 & 85 \\
\hline Spain & 85 & 57 & 74 & 59 & 57 & 81 \\
\hline Portugal & 45 & 47 & 71 & 50 & 31 & 68 \\
\hline Average & 51 & 34 & 74 & 54 & 36 & 75 \\
\hline
\end{tabular}

Notes: The entries are the percentage of the variation attributable to the global factor. Columns 1-3 report results from analysis using the model with time-varying parameters and columns 4-6 report results from analysis using the model with constant parameters. Columns 1 and 4 report the variation in per-capita GDP growth for individual countries attributable to the global GDP factor, columns 2 and 5 report the variation in per-capita investment growth for individual countries attributable to the global investment factor and column 3 and 6 report the variation in inflation for individual countries attributable to the global inflation factor. 
shocks in other two financial factors. Despite having the largest impact, the effects of the shocks in equity-price factor are more short-lived compared to the credit and house-price shocks. Case et al. $(2005,2011)$ find that the wealth effect due to non-financial wealth (wealth in real estate) is quantitatively larger than the effect due to financial wealth (wealth in stocks), which could explain relatively persistent effect of the house-price shock.

For the GDP and investment factors, the responses to the global credit shocks are decreasing over time, while they are increasing due to the global equity-price and houseprice shocks. However, the changes are small. Moreover, there are visible increase in responses to all three shocks during the 1990's savings and loan crisis, and further increase in responses to the equity-price and house-price shocks during the recent financial crisis. Responses to the equity-price shocks also increase during the stock market crash of 2000.

The global macroeconomic factors show relatively larger responses to the global houseprice shock after 2000. The responses of the global GDP and investment factors to the global house-price shock show further increase around the recent financial crisis. Also, as documented in Table 2.3, the global house-price cycle has become quantitatively significant in recent years. The results are consistent with the notion that the global house-price shocks have a bigger impact on the macroeconomic sector around the world after the turn of the century.

As documented in the previous section, the effect of global shocks are heterogeneous across countries. For the macroeconomic series of an individual country, the responses depend on how much of the variation in the series is attributable to the global factors of the underlying variables. For instance, the negative equity-price shock is associated with a decline in the global GDP factor by about 0.25 standard deviation. Since the variation of GDP attributable to the global GDP factor is different for different countries, the effect of the global equity-price shock is different as well. For instance, based on Table 2.4, a decline of 0.25 standard deviation in the global GDP factor explains about 0.05 standard 
deviation decline in the GDP of the US, whereas it explains a decline of about 0.19 standard deviation in the GDP of the UK.

In summary, the findings suggest that the global financial shocks transmit to the global macroeconomic sector. The findings are consistent with the existing studies on the effects of global shocks or cross-border spillovers (Cesa-Bianchi (2013); Cesa-Bianchi et al. (2015); Ciccarelli et al. (2012); Eickmeier and Ng (2011); Gambetti and Musso (2017)).

The global equity-price shock generates larger responses from the global macroeconomic sector compared to global credit and house-price shocks, but the effects are relatively shortlived. There is evidence of time variation in transmission of the financial shocks, especially the equity-price and house-price shocks. The increase in the transmission of the equityprice and house-price shocks are larger during crisis periods, especially during the recent financial crisis, compared to normal times. The findings in this sub-section are novel.

\section{Responses to the Country-specific Shocks}

Next, I study the international transmission of the financial shocks in three select countries: the United States, the United Kingdom and Germany. First, I study the effects of shocks to the financial variables of the US. Figure 2.8 illustrates the responses of the global macroeconomic factors to negative shocks in the US financial variables. To save space, I present responses estimated for each time periods only, over the horizon of 18 years. Rows 1, 2 and 3 illustrate responses to the US credit, equity-price and house-price shocks respectively. The first column plots the median impulse responses of the global GDP factor, second column plots the median impulse responses of the global investment factor and third column plots the median impulse responses of the global inflation factor.

The responses of the global macroeconomic factors are mostly similar qualitatively to that of the responses to the global financial shocks. There is significant time variation in the responses to the US financial shocks. The effects of credit shock appear to be getting 
Figure 2.5: Impulse Response of Global GDP factor to Shock in Global Factors of Credit, Equity Prices and Housing Prices, respectively

(a) Credit
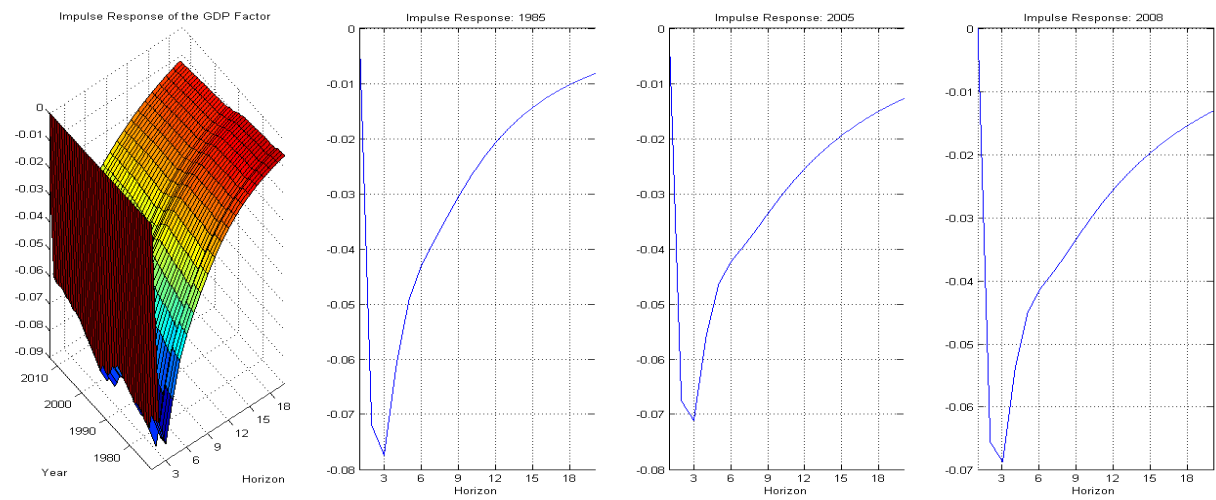

(b) Equity Prices
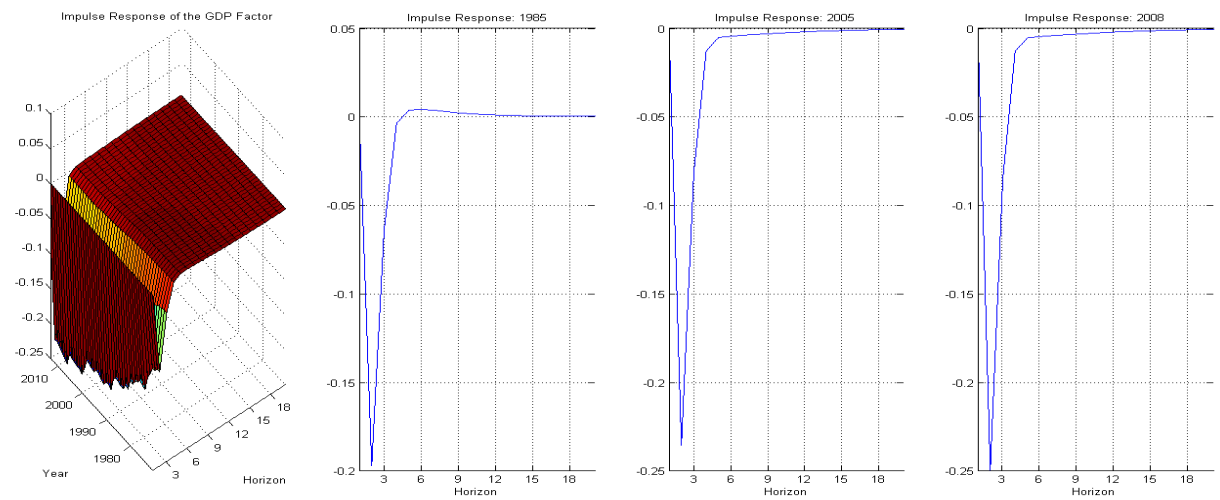

(c) House Prices
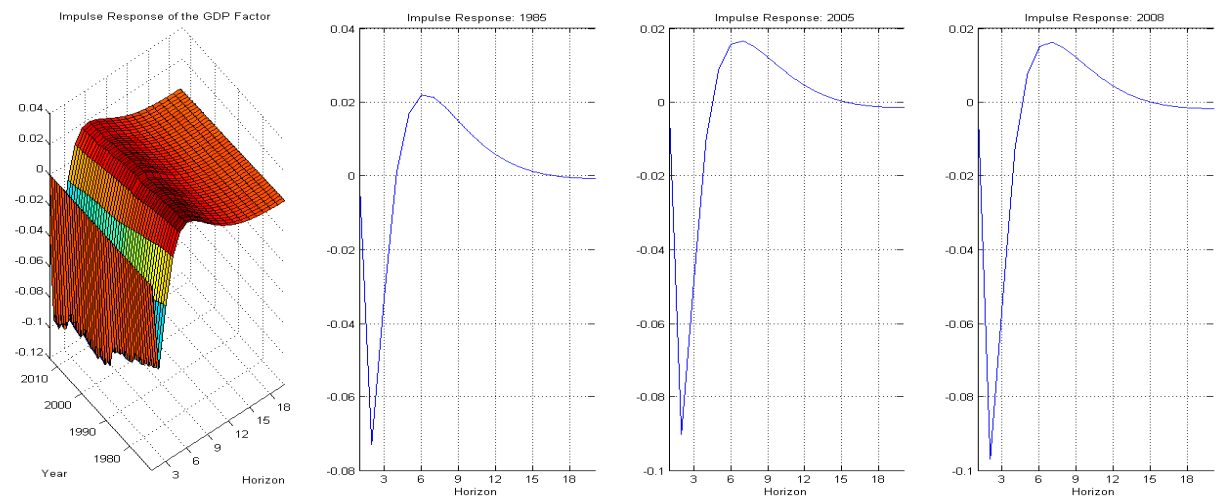

Figures plot the impulse responses of the global GDP factor to one standard deviation negative shock to the global factors of the financial variables. Rows 1, 2 and 3 illustrate responses to the shock to the global credit, equity-price and house-price factors respectively. First column plots the median impulse responses to the shock estimated for each time periods over the horizon of 18 years. Second, third and fourth column plot responses to the shocks in 1985, 2005 and 2008 respectively. 
Figure 2.6: Impulse Response of Global Investment factor to Shock in Global Factors of Credit, Equity Prices and Housing Prices, respectively

(a) Credit
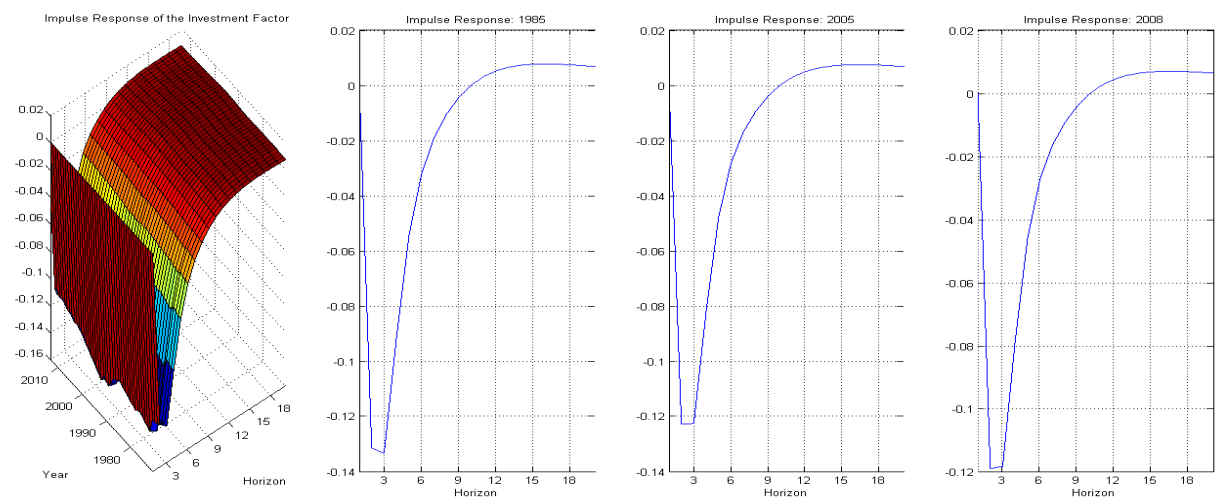

(b) Equity Prices
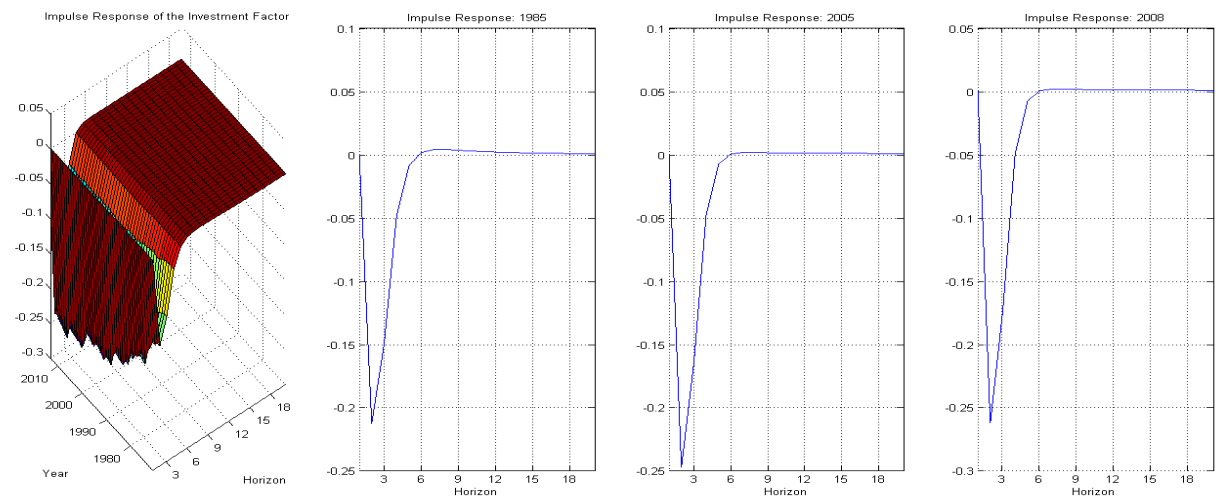

(c) House Prices
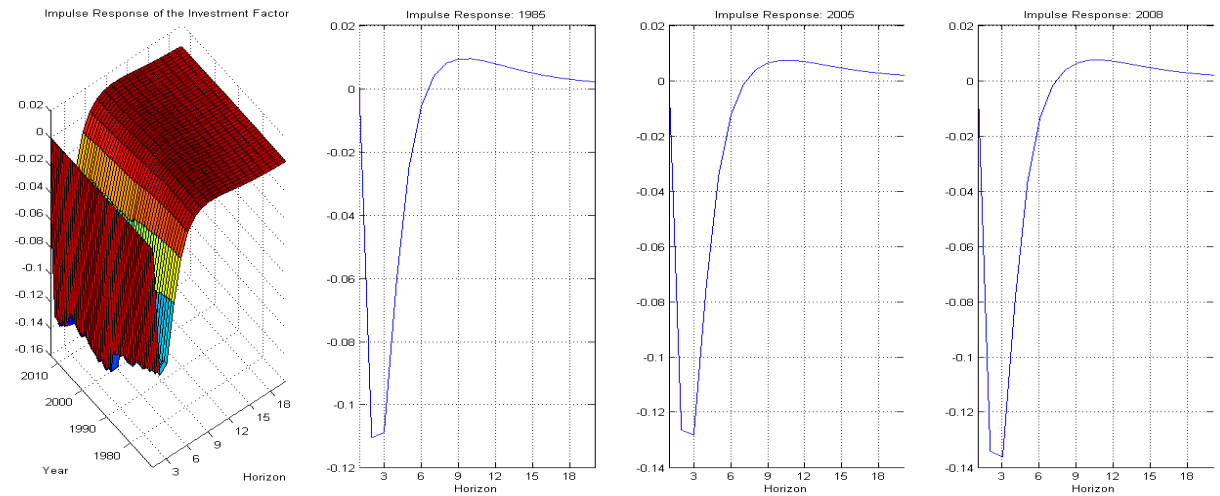

Figures plot the impulse responses of the global investment factor to one standard deviation negative shock to the global factors of the financial variables. Rows 1, 2 and 3 illustrate responses to the shock to the global credit, equity-price and house-price factors respectively. First column plots the median impulse responses to the shock estimated for each time periods over the horizon of 18 years. Second, third and fourth column plot responses to the shocks in 1985, 2005 and 2008 respectively. 
Figure 2.7: Impulse Response of Global Inflation factor to Shock in Global Factors of Credit, Equity Prices and Housing Prices, respectively

(a) Credit
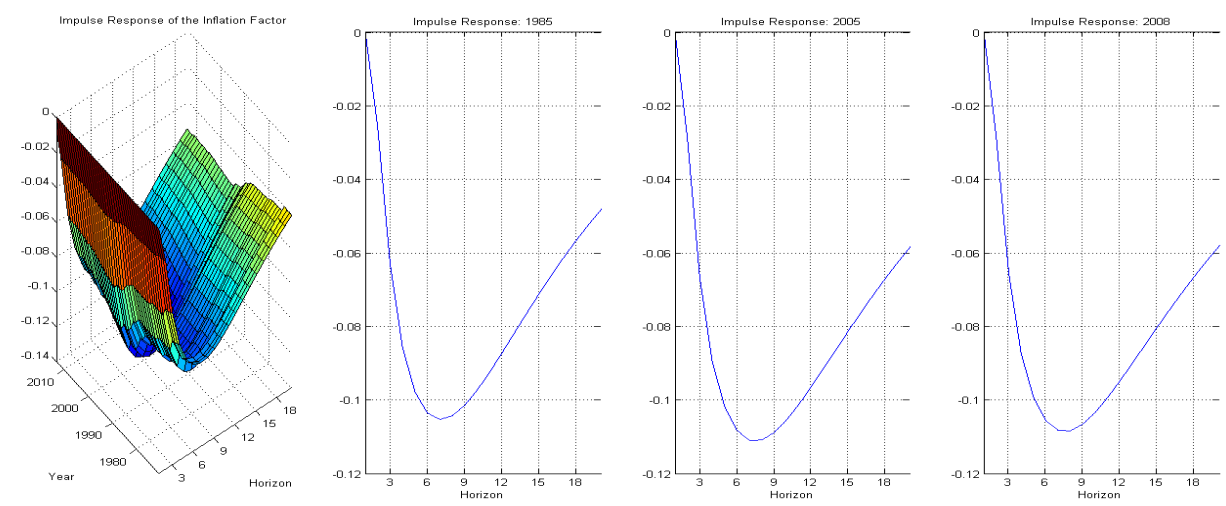

(b) Equity Prices
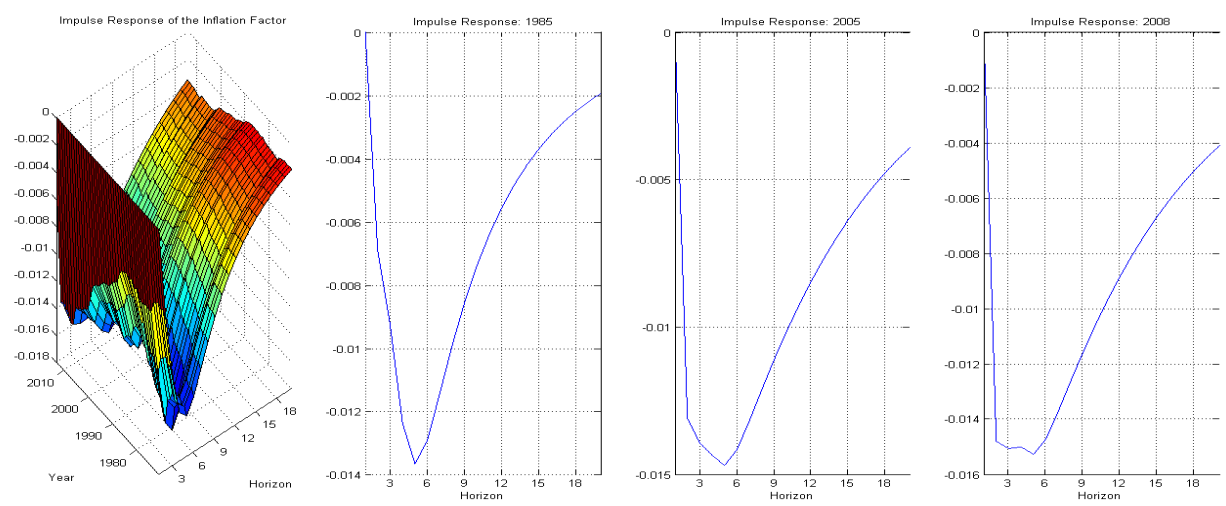

(c) House Prices
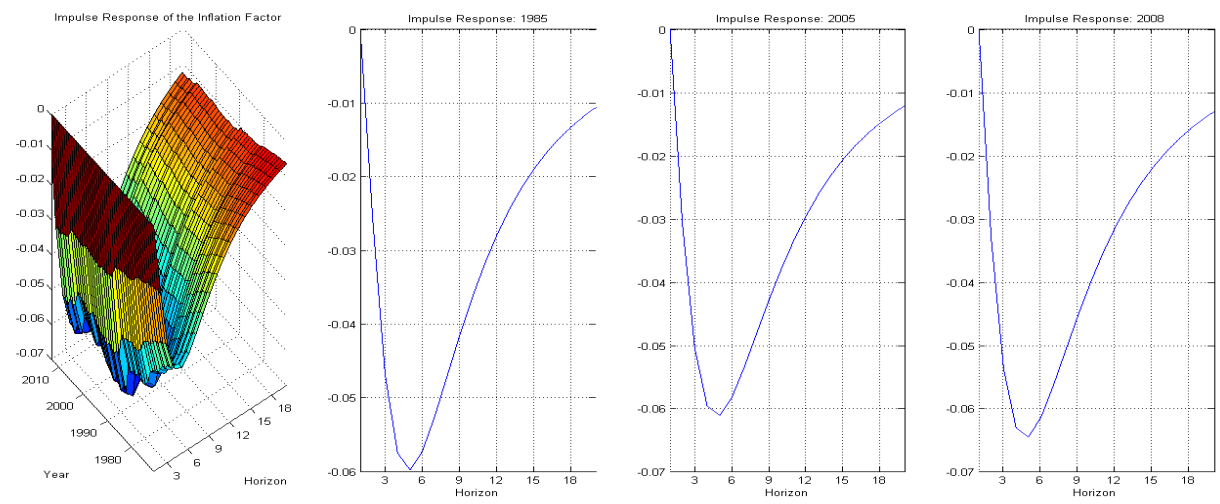

Figures plot the impulse responses of the global inflation factor to one standard deviation negative shock to the global factors of the financial variables. Rows 1, 2 and 3 illustrate responses to the shock to the global credit, equity-price and house-price factors respectively. First column plots the median impulse responses to the shock estimated for each time periods over the horizon of 18 years. Second, third and fourth column plot responses to the shocks in 1985, 2005 and 2008 respectively. 
slightly smaller over time, however, the effects of the equity-price shock and the houseprice shock are growing in magnitude over time. The effects of the equity-price shock are larger during, and after, the 2000 crisis, and there is further increase in responses during the recent financial crisis. For the GDP and investment factors, the responses to the house-price shock are stable until the mid-2000s but increase sharply around the financial crisis. The findings support the observation that the housing crisis in the US contributed to the global recession.

Interestingly, while the effect of the house-price shock on the inflation factor is as expected, the effects of the credit and equity-price shock imply a price puzzle. This is most likely due to aggregate supply effect dominating aggregate demand effect. ${ }^{27}$

Second, I study the effects of shocks in the financial variables of the UK on the global macroeconomic factors. Figure 2.9 illustrates the responses of the global factors of GDP, investment and inflation to negative shocks in the UK credit, equity price and house prices. The effects of the UK credit shock is quantitatively very small. For the house-price shock, the responses of the macroeconomic factors are again quite small, except for the investment factor, and do not show significant time variation. The responses of both GDP and investment factor to the equity-price shock are decreasing over time but the trend does not change drastically during the financial crises.

Third, I study the effects of shocks in the financial variables of Germany on the global macroeconomic factors. Figure 2.10 illustrates the responses of the global factors of GDP, investment and inflation to negative shocks in the credit, equity price and house price of Germany. The responses of the global inflation factor are quantitatively very small. The effects of the German house-price shocks are fairly small as well. Hence, I focus on the responses of the global GDP and investment factors to the shocks in German credit and

\footnotetext{
${ }^{27}$ the effect could be negative or positive depending on whether demand channel (through negative wealth effect) or supply channel (lower availability of funds and working capital) is bigger. Studying supply and demand shocks separately can shed light into understanding the mechanisms at work.
} 
Figure 2.8: Impulse Response of the Global Macroeconomic Factors to the US Financial Shocks
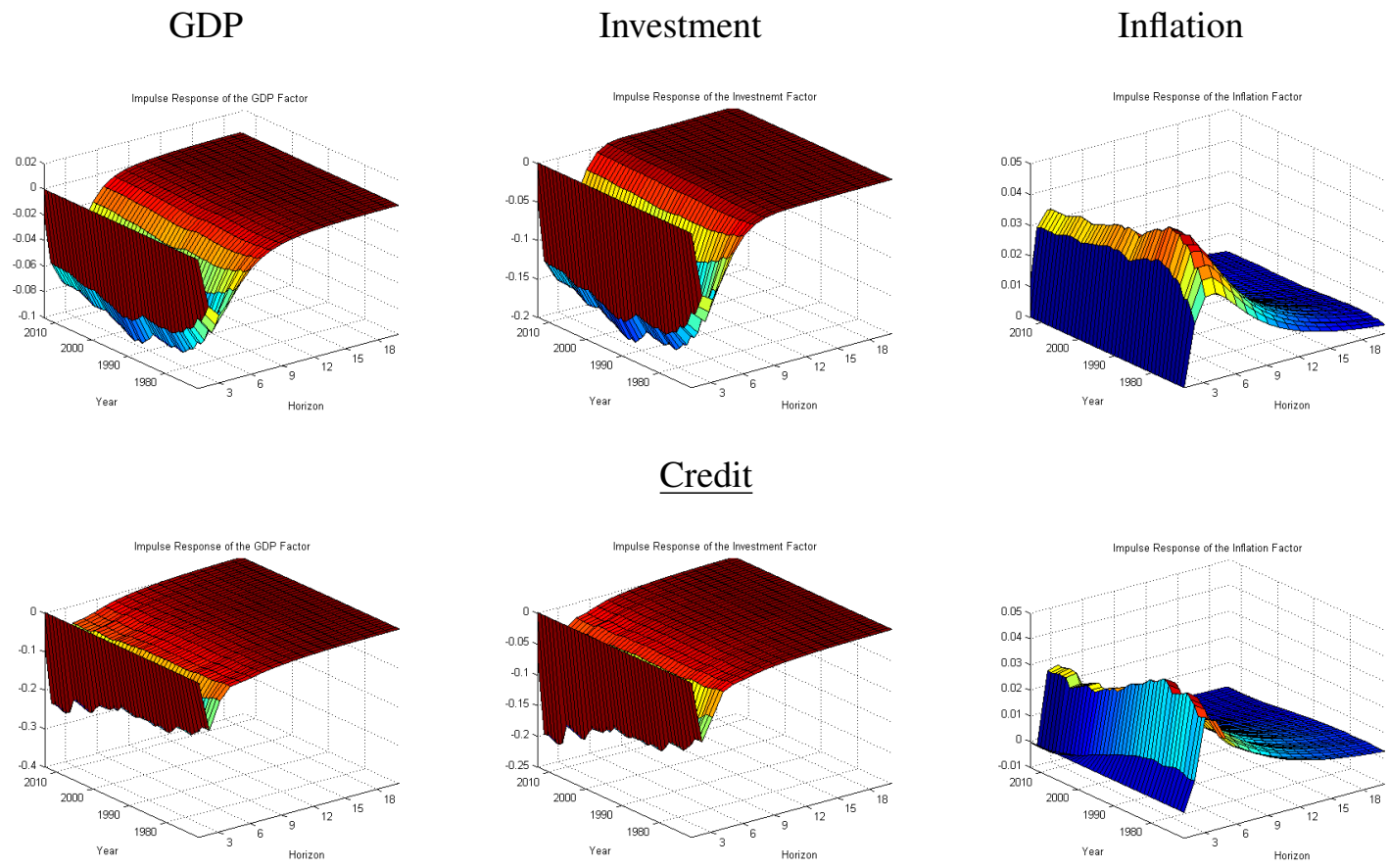

\section{$\underline{\text { Equity Price }}$}
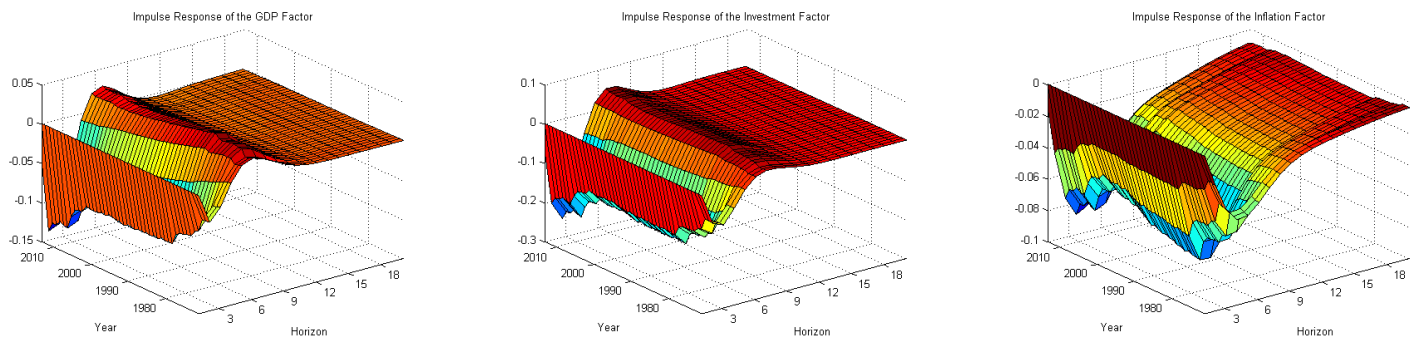

\section{$\underline{\text { House Price }}$}

Figures plot the impulse responses of the global macroeconomic factors to one standard deviation negative shock to the US financial shocks. Rows 1, 2 and 3 illustrate responses to the US credit, equity-price and house-price shocks respectively. First column plots the median impulse responses of the global GDP factor, second column plots the median impulse responses of the global investment factor and third column plots the median impulse responses of the global inflation factor estimated for the full sample over the horizon of 18 years. 
Figure 2.9: Impulse Response of the Global Macroeconomic Factors to the UK Financial Shocks
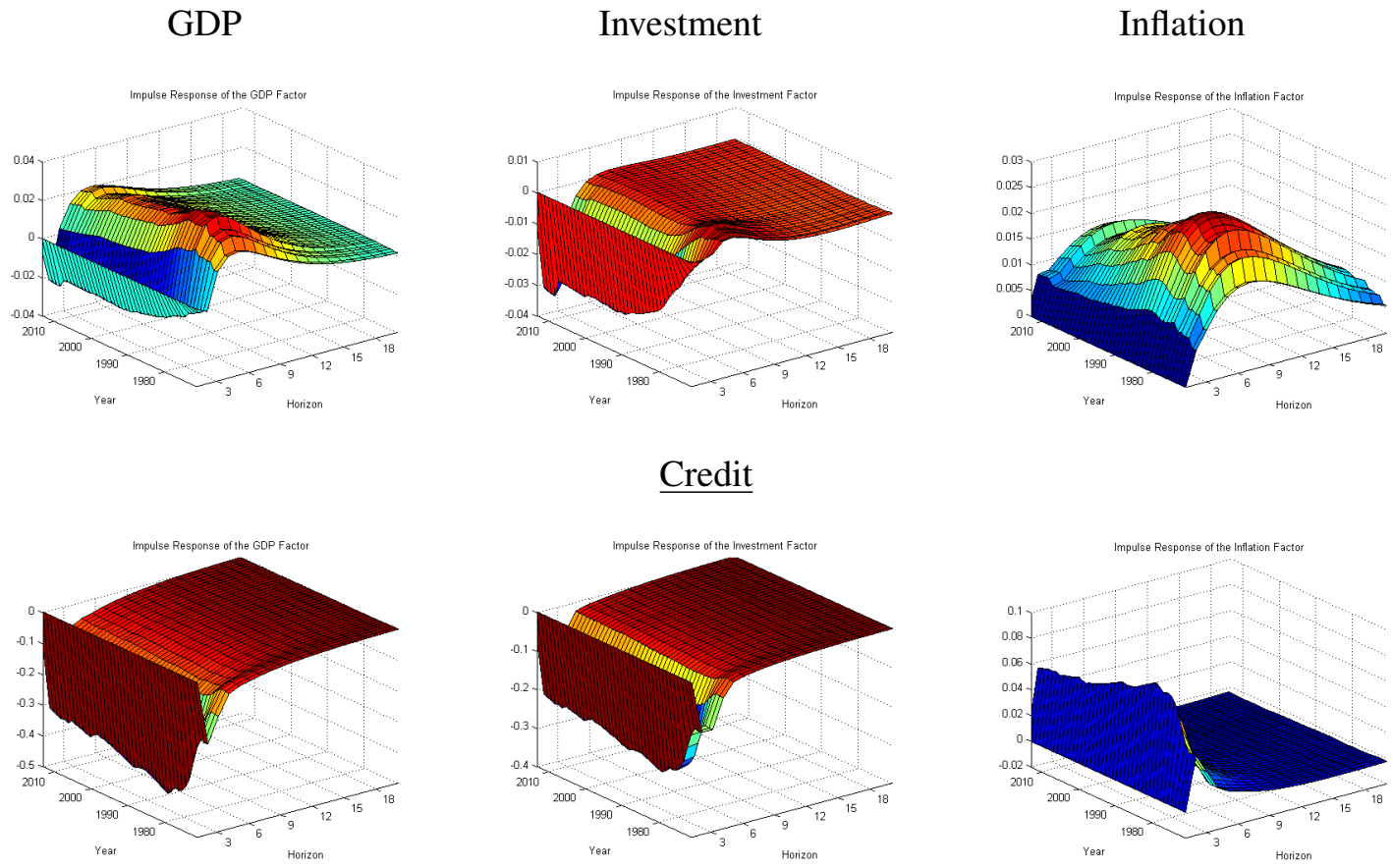

\section{$\underline{\text { Equity Price }}$}
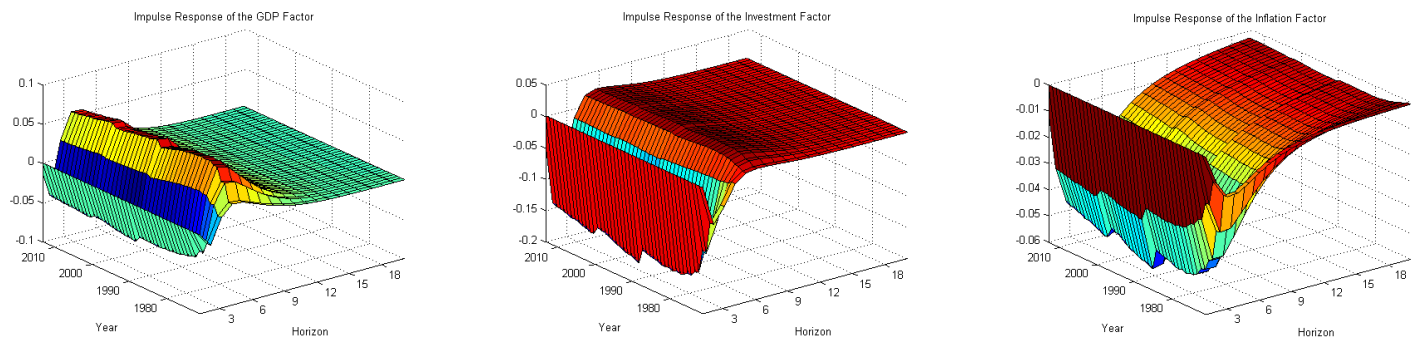

\section{$\underline{\text { House Price }}$}

Figures plot the impulse responses of the global macroeconomic factors to one standard deviation negative shock to the UK financial shocks. Rows 1, 2 and 3 illustrate responses to the UK credit, equity-price and house-price shocks respectively. First column plots the median impulse responses of the global GDP factor, second column plots the median impulse responses of the global investment factor and third column plots the median impulse responses of the global inflation factor estimated for the full sample over the horizon of 18 years. 
equity-price factors.

The German credit and equity-price shocks have qualitatively similar effects on the global GDP and investment factors as observed for the US credit and equity-price shocks. It is easy to see that there are drastic changes in responses around 1990s. The increase during the time is not unexpected as two major political and economic event occurred around the time. First, in 1990, the famous Berlin wall was torn down to form a unified Germany, which was followed by Germany joining the Maastricht Treaty on the European Union. Moreover, there are drastic changes in responses to the equity-price shock during the recent financial crisis. Hence similar to the effect of the US equity-price shock, the impact of German equity-price shock has grown in prominence, especially during the 1990s and the recent financial crisis.

In summary, I find that the country-specific financial shocks of the US, the UK and Germany transmit to the global macroeconomic sector. I also find that there is significant time-variation in the responses of global macroeconomic factors to the financial shocks. The credit and equity-price shocks of Germany show a significant increase in transmission during the 1990s crisis. The US and German equity-price shocks show a significant increase in transmission during the 2000s stock market crash. In the recent financial crisis, the US equity-price and house-price shocks show a significant increase in transmission, suggesting a non-negligible role of the US equity-price and house-price shocks during the financial crisis. One reason for the increased effect of the house-price shock in the second half of the 2000s could be that the extension of subprime mortgage lending triggered the increase in house prices, which is picked up by the house-price shocks. ${ }^{28}$ This allowed households to borrow at an easy term and intermediaries to increase lending as a result of higher net worth. The decline in house prices since 2006 led to reversal of these develop-

\footnotetext{
${ }^{28}$ Linking changes in parameters directly to variables capturing the events might shed light on the origin of the crisis.
} 
Figure 2.10: Impulse Response of the Global Macroeconomic Factors to the German Financial Shocks
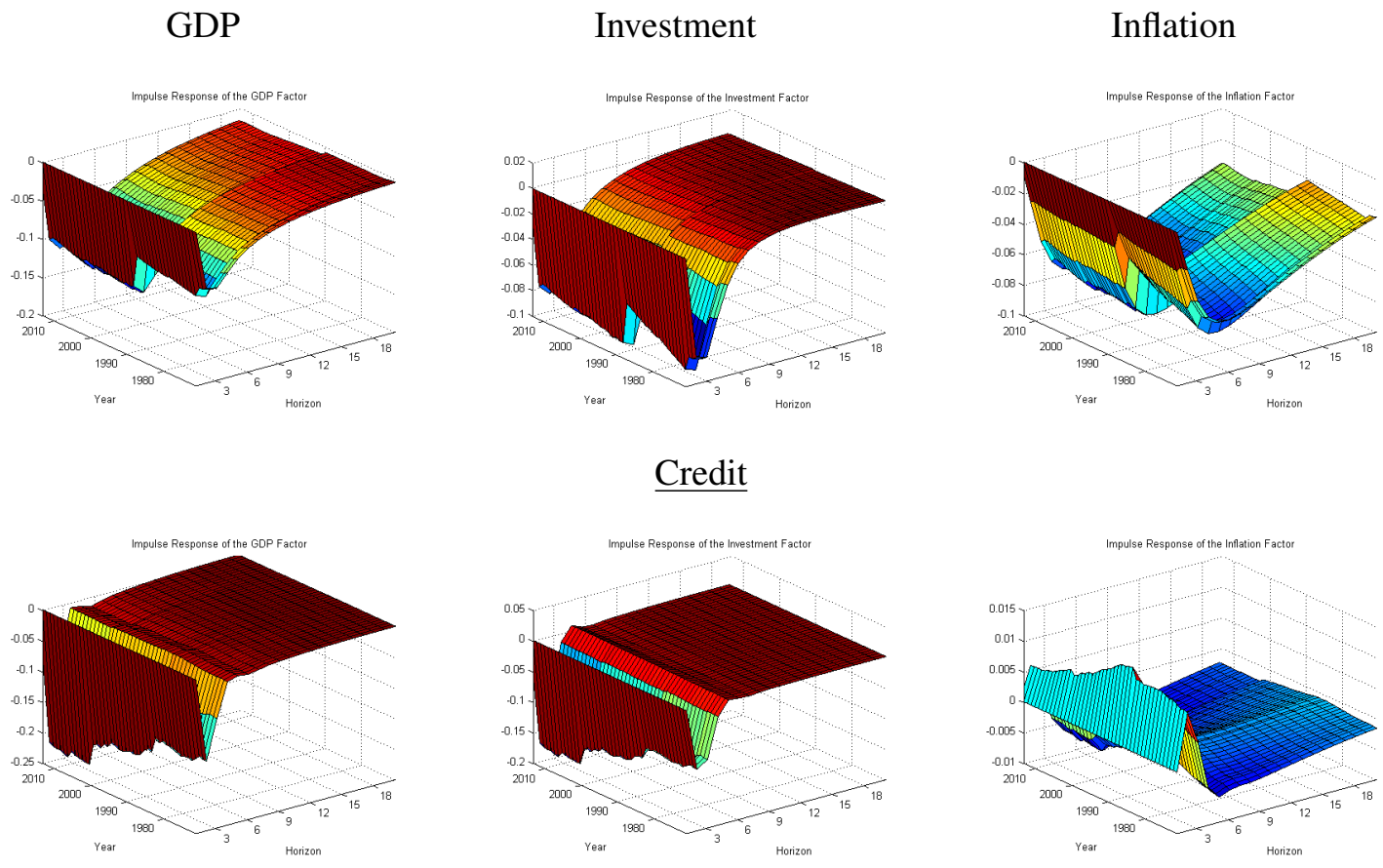

\section{$\underline{\text { Equity Price }}$}
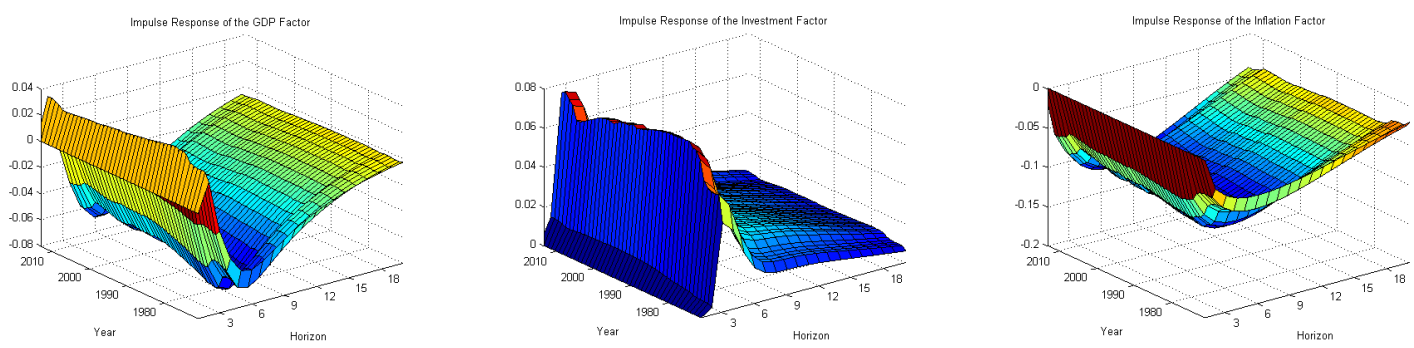

\section{$\underline{\text { House Price }}$}

Figures plot the impulse responses of the global macroeconomic factors to one standard deviation negative shock to the German financial shocks. Rows 1, 2 and 3 illustrate responses to the German credit, equity-price and house-price shocks respectively. First column plots the median impulse responses of the global GDP factor, second column plots the median impulse responses of the global investment factor and third column plots the median impulse responses of the global inflation factor estimated for the full sample over the horizon of 18 years. 
ments with negative effect on the macroeconomic sector. Hence, the house-price shocks have larger effects on macroeconomic sector when collateral effects are taken into account. The amplification mechanism is similar to those explained in the theoretical literature that implement an amplification mechanism (or financial accelerator). ${ }^{29}$

The findings are consistent with the actual observations during the crises. The findings also reinforce the studies that find similar time variation in the effects of the financial shocks (Abbate et al. (2016); Prieto et al. (2016); Kaufmann and Valderrama (2010); Davig et al. (2010); Guerrieri and Iacoviello (2017); Eickmeier and Ng (2011); Ciccarelli et al. (2012); Hubrich and Tetlow (2015); Nason and Tallman (2015); Gambetti and Musso (2017)). Most of the studies find increase in effect of the financial shocks during the crisis period compared to normal times. One thing to note is the vast majority of the papers attribute most of the time-varying contribution of the financial shocks to changes in the size of the shocks. ${ }^{30}$ The findings in this sub-section imply that the transmission of the financial shocks are changing over time, especially during the crisis periods. I study the time variation in the size of the shocks by analyzing time-varying volatility of the shocks in next sub-section.

\section{Shocks Volatilities}

The analysis thus far has shown non-negligible time variation in transmission of the financial shocks to the global macroeconomic sectors. In this sub-section, I study if there is time variation in the size of the shocks as well. Figure 2.11 presents the variances of the orthogonalized shocks. Rows 1, 2 and 3 illustrate the variances of the Credit, equity-price and

\footnotetext{
${ }^{29}$ See Bernanke et al. (1999); Carlstrom and Fuerst (1997); Kiyotaki and Moore (1997); Geanakoplos (2010); Adrian et al. (2013). Iacoviello and Neri (2010) show similar amplified effect in an estimated DSGE model.

${ }^{30}$ Except for Kaufmann and Valderrama (2010); Hubrich and Tetlow (2015); Eickmeier and Ng (2011); Gambetti and Musso (2017) and Prieto et al. (2016) who find change in transmission mechanism during crisis period as well as shock sizes.
} 
house-price shocks respectively. The first column plots the variances of the global shocks. The second, third and fourth columns plot the variances of shocks to the financial variables of the US, the UK and Germany respectively. In general, the presence of time variation in the shock sizes is evident. The volatilities of the global shocks increase, suggesting an increase in shock sizes, during most of the crisis in the sample period. The global shocks, the US equity-price and house-price shocks show a significant increase in size during the recent financial crisis. The size of the credit shock of Germany increases significantly during the 1990s crisis. The findings are in line with most of the studies discussed in the previous sub-section, and support the use of time-varying shock volatilities. The findings in this section imply that the time variation in the effects of the financial shocks on the global macroeconomic sector can be attributed to both change in the transmission mechanism and the size of the shocks.

Increase in the transmission and the size of the house-price shocks (both global and the US) might help explain the slow recovery following the Great Recession. First, the combination of magnitude of increase in the transmission and the size of the shocks is unprecedented in the sample. In that sense, the Great Recession was different from the previous recessions. Second, the persistence of the shocks are relatively longer (3-6 years). These two findings together could imply longer impact due to the house-price shocks and hence, slower recovery. Prieto et al. (2016); Justiniano et al. (2015) explain similar role of the house-price shocks in slower recovery from the Great Recession. Claessens et al. (2012) also show that recessions associated with housing crisis tend to be deeper and longer.

Moreover, the findings thus far show that not all crises are the same. For instance, the house-price shocks play an important role in the Global Financial Crisis, while the shocks are not as important during other crises. The equity-price shocks show significant increase during the 2000 stock market crash, while other shocks do not. Hence, financial crises are different in terms of their source and hence, impacts and recovery from the crises are 
Figure 2.11: Volatility of the Estimated Financial Shocks

Global
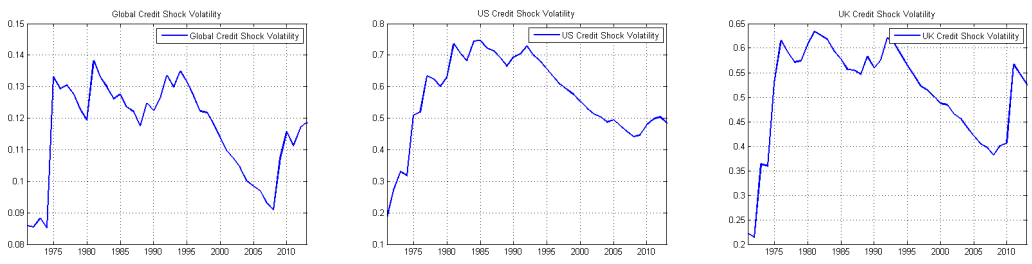

$\underline{\text { Credit }}$
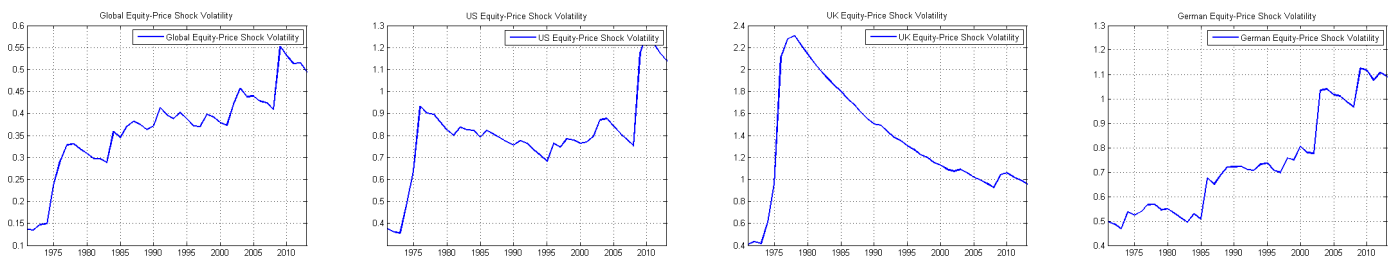

Equity Price
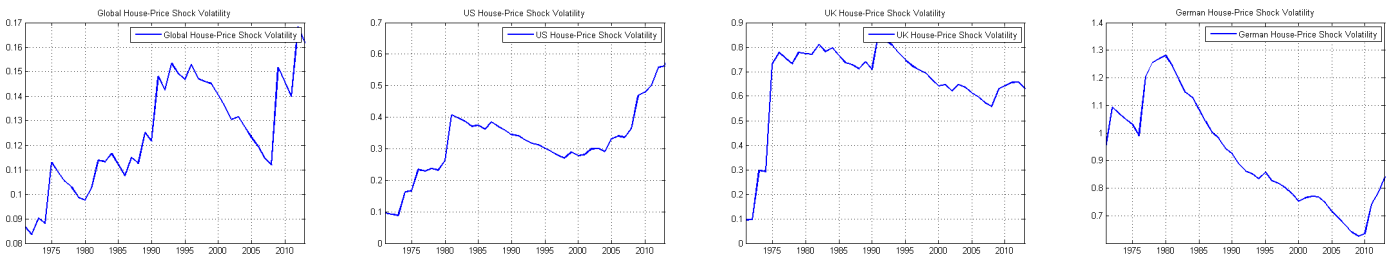

$\underline{\text { House Price }}$

Figures plot the variances of estimated financial shocks (median estimates). Rows 1, 2 and 3 illustrate variances of the Credit, equity-price and house-price shocks respectively. First column plots the variance of global shocks. Second, third and fourth columns plot the variances of shocks to the financial variables of the US, the UK and Germany respectively.

different as well.

\subsection{Robustness Tests}

To probe the robustness of the main results, I perform additional tests. First, I compare the main findings with those from the constant-parameter model. Second, I use the timevarying parameter model to analyze the US data and compare with the existing literature. Third, I include global consumption factor in the VAR. For the sake of brevity, I report the 
responses of the GDP factor only.

\subsubsection{Analysis Using Constant-parameter Model}

Section 2.4 reports the estimated GDP and financial factors, and the variance decompositions from constant-parameter model (CP-model), along with the time-varying parameter model (TVP-model). As reported in the section, findings from the CP-model are similar to that from the TVP-model, illustrating robustness of the findings. In this section, I report impulse responses of the GDP factor to the financial shocks using the CP-model, illustrated in figure 2.12. The first, second and third row present responses of the global GDP factor to the global credit shock, the global equity-price shock and the global house-price shock respectively. The first column presents analysis on the entire sample period, whereas the second and third column are on subset of the sample period to represent shocks in 1978 and 2005 respectively. By studying responses to the shocks at different time period, I better understand possible time variation in the transmission of the shocks. The direction of the responses are as expected. Now, comparing the responses to the shocks at different time periods, it is visible that the responses are changing over time. First, the responses of the global GDP factor to the financial shocks in 1978 are relatively small. Then the responses to the shocks in 2005 are larger compared to that of the shocks in 1978. The reason is that the series picks up the information of 1980s, 1990s and early 2000s, during which time, there were three different crisis. This implies that the responses during those time periods were larger than those before 1978. The responses increase further to the shock in 2013 (full sample) implying that there were larger effect during the recent financial crisis than historically. The effects of the equity-price and the house-price shocks grow significantly larger compared to the credit shocks, implying that the equity-price and the house-price shocks have larger impacts on macroeconomic fluctuations in the last past few crises. These findings reinforce the findings that the transmission of the shocks are 
Figure 2.12: Impulse Response of the Global GDP Factor to the Global Financial Shocks
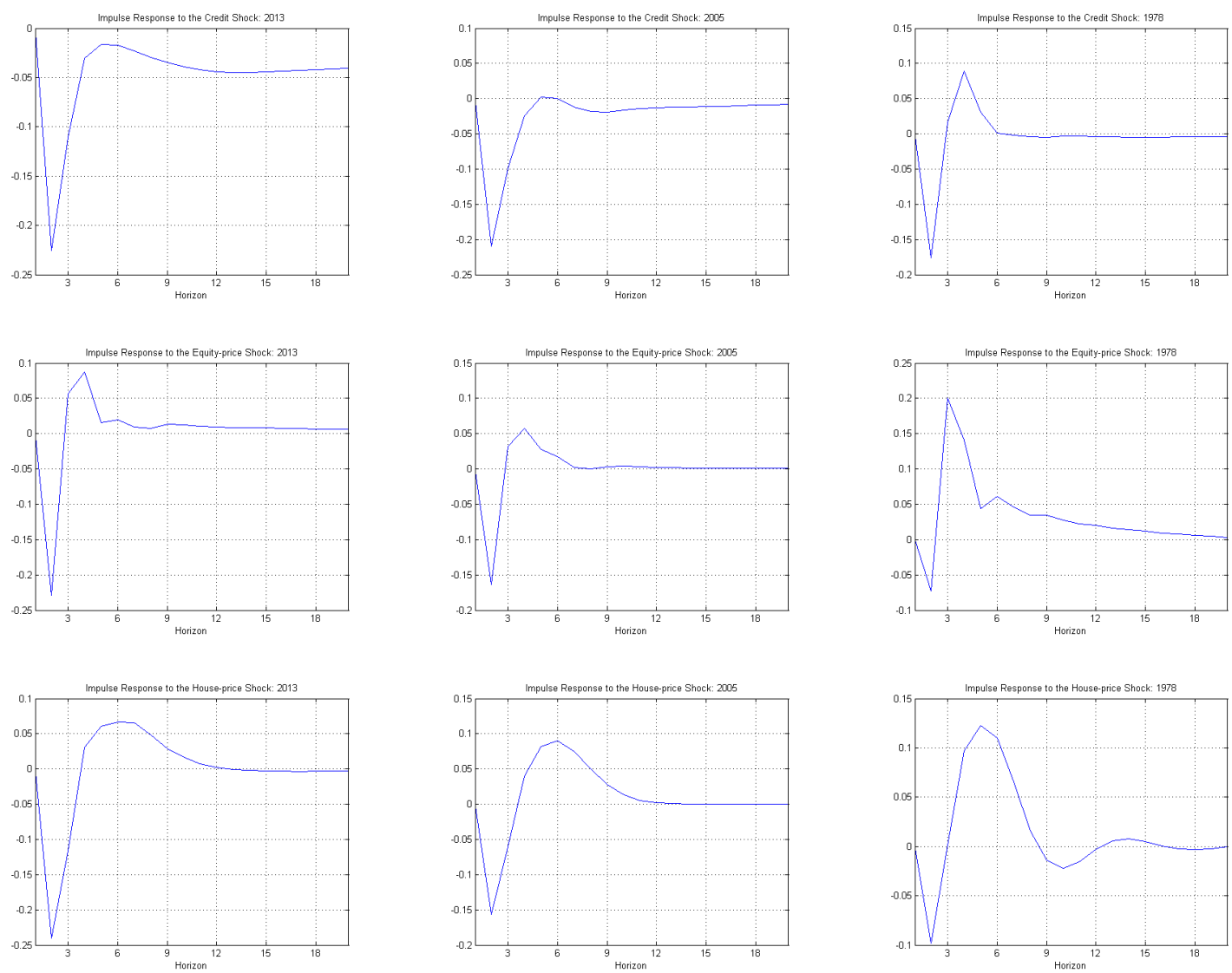

Figures plot the impulse responses of the global GDP factor to one standard deviation negative shock to the global financial shocks using constant-parameter model. Rows 1, 2 and 3 illustrate responses to the global credit, equity-price and house-price shocks respectively. First column plots the median impulse responses to the shocks estimated for the full sample over the horizon of 20 years. Second and third column plot responses to the shocks in 2005 and 1978 respectively.

time-varying, with possible larger impact during the crisis periods.

\subsubsection{Analysis on the US}

Next, I study the time-varying macro-financial relationship in the US and compare the findings to those of the existing literature. Figure 2.13 presents the impulse responses of the US GDP growth to the shocks in the US financial variables, and their volatilities, for each time periods over the horizon of 18 years. Qualitatively, the results are similar to that of Section 2.4. The GDP growth decreases in response to all three shocks. The credit shock 
generates relatively larger response during the 1990s crisis compared to other time periods. The equity-price shock similarly generates larger response during the 2000 s and the recent financial crisis. Impact of the house-price shock increases during the recent financial crisis as well. Quantitatively, the impacts of the equity-price and the house-price shocks are significantly larger than the credit shock in the recent financial crisis.

The credit and the equity-price shock volatilities increase sharply in the 1970s crisis. The credit shock volatility also increases sharply in the 1990s savings and loan crisis, while the equity-price shock volatility increases during the 2000 s stock market crash. All three shock volatilities increase significantly during the recent financial crisis.

These findings are consistent with the historical observations and the findings in the literature illustrating the validity of the methodology used in the paper. The studies that focus on the US report similar increased effects of the financial shocks during the crisis periods. $^{31}$

\footnotetext{
${ }^{31}$ See Abbate et al. (2016); Prieto et al. (2016); Kaufmann and Valderrama (2010); Davig et al. (2010); Eickmeier et al. (2011); Guerrieri and Iacoviello (2017); Ciccarelli et al. (2012); Hubrich and Tetlow (2015); Nason and Tallman (2015); Gambetti and Musso (2017). Kaufmann and Valderrama (2010); Hubrich and Tetlow (2015); Eickmeier et al. (2011); Gambetti and Musso (2017) and Prieto et al. (2016) also find changes in the transmission during the crisis period.
} 
Figure 2.13: Effects of the US Financial Shocks on the US GDP Growth

(a) Credit Shock
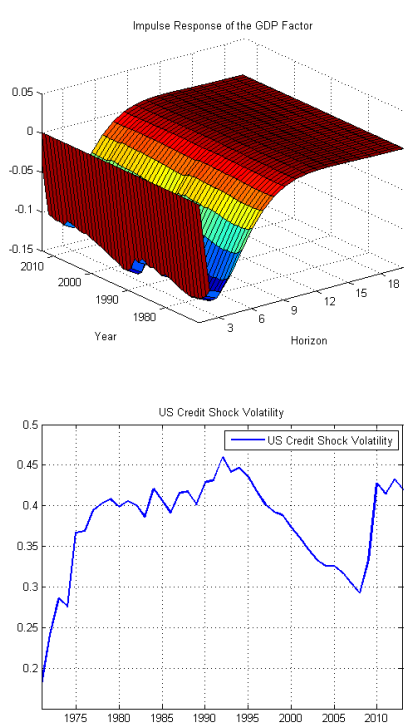

(b) Equity-Price Shock
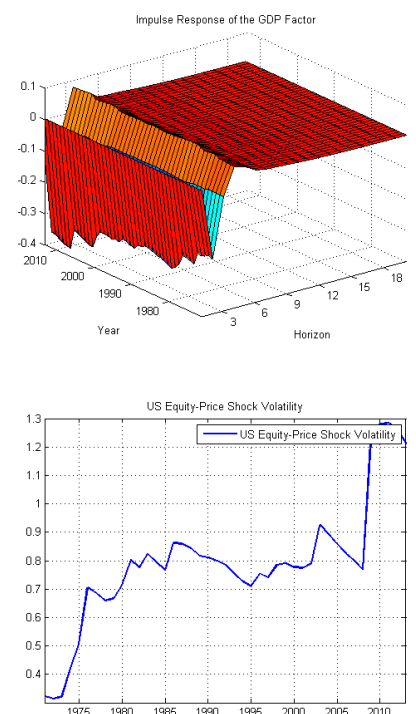

(c) House-Price Shock
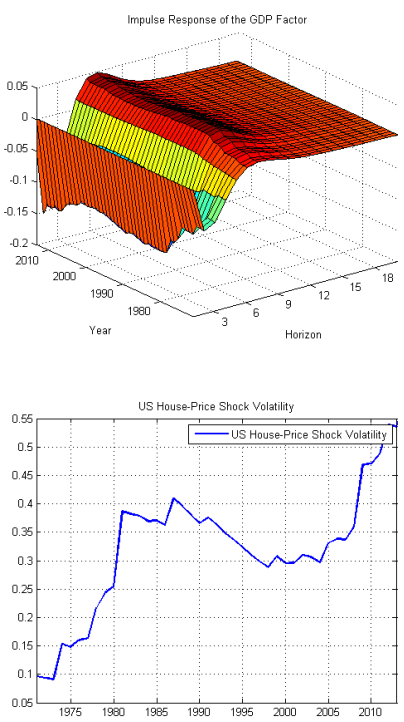

Figures plot the impulse responses of the US GDP growth to one standard deviation negative shock to the financial variables of the US, and the volatilities of the shocks. Figures in the first row illustrate responses to the US credit shock, equity-price shock and house-price shock respectively, estimated for each time periods over the horizon of 18 years. Figures on the second row illustrate volatilities of the US credit shock, equity-price shock and house-price shock respectively

\subsubsection{Including Consumption in the Model}

As another robustness test, I include the global consumption factor in the TVP-FAVAR to test if the results are sensitive to choice of variables. I order the consumption first based on the permanent income hypothesis and the fact that consumption growth is smoother historically than the GDP growth. ${ }^{32}$ Figure 2.14 presents the impulse responses of the global GDP factor to the global financial shocks, and the volatilities of the shocks, for each time periods over the horizon of 18 years. The findings are similar to the analysis without including the global consumption factor in Section 2.4. The findings of the paper are not affected significantly by the change made.

The robustness tests presented in this section support the main findings of the paper and

\footnotetext{
${ }^{32}$ Based on FRED's database.
} 
validates the choice of the data and model used in the paper.

Figure 2.14: Effects of the Global Financial Shocks on the Global GDP Factor

(a) Credit Shock
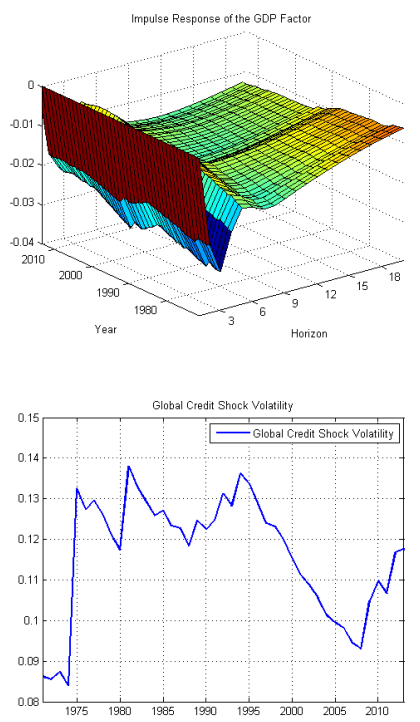

(b) Equity-Price Shock
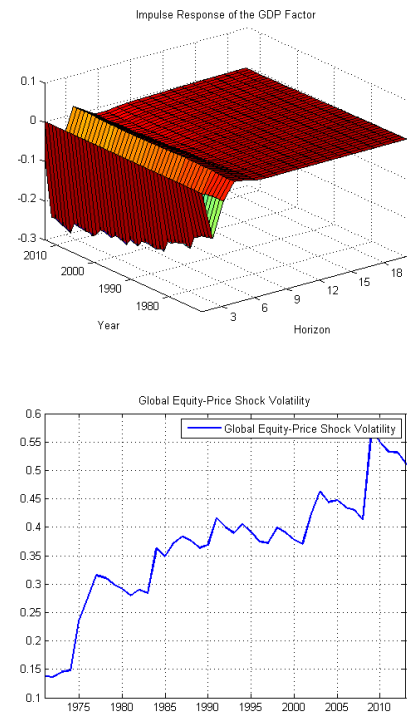

(c) House-Price Shock
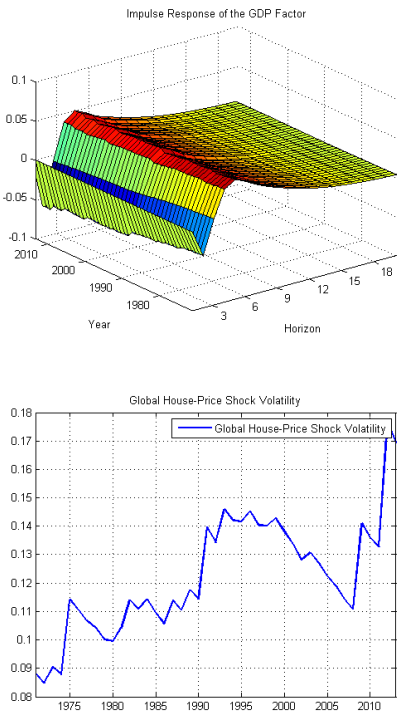

Figures plot the impulse responses of the global GDP factor to one standard deviation negative shock to the global financial factors, and the volatilities of the shocks. Figures in the first row illustrate responses to the global credit shock, equity-price shock and house-price shock respectively, estimated for each time periods over the horizon of 18 years. Figures on the second row illustrate volatilities of the global credit shock, equity-price shock and house-price shock respectively. The TVP-FAVAR used in the analysis includes global

consumption factor.

\subsection{Conclusion}

In this paper, I examine time-varying linkages between global financial and macroeconomic sectors. First, I examine the existence of global financial cycles using time-varying parameter dynamic factor model. Then I study if the global and country-specific financial sectors are important source of shocks for the global macroeconomic sector. I analyze whether global and country-specific credit, equity price and house price shocks contribute to the fluctuations in the global macroeconomic sector. I also examine if there is time variation in the contribution of the financial shocks, especially during financial crises. I study time variation in both the transmission of the shocks to the global macroeconomic sector and the 
size of the shocks. I use time-varying parameter factor-augmented vector autoregression (TVP-FAVAR) model with stochastic volatility to study the effects of the financial shocks. I analyze impulse responses to the shocks of the same size to isolate changes in transmission mechanism from changes in the size of the shocks, and analyze volatility of the shocks to study time variation in size of the shocks.

I find evidence of quantitatively significant global cycles in credit and equity price. Moreover, the cycles are stronger in the years leading up to and following the crisis. The house-price growths are mostly driven by the idiosyncratic components over the sample period, but the house-price cycle has become quantitatively significant since the turn of the century. The findings imply growing comovements in the financial sectors across countries. I do not find evidence of quantitatively significant joint global financial cycle encompassing all three financial variables over the entire sample period.

I find that both the global and the country-specific shocks contribute to the fluctuations in the global cycles of macroeconomic variables. The equity-price shocks generate quantitatively larger responses than the credit and the house-price shocks, but are less persistent. The effects of the equity-price and the house-price shocks are increasing after the turn of the century. I find evidence of time variation in the size and the transmission of the financial shocks, especially the equity-price and house-price shocks. I find evidence of an increase in the transmission of the financial shocks as well as an increase in the size of the shocks during various financial crises, especially during the recent financial crisis. The contribution of the global and the US equity-price and house-price shocks increase significantly during the recent financial crisis. The findings show that different financial crises are different in nature. The house-price shocks play an important role in the Global Financial Crisis, whereas the equity-price shocks drive the 2000 stock market crash.

The model is also able to produce heterogeneous effects of the financial shocks across countries. There is large degree of heterogeneity on the share of variance attributable to the 
global factors across countries, so the shocks that affect the global factors affect different countries differently.

Understanding the nature and sources of comovements of the financial and macroeconomic sector, and their relationship at a global level is essential for macroeconomic policymaking at a national level, as well as coordination of policies between countries. It is also essential for building on the existing theoretical literature and designing models that explain the relationship better. A better understanding of such relationship empirically is an important building block for designing dynamic models that can replicate changing nature of the relationship and analyze policy responses to different shocks. 


\section{Chapter 3}

\section{Decentralization and Regional}

\section{Convergence: Evidence from Night-time Lights Data}

\subsection{Introduction}

In the last few decades, more than 70 countries have implemented some form of decentralization reform by giving subnational governments power to tax, spend, legislate, and elect government officials within their jurisdiction. Decentralization has been at the center of institutional reforms not only in developed countries, but also in many developing and transition economies in Africa, Asia, and Latin America (Garman et al., 2001; Bardhan, 2002; Hooghe et al., 2010). This momentum is expected to continue as subnational movements, national governments, and multilateral organizations often praise the benefits of decentralized governments (Burki et al., 1999; The World Bank, 2000).

One of the primary stated objectives of decentralization is to improve economic growth. Decentralization can improve economic growth by increasing the effectiveness and effi- 
ciency of the public sector, by fostering competition among regional governments, and by better matching resources and preferences of communities and governments (Teibout, 1956; Oates, 1993; Weingast, 1995; Qian and Weingast, 1997; Ezcurra and Pascual, 2008; Arcalean et al., 2010). These "market preserving" theories are supported by empirical findings for developed countries (Akai and Sakata, 2002; Fisman and Gatti, 2002; Gemmell et al., 2013; Sobel et al., 2013). However, there is very little empirical evidence to support such reforms in developing countries.

A major argument against decentralization is the belief that it can inhibit growth in poorer regions, creating an even larger disparity between richer and poorer regions. Decentralization can increase regional inequality through various channels. First, limited state capacity and weaker endowments in poorer regions can lead to lower infrastructure spending in schools, roads, and electricity. Second, richer regions can provide comparable public goods at a lower average tax per resident than poorer regions, which makes poorer regions less attractive to businesses and investments. Third, governments in poorer regions are more prone to elite capture than governments in richer regions or national governments (Prud'Homme, 1995; Tanzi, 1995; Bardhan and Mookherjee, 2005). ${ }^{1}$ Finally, decentralization can limit the redistributive role of the central government, further worsening regional disparity (Meltzer and Richard, 1981).

Thus, whether decentralization causes regional convergence is ultimately an empirical question. Yet, due to lack of comparable data, quantifying the impact of decentralization from actual country experience has proved elusive, especially in developing countries.

This paper fills that gap by analyzing whether decentralization promotes or hinders convergence between a country's rich and poor regions using a sample of 69 developed and developing countries across the world. I find strong evidence of unconditional within-

\footnotetext{
${ }^{1}$ The elite capture is used to describe situations in which political and economic elites misappropriate resources and public funds.
} 
country convergence across the world, using both first-level and second-level subnational data. ${ }^{2}$ However, I find that decentralization slows down the speed of such regional convergence. These results are statistically significant and economically meaningful in the case of developing countries, whereas the estimates are mostly statistically insignificant for the high-income countries. For instance, calculations based on the coefficients from my preferred specifications (Table 3.3 Panel A) suggests that if the decentralization index of a country changes from the lowest possible value to the highest possible value, the growth rate of a region that is halfway to the country frontier (i.e., country's richest region) would decrease by about 8 percent. The estimates from other specifications also suggest that decentralization slows down the speed of regional convergence towards zero and in a few specifications it even leads to regional divergence, although at a negligible rate.

I also analyze the impact of changes in different components of decentralization such as fiscal autonomy, institutional depth, policy autonomy, and political representation on regional convergence. The sub-component analysis reinforces my baseline findings that decentralization substantially slows down the regional convergence in the developing countries. There is some heterogeneity in the magnitude of convergence coefficients across different components of decentralization, but one pattern stands out: the majority of the estimates for the developing countries are statistically significant, but the estimates for the high-income countries are mostly statistically insignificant.

I find that decentralization hinders not only within-country regional convergence but also within-first-subnational division regional convergence. In fact, the convergence coefficients of within-first-subnational division are larger than within-country convergence coefficients. This suggests that the growth of first subnational regions in developing countries is mostly driven by the growth of a few second subnational regions within that first

\footnotetext{
${ }^{2}$ To put into perspective, first subnational government for the United States are the states and second subnational government are counties.
} 
subnational region.

There are various challenges in estimating the actual impact of decentralization. First, subnational government data on economic activity do not exist in most of the developing countries. Second, existing measures of decentralization such as expenditures going through the subnational budgets or revenues raised by subnational governments do not accurately reflect the true measure of fiscal decentralization. For instance, using existing measures of decentralization, countries such as Sweden, Norway, Finland, and Denmark, where subnational governments spend and tax according to national laws, appear equally decentralized as countries such as Germany and the United States, where subnational governments enjoy genuine autonomy. Third, since most of the convergence literature uses country-level data, they are unable to mitigate endogeneity problems tied to omitted variables and reverse-causality (Ebel and Yilmaz, 2002; Thornton, 2007; Hooghe et al., 2016; Martinez-Vazquez et al., 2017).

The paper addresses all of these challenges, contributing to two strands of literature: decentralization and convergence. First, to circumvent the subnational data unavailability problem, I create a proxy for subnational income per capita by combining night-time lights data captured by U.S Air Force Satellite with georeferenced subnational population data from the Gridded Population of the World database. There are various advantages of using satellite data to measure economic activity: it provides data for a large number of countries, makes data immune to manipulation by national or subnational governments, and makes data highly comparable across countries since the differences in fiscal or statistical capacity across countries do not affect data quality. Due to these advantages, satellite data have been used extensively to measure economic activity both at the national level and the subnational level (see Donaldson and Storeygard (2016) for an excellent survey of such studies). However, Lessmann and Seidel (2017) is the only study I am aware of that 
uses satellite data to analyze regional convergence. ${ }^{3}$ The previous literature on the effects of decentralization has been limited to country-level analysis (Xie et al., 1999; Akai and Sakata, 2002; Sobel et al., 2013) or regional analysis of high-income economies (Thornton, 2007; Baskaran and Feld, 2013; Gemmell et al., 2013; Sorens, 2014). ${ }^{4}$ However, there are very few studies on developing countries. Moreover, they are all individual country cases such as Bagchi (2003) on India, Bonet (2006) on Colombia, Hill (2008) on Indonesia and Philippines, and Zhang and Zou (1998) and Liu et al. (2017) on China. Thus, my primary contribution is to expand the literature on the impact of decentralization to include a large number of developing countries.

Second, I contribute to the decentralization literature by using newly available data on decentralization, the Regional Authority Index, which improves previous measures used in the literature in two important ways (Hooghe et al., 2016; Sorens, 2015). First, it provides a comprehensive picture of decentralization by measuring it across dimensions such as fiscal autonomy, borrowing autonomy, institutional depth, policy autonomy, and representation. Second, it measures decentralization more accurately since this measure is derived from actual laws that are institutionalized and circumscribed, and are collected from documents such as constitutions, laws, executive orders, statutes or other written documents that are publicly available. ${ }^{5}$ There are few studies (Fan et al., 2009; Rodriguez-Pose and Ezcurra, 2010; Hammond and Tosun, 2011; Sorens, 2014) that use a more comprehensive measure

\footnotetext{
${ }^{3}$ my study differs from Lessmann and Seidel (2017) in two major ways. First, they focus on providing the evidence of regional convergence whereas I examine the role of decentralization in facilitating regional convergence. Second, their unit of observation is a country whereas my unit of observation is a subnational region.

${ }^{4}$ There is another strand of literature that studies the impact of decentralization on a country-level measure of regional disparity such as the Gini coefficient or the coefficient of variation. These studies also mostly focus on developed countries due to the lack of data (Canaleta et al., 2004; Lessmann, 2009; Rodriguez-Pose and Ezcurra, 2010)

${ }^{5}$ Following a different approach, Thornton (2007) and Baskaran and Feld (2013) use disaggregated data on the sources of tax revenue to create a more accurate measure of decentralization (e.g., own-source subnational revenue as a share of total national revenue). Unfortunately, due to data limitations their sample is limited to the OECD countries.
} 
of decentralization like ours, however, Sorens (2014) is the only study that studies the impact of decentralization on regional convergence. Thus, I contribute to the decentralization literature by expanding it to include measures other than fiscal decentralization.

Third, I combine national data on decentralization with subnational data on per capita income, which allows us to significantly mitigate the endogeneity problems tied to omitted variables and reverse-causality in country-level convergence literature. First, I augment the conventional convergence model by including country fixed effects as well as the growth of a country's frontier region as independent variables. This allows us to control for the time-invariant country characteristics as well as the country's overall growth performance and potentially the omitted factors that exert mutual influence on the country's growth and decentralization tendencies. Second, I use the region's distance-to-country-frontier to capture the region's relative development level rather than its initial income level since the region's distance-to-country-frontier is mostly independent of the country's development level or growth rate. Thus, I argue that it is unlikely that country-level decentralization reforms are prompted by higher regional growth rate, conditional on country-fixed effects and frontier region's growth (Aghion et al., 2005; Che and Spilimbergo, 2012).

The rest of the paper is organized as follows. In section 3.2, I discuss the data collection process and their sources. In section 3.3, I present my empirical model for testing the effect of decentralization on regional convergence. I present my findings in section 3.4, robustness of the baseline results in section 3.5, and review possible mechanisms in 3.6. Finally, in section 3.7, I conclude the paper.

\subsection{Data}

I study the effect of decentralization on regional convergence of administrative regions at first and second subnational government for 69 countries from 1992 to 2010. Compara- 
ble data on income per capita at the subnational level are scarce. Hence, I construct an annual panel dataset of economic activity and economic activity per person at the second subnational level by combining satellite data on night-time lights with georeferenced data on population. I combine these data with country-level measures of decentralization from Regional Authority Index (RAI) compiled by Hooghe et al. (2016) and Regional Autonomy in Developing Democracies dataset compiled by Sorens (2015).

The night-time lights data is recorded by the satellites from the United States Air Force Defense Meteorological Satellite Program (DMSP) using Operational Linescan System sensors. Each satellite observes every location on the planet every night at some instant between 8:30 PM and 10:00 PM local time. The data is then processed by the scientists at the National Oceanic and Atmospheric Administration's (NOAA) National Geophysical Data Center (NGDC) before releasing it to the public. The scientists process the data to remove observations for places where the earth's surface is obscured by the cloud so that the human-made lights are properly recorded. They also remove the places experiencing the bright half of the lunar cycle, the summer months when the sun sets late, auroral activity (the northern and southern lights), and forest fires. These restrictions remove intense sources of natural light, leaving mostly human-made light. Finally, data from all orbits of a given satellite in a given year are averaged over all valid nights to produce a satellite-year dataset. It is this dataset that is distributed to the public (Henderson et al., 2012). ${ }^{6}$

Each satellite-year dataset is a grid reporting the intensity of lights for every 30 arcsecond output pixel (approximately 0.86 square kilometers at the equator) between 65 degrees south and 75 degrees north latitude. The exclusion of high-latitude zones affects about 10,000 people or 0.0002 percent of the world's population. I further exclude pixels from regions that produce intense night-time lights due to gas flares. ${ }^{7}$

\footnotetext{
${ }^{6}$ The data is available to download at https://ngdc.noaa.gov/eog/dmsp/downloadV4composites.html

${ }^{7} \mathrm{Gas}$ flaring is a practice of burning the natural gas produced as a byproduct in the process of producing petroleum. If there is gas flaring, it emits intense light. Thus, I remove the pixels where the GADM database
} 
The intensity of light at each pixel is recorded as an integer between 0 (implying no detectable light) and 63 (implying maximum detectable light). The lights data is top-coded at 63, which affects a small fraction of pixels (0.1 percent), generally in rich and dense areas. $^{8}$ The de facto sensor settings vary over time across satellites and with the age of a satellite, so that comparisons of raw digital numbers over the years can be problematic. However, as suggested by Henderson et al. (2012), I can control for such issues with year fixed effects. For years with multiple satellite readings, I calculate simple averages across satellites. I then aggregate the data at the second administrative region using the map from the Global Administrative Areas (GADM) database. ${ }^{9}$ I add 1 to the recorded night-time lights data in all of the second-subnational regions. There are two reasons for doing so. First, the night-time lights of 0 do not necessarily mean there is no presence of humanmade light. It only means that no human-made light is detectable by the satellite from outer-space. It is possible there is at least some economic activity in the region when nighttime lights data reading is 0 . Second, my outcome variable is measured in the log, hence avoiding a value of zero allows us to take the log of all of the observations. The dependent variable then is the total night-time lights intensity $\left(\right.$ Light $\left.t_{i c t}\right)$ for region $i$ in country $c$ at time $t$.

I obtain population information at the subnational level from the Gridded Population of the World (GPW) database developed by the Center for International Earth Science Network (CIESIN) at Columbia University. The GPW data are constructed using population census tables from various subnational levels (such as city and region). I use GPW v4 has flagged gas flaring.

${ }^{8}$ If top-coding is extensive, then it can limit the variation in lights data in rich and dense areas, thus, the variation in the population data will drive the variation in lights per capita of these regions. Fortunately, top-coding only affects 0.1 percent of pixels. Moreover, since the lights data is collected at approximately 1 square kilometer only a few grids are top-coded even in the richest second subnational regions such as New York county.

${ }^{9} \mathrm{GADM}$ is a spatial database of the location of the world's administrative boundaries and is available at http://www.gadm.org/. I use version 2.8, which was released in November, 2015. 
as the primary population database and supplement it with GPW v3 for the years 1990 and $1995 .{ }^{10}$ CIESIN provides population data for every fifth year, so I linearly interpolate data for missing years. Hence, my study includes lights per capita data on 45, 279 level 2 subnational regions within 2,542 level 1 subnational regions from 130 countries for years between 1992 and 2013.

To measure decentralization at the country level, I use the Regional Authority Index (RAI) compiled by Hooghe et al. (2016) and Regional Autonomy in Developing Democracies dataset compiled by Sorens (2015). The Hooghe et al. (2016) RAI data is available for 81 countries from 1950 to 2010. I add 8 countries from Sorens (2015)'s update of the Hooghe et al. (2016) data, giving us 89 countries in total. ${ }^{11}$

Most of the studies in the literature use tax and expenditure data from the International Monetary Fund (IMF)'s Government Financial Statistics (GFS) to construct a measure of fiscal decentralization. First of all, as explained in ? and ?, there are significant gaps in the coverage of IMF data, especially in the case of developing countries. Moreover, expenditures going through the subnational budgets or revenues raised by subnational governments do not accurately reflect the true measure of fiscal decentralization, the authority that subnational governments exercise in its territory. For instance, using existing measures of decentralization, countries such as Sweden, Norway, Finland, and Denmark, where subnational governments spend and tax according to national laws, appear equally decentralized as countries such as Germany and the United States, where subnational governments enjoy genuine autonomy (see Ebel and Yilmaz (2002); Hooghe et al. (2016)). Thus I use decentralization measures from Regional Authority Index (RAI) compiled by Hooghe et al.

\footnotetext{
${ }^{10}$ For details, see http://sedac.ciesin.columbia .edu/data/collection/gpw-v.

${ }^{11}$ I could use 8 out of 17 countries from Sorens (2015) that are not in Hooghe et al. (2016). Sorens (2015)'s data are on the subnational level with different naming convention than ours, but it does not have data on subnational population, hence making it difficult to aggregate the data to create a measure of decentralization following Hooghe et al. (2016) approach. I use 8 of the countries because they only have one subnational level, so I can use the index as country aggregate.
} 
(2016) and Regional Autonomy in Developing Democracies dataset compiled by Sorens (2015), which measures the authority of regional governments across fiscal, political, and administrative dimensions, hence providing a better measure of decentralization.

There are two components of the RAI: self-rule and shared-rule. Self-rule measures regional government's authority within its jurisdiction and shared-rule measures its influence on the central government. For my study, I use self-rule as the measure of decentralization. Self-rule measures the authority of the regional government across five dimensions. ${ }^{12}$ They are (i) institutional depth, which encodes the extent to which a regional government can make autonomous policy decision; (ii) policy scope, which tracks the authority over policy within its jurisdiction; (iii) fiscal autonomy, which encodes the authority to set the rules for taxation (rate and base) and spending in its jurisdiction; (iv) borrowing autonomy, which encode the capacity of a regional government to independently borrow in financial markets; and (v) representation, which encodes the autonomy of a regional government in selecting legislative and executive bodies in its jurisdiction.

The value for institutional depth and borrowing autonomy range from 0 to 3 and the value for policy scope, fiscal autonomy, and representation range from 0 to 4 . Thus, the regional self-rule measure I use in the baseline analysis ranges from 0 to 15 , where 0 indicates a highly centralized system and 15 indicates a highly decentralized system. ${ }^{13}$ These regional self-rule scores are then aggregated at the country level to generate the country level measure of self-rule. ${ }^{14}$ I normalize the indices to be between 0 and 1 , with 0 being the

\footnotetext{
${ }^{12}$ Sorens (2015) measure of self-rule does not include borrowing autonomy, hence, I create two different self-rule measures, one including and the other one excluding the borrowing autonomy. For baseline specifications, I use the measure excluding borrowing autonomy as it gives us a larger sample size. The result using all five components of decentralization is very similar and is presented in the robustness section.

${ }^{13}$ The self-rule measure including all five components ranges from 0 to 18 for each regional tier and individual regional governments in a country.

${ }^{14}$ Hooghe et al. (2016) aggregate the regional self-rule scores in three steps. First, they calculate a score for each standard and non-standard regions in a regional tier. Second, they weight scores by population. If a tier is composed of regions with different scores, a score for that tier is calculated by weighting each region's score by its share in the national population. Third, they sum the weighted regional scores for each tier. Thus, in a few cases, the self-rule measure at the country-level exceeds 15 when using the four components or 18
} 
minimum level of decentralization and 1 being the maximum. ${ }^{15}$

Based on the self-rule measure, the most decentralized countries in my sample are the United States, Belgium, Germany, Italy, and Spain, while the least decentralized countries are Albania, Costa Rica, Croatia, Czech Republic, El Salvadore, Estonia, Latvia, Lithuania, Slovakia, and Slovenia. Figure 3.1 displays the distribution of self-rule scores in 1992. As illustrated in the figure, most of the country's self-rule score is towards the lower tail of the distribution, indicating a low level of decentralization in 1992. Many countries in my sample experience some level of decentralization over the sample period. The countries with the biggest change in self-rule are listed in Table 3.1.

Figure 3.1: Distribution of Self-Rule in 1992

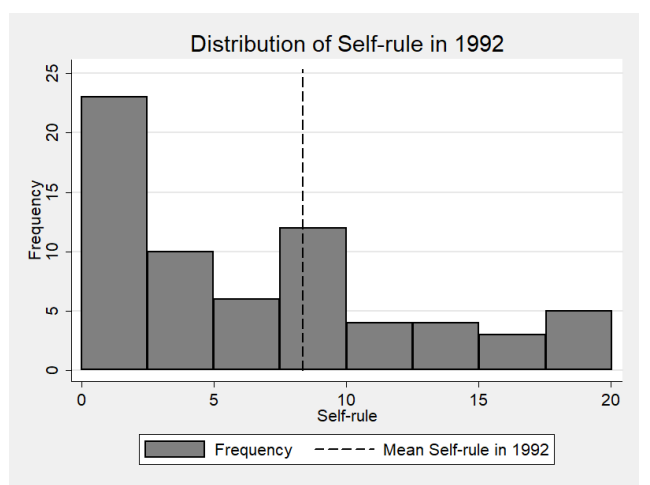

Notes: The histogram presents the distribution of self-rule measure for 69 countries in 1992. The vertical dashed line is the mean value of self-rule in 1992.
Table 3.1: Countries with Biggest Change in Self-Rule

\begin{tabular}{l|l}
\hline Country & Change in Self-Rule \\
\hline Indonesia & 14 \\
South Korea & 10 \\
Croatia & 9 \\
Czech Republic & 9 \\
Greece & 9 \\
Slovak Republic & 8 \\
Bolivia & 8 \\
Paraguay & 7 \\
Italy & 7 \\
Finland & 6 \\
\hline
\end{tabular}

Notes: The table lists the countries with biggest change in self-rule from 1992 to 2010.

I obtain a regional panel of 69 countries from 1992 to 2010 after the merging of the cleaned version of night-lights per capita data with the decentralization data. ${ }^{16}$

when using five components of self-rule. See Hooghe et al. (2016) for details.

${ }^{15}$ When normalizing, I divide by the maximum value of the actual country-level self-rule rather than 15 in my baseline specifications or 18 when including borrowing autonomy.

${ }^{16}$ I exclude 20 countries that have data on decentralization from the analysis because they either do not have second subnational regions or their lights data are potentially contaminated by glares from large water bodies nearby. Most of these countries are small islands with a population less than 500,000 and excluding them do not affect the outcomes significantly. 


\subsection{Empirical Framework}

In this section, I outline the empirical framework I use to analyze the role of decentralization on regional convergence. I am interested in learning whether or not poor regions of a country catch up with the frontier regions of the country, which is called a $\beta$-convergence in the growth literature. ${ }^{17}$ To do so, I first introduce a few variables. I define Frontier region, which is the region that has the highest lights per capita among all regions within a country in a given year. Then, I define Distance, which is the log difference in lights per capita between a region and the frontier region of a respective country. The Distance measures how far a region is from the Frontier region and is expressed as,

$$
\text { Distance }_{i c t}=\ln \left(\text { Light }_{i c t}\right)-\ln \left(\text { Light }_{c t}^{\text {frontier }}\right)
$$

where, Light $t_{i c t}$ is the total lights per capita for region $i$ of country $c$ at year $t$, and Light $t_{c t}^{\text {frontier }}$ is the total lights per capita for the Frontier region of country $c$ at year $t$.

The growth rate of lights per capita in region $i$ of country $c$ at time $t$ is expressed as,

$$
\Delta Y_{i c t}=\ln \left(L i g h t_{i c t}\right)-\ln \left(L i g h t_{i c t-1}\right)
$$

The baseline specification I use to study the effect of decentralization on $\beta$-convergence

\footnotetext{
${ }^{17}$ In the growth literature, $\beta$-convergence implies a negative partial correlation between growth in income per capita over time and its initial level, while the $\sigma$-convergence implies that the dispersion of real income per capita across economies decreases over time. In this study, I focus on $\beta$-convergence for two reasons. First, $\beta$-convergence is a necessary condition for $\sigma$-convergence (Quah, 1993, 1997). Second, analyzing $\sigma$-convergence would require us to aggregate my data at the country-level, while studying $\beta$-convergence allows us to use the data at the subnational level. The country-level measure of convergence estimates thus would not have sufficient power to analyze the sub-samples of countries, which is the main contribution of my paper. Second, it is harder to mitigate endogeneity concerns when the decentralization, as well as the unit of observation, is at the same (i.e., country) level.
} 
is then given by,

$$
\begin{gathered}
\Delta Y_{i c t}=\beta_{0}+\beta_{1} \text { Distance }_{i c t-1}+\beta_{2} \text { Decentralization }_{c t-1} \\
+\beta_{3} \text { Distance }_{i c t-1} * \text { Decentralization }_{c t-1}+\beta_{4} \Delta Y_{c t}^{\text {frontier }}+\lambda_{c}+\delta_{t}+e_{i j t}
\end{gathered}
$$

where Decentralization Dt-1 $_{1}$ is the measure of decentralization, $\Delta Y_{c t}^{\text {Frontier }}$ is the growth rate of frontier region and Distance $_{i c t-1} *$ Decentralization $_{c t-1}$ is the interaction term. $\lambda$ are country fixed effects that control for time-invariant country characteristics such as geography, and $\delta$ are year fixed effects that control for unobservables specific for the year, as well as variation in data due to different satellite settings. ${ }^{18}$ The primary coefficient of interest is $\beta_{3}$ as it indicates whether decentralization promotes convergence (i.e., negative $\beta_{3}$ ) or hinders convergence (i.e., positive $\beta_{3}$ ).

The endogeneity problem due to omitted variables and reverse-causality found in countrylevel convergence regressions is reduced by combining national data on decentralization with subnational data on per capita income. First, I include country fixed effects as well as the growth of a country's frontier region as independent variables. This allows us to control for the time-invariant country characteristics as well as country's overall growth performance and potentially the omitted factors that exert mutual influence on a country's growth and decentralization tendencies. Second, I use region's distance-to-country-frontier to capture region's relative development level rather than its initial income level since the region's distance-to-country-frontier is mostly independent of the country's development level or growth rate. Thus, I argue that it is unlikely that country-level decentralization reforms are prompted by higher regional growth rate, conditional on country-fixed effects and frontier region's growth. ${ }^{19}$

\footnotetext{
${ }^{18}$ I do not use regional fixed effects in my specifications because using regional fixed effects gives us the speed that each region converges to its own steady-state, instead of converging to the country frontier.

${ }^{19} \mathrm{~A}$ well-known econometric issue that occurs in a panel regression with a large number of countries and a small number of years is that when the lagged dependent variable is included in the regression, the fixedeffect estimate is inconsistent due to the correlation between the lagged dependent variable and the error term
} 


\subsection{Results}

\subsubsection{Regional Convergence}

Figures $3.2 \mathrm{a}$ and $3.2 \mathrm{~b}$ present within-country convergence graphs using data on first and second subnational levels respectively. The vertical axis plots the beta coefficients obtained from regressing regional growth rate of per capita night-lights between 1992 and 2010 on per capita night-time lights in the year 1992 for individual countries and the horizontal axis plots the coefficient's t-statistics. These coefficients measure unconditional within-country convergence since I do not use any other controls in the regression. These figures demonstrate strong convergence across regions in most of the countries around the world. ${ }^{20}$ Most of the estimates are negative and statistically significant at the conventional level, demonstrating a systematic tendency for regions that start with lower economic activity (measured here by night-time lights per capita) in 1992 to grow more rapidly over the next two decades compared to the regions that start with higher economic activity in 1992. However, there are some countries, especially high-income countries that experience regional divergence in my sample period, especially when using subnational level 1 data. ${ }^{21}$ Thus, I analyze the regional convergence tendencies for the full sample as well as the sample of high-income countries and developing countries next.

Table 3.2 presents the formal analysis of the graphs above using first and second subnational level data for the sample of 69 countries that have data on decentralization. ${ }^{22}$ Column

(Nickell, 1981). The typical bias in dynamic panels is much less of an issue in my case since I use regional data but I estimate the equation with only country-level fixed effects. Thus, if $\mathrm{N}$ is the number of regions in a country and $\mathrm{T}$ is the number of years in the sample. The inconsistency is to the order of $1 /(T * N)$, which would be less than $1 / 10,000$ in my specification with the smallest $\mathrm{N}$, instead of being $(1 / T)$, which would be $1 / 34$ in the same specification if I used country-level dynamic model.

${ }^{20}$ The graphs include the 69 countries in my sample. Graphs for 130 countries are presented in online appendix, and the results are similar.

${ }^{21}$ This finding is similar to Lessmann and Seidel (2017) where they also find that about a quarter of the countries experience regional divergence.

${ }^{22}$ I also analyze the sample of all 130 countries, the results are presented in online appendix and the results are similar. 


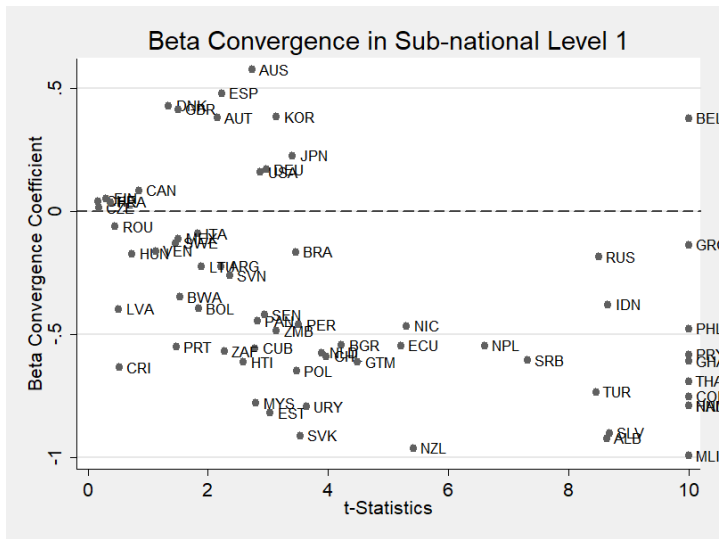

(a) First Subnational level

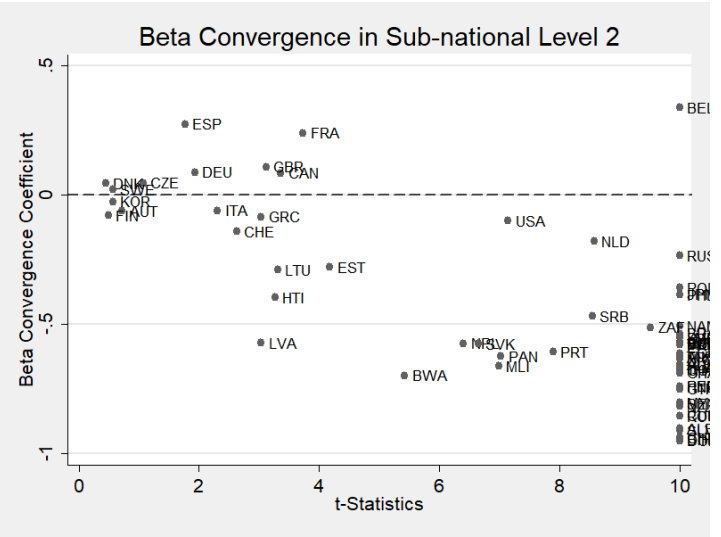

(b) Second Subnational level

Figure 3.2: Within-Country Convergence from 1992 to 2010 around the World

Notes: The variable on the vertical axis is the beta coefficient of regression capturing the average growth rate of night-time lights per capita on initial night-time lights per capita for individual countries in the sample of 69 countries, and the variable on the horizontal axis is the coefficient's t-statistics.

1 presents the analysis on the full sample of countries, column 2 presents the analysis on the sample of high-income countries, and column 3 presents the analysis on the sample of developing countries. ${ }^{23}$ Panel A presents the analysis using first subnational level data, and panel B presents the analysis using second subnational level data. The dependent variable for all of the regressions is the regional growth rate per capita. All specifications include country and year fixed effects, and none of them include region fixed effects or any other controls for regional characteristics, hence, the coefficients on lagged value of log of lights per capita (L.Log Light Per Capita) are the coefficients of within-country unconditional convergence. $^{24}$ The estimates range from -0.09 to -0.06 , which are quite large and economically meaningful. For instance, a convergence coefficient of -0.08 implies that a region that is halfway to the frontier region grows 5.5 percent faster than the frontier region $(0.08 * \ln (2))$. Even though I find regional convergence in all specifications, the estimates

\footnotetext{
${ }^{23}$ Country classifications are based on the World Bank's classification. I classify all the countries that are not in the high-income group as developing countries. Developing countries consist of upper-middle-income countries, lower-middle income countries, and low-income countries.

${ }^{24}$ Analysis excluding year fixed effects for the sample of 130 countries are presented in online appendix and the results are qualitatively similar with slightly larger coefficients quantitatively.
} 
for the developing countries are larger and robustly significant, while the estimates for the high-income countries are smaller and their statistical significance are not robust to specification changes. Thus, I conclude that there is a strong and robust regional convergence in developing countries.

In the next subsection, I examine the impact of decentralization on the speed of regional convergence. Since backward regions tend to catch up with frontier regions regardless of policies, the hope then is that decentralization speeds up the convergence process. However, I find that decentralization hinders convergence in developing countries.

Table 3.2: Within-Country Convergence

\begin{tabular}{|c|c|c|c|}
\hline & Full Sample & High-income Countries & Developing Countries \\
\hline \multicolumn{4}{|c|}{ Panel A: First Subnational Level } \\
\hline L.Log Light Per Capita & $\begin{array}{c}-0.0797^{* * *} \\
(0.0166)\end{array}$ & $\begin{array}{l}-0.0686 \\
(0.0421)\end{array}$ & $\begin{array}{c}-0.0808^{* * *} \\
(0.00996)\end{array}$ \\
\hline Number of countries & 69 & 35 & 34 \\
\hline Number of observations & 25,135 & 11,538 & 13,597 \\
\hline \multicolumn{4}{|c|}{ Panel B: Second Subnational Level } \\
\hline L.Log Light Per Capita & $\begin{array}{c}-0.0882^{* * *} \\
(0.0170)\end{array}$ & $\begin{array}{c}-0.0635^{* *} \\
(0.0244)\end{array}$ & $\begin{array}{c}-0.0921^{* * *} \\
(0.0204)\end{array}$ \\
\hline Number of countries & 69 & 35 & 34 \\
\hline Number of observations & 552,525 & 236,952 & 315,573 \\
\hline \multicolumn{4}{|c|}{$\begin{array}{l}\text { Notes: The outcome variables in all specifications is subnational level growth rate of lights per } \\
\text { capita. Columns } 1 \text { uses all countries with requisite data, columns } 2 \text { uses high-income countries } \\
\text { with requisite data and columns } 3 \text { uses developing countries with requisite data. All regressions } \\
\text { include country fixed effects and year fixed effects. Panel A presents analysis using first subna- } \\
\text { tional level data and panel B presents analysis using second subnational level data. The standard } \\
\text { errors, in parenthesis, are clustered at the country level. }\end{array}$} \\
\hline
\end{tabular}

\subsubsection{Decentralization and Regional Convergence}

Table 3.3 shows the results for the baseline specification (equation 3.3). Column 1 is the analysis on the full sample of countries, column 2 is on the sample of high-income countries, and column 3 is on the sample of developing countries. Panel A presents the analysis using first subnational level data, and panel B presents the analysis using second subna- 
tional level data. The dependent variable is the regional growth rate per capita in each of the regressions. Each regression includes country fixed effects and year fixed effects. ${ }^{25}$ The distance from the frontier region is given by L.DistancePC, the per capita growth rate of the frontier region of each country is given by GrowthFrontier PC, and the measures of decentralization used (i.e., Self-rule) is given by L.Selfrule. ${ }^{26}$ The interaction terms of distance with measures of decentralization are the coefficients of interest, which indicates the impact of decentralization on the speed of convergence. I call them the convergence coefficient from now on.

The coefficient on the variable L.Distance is negative and statistically significant in all specifications. A negative coefficient implies that farther a region is from the frontier, higher its growth rate, reinforcing the idea that regions with the lower initial level of economic activity tend to grow faster in the absence of decentralization.

The convergence coefficients are positive and significant for the full sample, indicating that decentralization impedes regional convergence. When I divide the sample into highincome countries and developing countries, I find that the estimates are positive and significant at the 5 percent or better level for the developing countries. However, the estimates for the high-income countries are significant at the 10 percent when using first subnational level data and insignificant at the conventional level when using second subnational level data. The coefficients range from 0.09 to 0.12 , with coefficients of developing countries being slightly larger than that of the full sample.

These findings indicate that decentralization hinders regional convergence. The effect is always significant at the conventional level for the sample of developing countries, while they are not robust for the high-income countries. To analyze how economically significant

\footnotetext{
${ }^{25}$ The analysis excluding year fixed effects is presented in online appendix. The results are qualitatively similar with slightly larger coefficients quantitatively.

${ }^{26}$ I use self-rule measure that excludes borrowing autonomy in the baseline specifications because by excluding borrowing autonomy I can increase the sample of countries with all requisite data to 69 .
} 
these estimates are, I can look at the effect on the growth rates for certain regions compared to the frontier region of the country when the value of self-rule changes. To illustrate, in the full sample (column 1), the convergence coefficient of 0.112 implies that if the decentralization index of the country changes from the lowest possible value (i.e., 0) to the highest possible value (i.e., 1), the growth rate of a region that is halfway to the country frontier would decrease by about 8 percent. ${ }^{27}$ In a few specifications, the convergence coefficients suggest that decentralization is associated with regional divergence, although at a negligible rate. For instance, for the full sample, the difference in growth rate between the region and the frontier region of the country changes from about 8 percent to about 0.42 percent when decentralization index changes from 0 to 1 . However, for the sample of developing countries using first subnational level data, the difference in the growth rate between the region and the frontier region of the country changes from about 8 percent to about -0.14 percent, resulting in divergence.

These findings are in line with the studies that find the detrimental effect of decentralization on developing countries such as Zhang and Zou (1998); Davoodi and Zou (1998); Liu et al. (2017). Based on the findings for different sub-samples, I can conclude that decentralization hinders regional convergence in developing countries. The impact on high-income countries are not conclusive since the convergence coefficient for high-income countries is significant at $10 \%$ level when first subnational level data are used, but the significance disappears when second subnational level data are used. The implication of this analysis is substantial, especially in developing countries, as I find that regions which are relatively

\footnotetext{
${ }^{27}$ The coefficients in my study are larger than previous studies. This difference could be because previous studies compare the growth rate of a region to the country's average growth rate, while I compare it to the country's frontier region's growth rate. Thus, the difference is likely to be higher. In fact, in the robustness tests section, I analyze the convergence towards the country average and find the coefficient to be smaller (0.093, which implies 6\% slower convergence). Another reason could be due to my data since lights data is not a perfect proxy for the actual growth rate. For instance, Henderson et al. (2012) find that the elasticity between two growth rates is 1.15 , which implies that my coefficients slightly overstate the actual convergence coefficient.
} 
behind in development level tend to grow slower, and hence lag further behind, than a relatively more developed region within a country.

Table 3.3: Decentralization and Within-Country Convergence

\begin{tabular}{|c|c|c|c|}
\hline & Full Sample & High-income Countries & Developing Countries \\
\hline \multicolumn{4}{|c|}{ Panel A: First Subnational Level } \\
\hline L.Distance PC & $\begin{array}{r}-0.118^{* * *} \\
(0.0152)\end{array}$ & $\begin{array}{l}-0.132^{*} \\
(0.0752)\end{array}$ & $\begin{array}{l}-0.114^{* * *} \\
(0.0145)\end{array}$ \\
\hline Frontier Growth PC & $\begin{array}{l}0.408^{* * *} \\
(0.0580)\end{array}$ & $\begin{array}{l}0.420^{* * *} \\
(0.0673)\end{array}$ & $\begin{array}{l}0.359^{* * *} \\
(0.0782)\end{array}$ \\
\hline L.Selfrule & $\begin{array}{l}0.182^{* * *} \\
(0.0554)\end{array}$ & $\begin{array}{c}0.100 \\
(0.157)\end{array}$ & $\begin{array}{l}0.220^{* * *} \\
(0.0743)\end{array}$ \\
\hline L.Selfrule x Distance PC & $\begin{array}{l}0.112^{* * *} \\
(0.0279)\end{array}$ & $\begin{array}{c}0.127^{*} \\
(0.0722)\end{array}$ & $\begin{array}{l}0.116^{* * *} \\
(0.0360)\end{array}$ \\
\hline $\begin{array}{l}\text { Number of countries } \\
\text { Number of observations }\end{array}$ & $\begin{array}{c}69 \\
24,958\end{array}$ & $\begin{array}{c}35 \\
11,433\end{array}$ & $\begin{array}{c}34 \\
13,525\end{array}$ \\
\hline \multicolumn{4}{|c|}{ Panel B: Second Subnational Level } \\
\hline L.Distance PC & $\begin{array}{r}-0.128^{* * *} \\
(0.0283)\end{array}$ & $\begin{array}{l}-0.0949^{* *} \\
(0.0443)\end{array}$ & $\begin{array}{l}-0.140^{* * *} \\
(0.0334)\end{array}$ \\
\hline Frontier Growth PC & $\begin{array}{c}0.0594 \\
(0.0708)\end{array}$ & $\begin{array}{l}0.0617^{*} \\
(0.0326)\end{array}$ & $\begin{array}{l}0.293^{* * *} \\
(0.0550)\end{array}$ \\
\hline L.Selfrule & $\begin{array}{c}0.237 \\
(0.231)\end{array}$ & $\begin{array}{l}0.0507 \\
(0.228)\end{array}$ & $\begin{array}{c}0.344 \\
(0.302)\end{array}$ \\
\hline L.Selfrule x Distance PC & $\begin{array}{l}0.0985^{* *} \\
(0.0392) \\
\end{array}$ & $\begin{array}{c}0.0760 \\
(0.0684) \\
\end{array}$ & $\begin{array}{c}0.117^{* *} \\
(0.0440) \\
\end{array}$ \\
\hline Number of countries & 69 & 35 & 34 \\
\hline Number of observations & 549,857 & 234,731 & 315,126 \\
\hline
\end{tabular}

Notes: The outcome variables in all specifications is subnational level growth rate of lights per capita. Column 1 uses all countries with requisite data, column 2 uses high-income countries with requisite data and column 3 uses developing countries with requisite data. All regressions include country fixed effects and year fixed effects. Panel A presents analysis using first subnational level data and panel B presents analysis using second subnational level data. The standard errors, in parenthesis, are clustered at the country level.

$* p<.1, * * p<.05, * * * p<.01$. 


\subsubsection{Components of Decentralization and Regional Convergence}

In this section, I study how individual components of decentralization (i.e., fiscal autonomy, institutional depth, policy autonomy, and representation) affect regional convergence. ${ }^{28}$ The results are presented in Table 3.4. ${ }^{29}$ Panel A presents results for analysis using first subnational level data and panel B presents results for analysis using second subnational level data. Column 1 presents results for the full sample, column 2 presents results for the sample of high-income countries, and column 3 presents results for the sample of developing countries.

For the full sample, I find that almost all of the components have a significant impact on convergence. The convergence coefficients on the institutional depth, policy autonomy, and representation are all positive, range from 0.05 to 0.20 , and significant using both first and second subnational level data. Whereas, fiscal autonomy (0.09) is positive and significant using second subnational level data only.

The sub-component analysis reinforces the findings from the analysis of the overall decentralization index that there is no robustly significant impact of decentralization on high-income countries. In the sample of high-income countries, I do not find a significant effect of any of the components of decentralization, except for Policy Autonomy which is statistically significant when first subnational level data are used but only at 10\% significance level.

In the case of developing countries, the result is more nuanced but provides evidence that all components of decentralization substantially reduces regional convergence. I find that fiscal autonomy and representation have the robust impact on regional convergence. The estimated coefficients range from 0.07 to 0.12 and are significant at the conventional

\footnotetext{
${ }^{28}$ For consistency, I exclude borrowing autonomy from the analysis as I use self-rule measure without borrowing autonomy in the baseline analysis.

${ }^{29}$ To save space, I only present estimates of the convergence coefficients from regressions that include year fixed effects. The specifications excluding year fixed effects yield similar results, both quantitatively and qualitatively
} 
level using both first and second subnational level data. The institutional depth and policy autonomy indicators also suggest that decentralization hinders convergence, but the estimates are not robustly significant. The coefficient on institutional depth (0.179) is significant using first subnational data only, and policy autonomy (0.132) is significant using second subnational level data only.

\subsubsection{Decentralization and Within-First-Subnational Region Conver- gence}

In this section, I extend my analysis on the effect of decentralization to study if decentralization promotes or hinders convergence between the poor and rich regions within each first subnational level division of a country. To do so, I use second subnational level data and add first subnational level region fixed effects to the baseline regression. Thus, I can interpret the coefficient on the interaction between distance and measures of decentralization as the impact of decentralization on within-first-subnational level regional convergence. Note that I also modify the variable Distance, which now represents distance to the frontier second subnational level region within a first subnational level region. Specifically, Distance is now defined as,

$$
\text { Distance }_{i j c t}=\ln \left(\text { Light }_{i j c t}\right)-\ln \left(\text { Light }_{j c t}^{\text {Frontier }}\right)
$$

where Light $t_{j c t}^{\text {Frontier }}$ is the light per capita of frontier second subnational level region in first subnational level region $j$. The impact of decentralization on within-first-subnational 
Table 3.4: Components of Decentralization and Within-Country Convergence

Full Sample $\quad$ High-income Countries $\quad$ Developing Countries

\begin{tabular}{|c|c|c|c|}
\hline \multicolumn{4}{|c|}{ Panel A: First Subnational Level } \\
\hline Fiscal Autonomy & $\begin{array}{l}0.00856 \\
(0.0927)\end{array}$ & $\begin{array}{l}-0.0568 \\
(0.100)\end{array}$ & $\begin{array}{l}0.113 * * * \\
(0.0404)\end{array}$ \\
\hline Institutional Depth & $\begin{array}{l}0.196 * * * \\
(0.0389)\end{array}$ & $\begin{array}{c}0.244 \\
(0.147)\end{array}$ & $\begin{array}{l}0.179 * * * \\
(0.0469)\end{array}$ \\
\hline Policy Autonomy & $\begin{array}{c}0.0771 * * * \\
(0.0254)\end{array}$ & $\begin{array}{c}0.111^{*} \\
(0.0623)\end{array}$ & $\begin{array}{c}0.0533 \\
(0.0412)\end{array}$ \\
\hline Representation & $\begin{array}{c}0.122 * * * \\
(0.0286) \\
\end{array}$ & $\begin{array}{c}0.16 \\
(0.102)\end{array}$ & $\begin{array}{c}0.0885 * * * \\
(0.0309)\end{array}$ \\
\hline $\begin{array}{l}\text { Number of Countries } \\
\text { Number of Observations }\end{array}$ & $\begin{array}{c}69 \\
24,958 \\
\end{array}$ & $\begin{array}{c}35 \\
11,433 \\
\end{array}$ & $\begin{array}{c}34 \\
13,525 \\
\end{array}$ \\
\hline \multicolumn{4}{|c|}{ Panel B: Second Subnational Level } \\
\hline Fiscal Autonomy & $\begin{array}{l}0.0902 * \\
(0.0499)\end{array}$ & $\begin{array}{c}0.0633 \\
(0.0705)\end{array}$ & $\begin{array}{c}0.117^{*} \\
(0.0599)\end{array}$ \\
\hline Institutional Depth & $\begin{array}{c}0.0895 * * \\
(0.0447)\end{array}$ & $\begin{array}{c}0.119 \\
(0.0886)\end{array}$ & $\begin{array}{c}0.0813 \\
(0.0549)\end{array}$ \\
\hline Policy Autonomy & $\begin{array}{l}0.102 * * \\
(0.0467)\end{array}$ & $\begin{array}{c}0.0475 \\
(0.0385)\end{array}$ & $\begin{array}{l}0.132 * * \\
(0.0630)\end{array}$ \\
\hline Representation & $\begin{array}{l}0.0531 * \\
(0.0290)\end{array}$ & $\begin{array}{c}0.0471 \\
(0.0621)\end{array}$ & $\begin{array}{l}0.0730 * * \\
(0.0315)\end{array}$ \\
\hline $\begin{array}{l}\text { Number of Countries } \\
\text { Number of Observations }\end{array}$ & $\begin{array}{c}69 \\
549,857\end{array}$ & $\begin{array}{c}35 \\
234,731\end{array}$ & $\begin{array}{c}34 \\
315,126\end{array}$ \\
\hline
\end{tabular}

Notes: The outcome variables in all specifications is subnational level growth rate of lights per capita. The coefficients reported are the convergence coefficients (coefficients of the interaction term between the decentralization measure used and the distance measure). Column 1 uses all countries with requisite data, column 2 uses high-income countries with requisite data and column 3 uses developing countries with requisite data. All regressions include country fixed effects and year fixed effects. Panel A presents analysis using first subnational level data and panel B presents analysis using second subnational level data. The standard errors, in parenthesis, are clustered at the country level.

$* p<.1, * * p<.05, * * * p<.01$. 
region convergence is then give by,

$$
\begin{gathered}
\Delta Y_{i j c t}=\beta_{0}+\beta_{1} \text { Distance }_{i j c t-1}+\beta_{2} \text { Decentralization }_{c t-1} \\
+\beta_{3} \text { Distance }_{i j c t-1} * \text { Decentralization }_{c t-1}+\beta_{4} \Delta Y_{j c t}^{\text {Frontier }}+\beta_{5} \Delta Y_{c t}^{\text {Frontier }} \\
+\gamma_{j c}+\lambda_{c}+\delta_{t}+e_{i j c t}
\end{gathered}
$$

where Distance $_{i c j t-1}$ is the distance to the frontier second subnational level region within a first subnational level region and Decentralization ${ }_{c t-1}$ is the measure of decentralization. The coefficient on the interaction term Distance $_{i c j t-1} *$ Decentralization $_{c t-1}$ is the coefficient of primary interest as it indicates whether decentralization promotes withinfirst-subnational level regional convergence (i.e., negative $\beta_{3}$ ) or hinders convergence (i.e., positive $\left.\beta_{3}\right) . \gamma_{j c}$ is the first subnational level region fixed effects, $\lambda_{c}$ is the country fixed effects, and $\delta_{t}$ is year fixed effects. I control for the first subnational region growth by including growth of frontier region within each of the first subnational regions, $\Delta Y_{j c t}^{\text {Frontier }}$. In some specifications, I also control for the country growth by including growth of first subnational level frontier region of the country, $\Delta Y_{c t}^{\text {Frontier }}$.

Table 3.5 presents the results. The results are similar to the baseline study. The convergence coefficients are positive and significant in the full sample and the sample of developing countries, but not significant at the conventional level for the high-income countries.

These findings suggest that decentralization hinders not only within-country convergence but also within-region convergence. The convergence coefficients are larger than in the analysis of within-country convergence for both the full sample and the sample of developing countries. Taken together, the results from within-country and within-region convergence suggest that the growth of first subnational level regions in developing countries is mostly driven by the growth of a few second subnational level regions within that first subnational level region. Since these within-region convergence estimates are larger 
than within-country convergence estimates from my baseline results, it also implies that the lack of regional convergence is more pronounced at the local level.

Table 3.5: Decentralization and Within-First-Subnational Region Convergence

\begin{tabular}{|c|c|c|c|c|c|c|}
\hline & \multicolumn{2}{|c|}{ Full Sample } & \multicolumn{2}{|c|}{ High-income Countries } & \multicolumn{2}{|c|}{ Developing Countries } \\
\hline L.Distance PC & $\begin{array}{c}-0.147^{* * *} \\
(0.0366)\end{array}$ & $\begin{array}{c}-0.147^{* * *} \\
(0.0367)\end{array}$ & $\begin{array}{c}-0.0933^{* *} \\
(0.0455)\end{array}$ & $\begin{array}{c}-0.0930^{* *} \\
(0.0451)\end{array}$ & $\begin{array}{c}-0.162^{* * *} \\
(0.0445)\end{array}$ & $\begin{array}{c}-0.162^{* * *} \\
(0.0443)\end{array}$ \\
\hline Level 2 Frontier Growth PC & $\begin{array}{l}0.582^{* * *} \\
(0.0677)\end{array}$ & $\begin{array}{l}0.592^{* * *} \\
(0.0633)\end{array}$ & $\begin{array}{c}0.539^{* * *} \\
(0.127)\end{array}$ & $\begin{array}{c}0.542^{* * *} \\
(0.129)\end{array}$ & $\begin{array}{l}0.598^{* * *} \\
(0.0540)\end{array}$ & $\begin{array}{l}0.577^{* * *} \\
(0.0516)\end{array}$ \\
\hline L.self-rule & $\begin{array}{c}0.163 \\
(0.147)\end{array}$ & $\begin{array}{c}0.173 \\
(0.141)\end{array}$ & $\begin{array}{l}-0.127 \\
(0.139)\end{array}$ & $\begin{array}{l}-0.121 \\
(0.136)\end{array}$ & $\begin{array}{c}0.290 \\
(0.208)\end{array}$ & $\begin{array}{c}0.276 \\
(0.208)\end{array}$ \\
\hline L.Self-rule x Distance PC & $\begin{array}{l}0.156^{* * *} \\
(0.0585)\end{array}$ & $\begin{array}{l}0.156^{* * *} \\
(0.0585)\end{array}$ & $\begin{array}{c}0.0937 \\
(0.0747)\end{array}$ & $\begin{array}{c}0.0933 \\
(0.0744)\end{array}$ & $\begin{array}{c}0.173^{* *} \\
(0.0697)\end{array}$ & $\begin{array}{c}0.172^{* *} \\
(0.0692)\end{array}$ \\
\hline Level 1 Frontier Growth PC & & $\begin{array}{c}-0.0436 \\
(0.0356)\end{array}$ & & $\begin{array}{l}-0.0127 \\
(0.0174)\end{array}$ & & $\begin{array}{l}0.0873^{*} \\
(0.0443)\end{array}$ \\
\hline Number of countries & 69 & 69 & 35 & 35 & 34 & 34 \\
\hline Number of observations & 549,857 & 549,857 & 234,731 & 234,731 & 315,126 & 315,126 \\
\hline
\end{tabular}

Notes: The outcome variables in all specifications is second subnational level growth rate of lights per capita. Columns 1 and 2 illustrate results for all countries with requisite data, Columns 3 and 4 illustrate results for highincome countries with requisite data and Columns 5 and 6 illustrate results for developing countries with requisite data. All specifications include country, year, and first subnational level region fixed effects. The standard errors, in parenthesis, are clustered at the country level.

$* p<.1, * * p<.05, * * * p<.01$. 


\subsection{Robustness Tests}

To probe the robustness of my main results, I perform a series of tests. First, I estimate regional convergence using the traditional approach that compares regional growth with country average instead of the frontier region's growth. Second, I estimate the baseline model by controlling for, as well as removing, level 1 regions that include country capitals. Third, I estimate baseline regression excluding one country at a time to study if any particular country is driving the result. Fourth, I conduct additional robustness tests which include analyzing regional convergence using the data on decentralization from Hooghe et al. (2016) only, using four-year averages of my panel data, comparing differences in convergence coefficients between high-income countries and developing countries using alternative definitions of high-income countries, removing potential outliers by trimming the data, and augmenting the baseline specification to include important control variables from the cross-country growth literature.

\subsubsection{Convergence Towards Country Average}

In this section, I study the impact of decentralization on convergence using a traditional approach that compares regional growth with country average instead of the frontier region's growth. The specification is as follows.

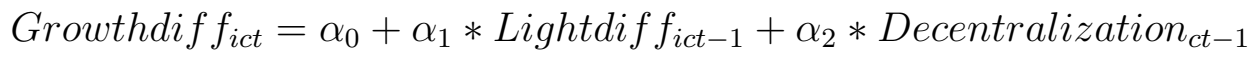

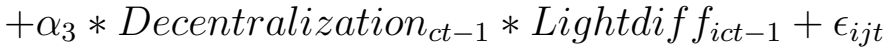

where GrowthDiff is the growth differential between a region and the country where it is located,

$$
\text { Growthdif } f_{i c t}=\left(\ln \left(\operatorname{Light}_{i c t}\right)-\ln \left(\operatorname{Light}_{i c t-1}\right)\right)-\left(\ln \left(\operatorname{Light}_{c t}\right)-\ln \left(\operatorname{Light}_{c t-1}\right)\right)
$$


and Lightdiff is the log difference in the level of night-time lights per capita between a region and the country it is located in,

$$
\operatorname{Lightdiff_{ict}}=\ln \left(\operatorname{Light}_{i c t}\right)-\ln \left(\operatorname{Light}_{c t}\right)
$$

In this specification, the impact of business cycles is eliminated from the series by subtracting the country-level growth rate. The coefficient of interest is denoted by $\alpha_{3}$, which measures the effect of decentralization on regional convergence. If $\alpha_{3}<0$, it implies faster convergence and if $\alpha_{3}>0$, it implies slower convergence or divergence due to decentralization. ${ }^{30}$

Table 3.6 presents the results. Panel A presents the analysis using first subnational level data and panel B presents the analysis using second subnational level data. Column 1 presents the result for the full sample, column 2 presents the result for the sample of highincome countries, and column 3 presents the result for the sample of developing countries. The variable Light diff is log difference of light per capita between a region and country as defined in equation 3.8. The interaction term between Light diff and decentralization measure are the coefficients of interest as they indicate the role of decentralization in the speed of convergence. The coefficients on Light diff are mostly negative and significant, suggesting higher growth in regions with lower initial lights per capita than the country's lights per capita.

The coefficients of convergence are positive and significant for the full sample and the sample of developing countries using both first and second subnational level data. The magnitudes of coefficients inform us how regional growth differential changes as the index for decentralization increases, at different values of the initial lights per capita differences.

\footnotetext{
${ }^{30}$ Following my baseline specifications, I do not include regional level fixed effects because the speed of convergence when the regional fixed effects are present is the speed that each region converges to its own steady-state, instead of converging to the country average.
} 
The magnitude of 0.093 in column 1 indicates that for a region with initial lights per capita 50 percent lower than country average, if the decentralization index of the country changes from the lowest possible value to the highest possible value, the predicted growth of the region would decrease by more than 6 percent.

The coefficients on the sample of high-income countries are not significant, hence the effects are inconclusive. These findings support the results from my baseline specifications that the decentralization has a detrimental impact on the convergence process in the sample of developing countries. Also, these results suggest that the choice of my baseline specification does not drive my findings.

Table 3.6: Decentralization and Within-Country Convergence Towards Country Average

\begin{tabular}{|c|c|c|c|}
\hline & Full Sample & High-income Countries & Developing Countries \\
\hline \multicolumn{4}{|c|}{ Panel A: First Subnational Level } \\
\hline L. Diff in GDP & $\begin{array}{c}-0.102^{* * *} \\
(0.0145)\end{array}$ & $\begin{array}{c}-0.104 \\
(0.0753)\end{array}$ & $\begin{array}{c}-0.0998^{* * *} \\
(0.0137)\end{array}$ \\
\hline L.Selfrule & $\begin{array}{l}-0.00754 \\
(0.00768)\end{array}$ & $\begin{array}{l}-0.0256^{* *} \\
(0.00985)\end{array}$ & $\begin{array}{l}0.00132 \\
(0.0125)\end{array}$ \\
\hline L.Selfrule x Light Diff & $\begin{array}{c}0.0930^{* * *} \\
(0.0263)\end{array}$ & $\begin{array}{c}0.100 \\
(0.0753)\end{array}$ & $\begin{array}{l}0.0830^{* *} \\
(0.0361)\end{array}$ \\
\hline $\begin{array}{l}\text { Number of countries } \\
\text { Number of observations }\end{array}$ & $\begin{array}{c}69 \\
24,958\end{array}$ & $\begin{array}{c}35 \\
11,433\end{array}$ & $\begin{array}{c}34 \\
13,525\end{array}$ \\
\hline \multicolumn{4}{|c|}{ Panel B: Second Subnational Level } \\
\hline L. Diff in GDP & $\begin{array}{c}-0.143^{* * *} \\
(0.0346)\end{array}$ & $\begin{array}{l}-0.101^{*} \\
(0.0507)\end{array}$ & $\begin{array}{l}-0.157^{* * *} \\
(0.0414)\end{array}$ \\
\hline L.Selfrule & $\begin{array}{c}0.0198 \\
(0.0255)\end{array}$ & $\begin{array}{l}-0.0251 \\
(0.0372)\end{array}$ & $\begin{array}{l}0.0863^{* *} \\
(0.0365)\end{array}$ \\
\hline L.Selfrule x Light Diff & $\begin{array}{c}0.136^{* *} \\
(0.0558)\end{array}$ & $\begin{array}{c}0.103 \\
(0.0833)\end{array}$ & $\begin{array}{l}0.151^{* *} \\
(0.0621)\end{array}$ \\
\hline $\begin{array}{l}\text { Number of countries } \\
\text { Number of observations }\end{array}$ & $\begin{array}{c}69 \\
549,857\end{array}$ & $\begin{array}{c}35 \\
234,731\end{array}$ & $\begin{array}{c}34 \\
315,126\end{array}$ \\
\hline
\end{tabular}

Notes: The outcome variables in all specifications is the growth differential between a region and the country it is located in. Column 1 uses all countries with requisite data, column 2 uses high-income countries with requisite data and column 3 uses developing countries with requisite data. Panel A presents analysis using first subnational level data and panel B presents analysis using second subnational level data. The standard errors, in parenthesis, are clustered at the country level.

$* p<.1, * * p<.05, * * * p<.01$. 


\subsubsection{Controlling for Country Capitals}

In this section, I control for level 1 regions where the country capitals are located. I do so in two ways: by adding a dummy variable for the regions with country capitals and by removing those regions entirely from the analysis. The purpose of the exercise is to mitigate endogeneity issue that may exist due to government policies being influenced by special federal or capital cities. This can be an issue in the developing countries where the capital cities are large and generate a significant share of national income. It is likely that the growth of these regions influences the government's policies in these countries. ${ }^{3132}$

Table 3.7 presents the results of the tests. To save space, I only report the convergence coefficients of each test. Column 1 presents the convergence coefficients from the analysis that controls for level 1 regions with country capital. Column 2 presents the convergence coefficients from the analysis that excludes those regions from the sample. Row 1 presents the analysis on the full sample of countries, row 2 on the sample of high-income countries, and row 3 on the sample of developing countries. Panel A presents the analysis using the first subnational level data, and panel B presents the analysis using the second subnational level data. Each regression includes country fixed effects and year fixed effects.

The results are similar to the baseline analysis. The convergence coefficients for the full sample and the sample of developing countries are positive and significant, indicating the detrimental effect of the decentralization on regional convergence. For the sample of highincome countries, the coefficients are positive and significant at $10 \%$ level only when first subnational level data are used. The findings alleviate the concern that the major capital

\footnotetext{
${ }^{31}$ The analysis also mitigates any issues that may have been caused by the top-coded regions as discussed before. Since the capital regions are most likely to include most of the top-coded regions, controlling for and removing them will also mitigate the concerns regarding top-coded regions.

${ }^{32}$ I chose to control for, and removing, level 1 regions with country capital instead of level 2 regions for two reasons. First, a lot of country capitals are themselves a level 1 region. Second, in a lot of countries, the capital city is the level 2 region itself. In those cases, neighboring level 2 regions could exert a similar influence on national policies. Also, the approach is more conservative than removing level 2 regions and hence, should mitigate the potential issue of endogeneity more.
} 
cities that influence national policies cause endogeneity problem and potentially bias the results.

Table 3.7: Decentralization and Within-Country Convergence

\begin{tabular}{lcc}
\hline \hline \multicolumn{2}{c}{ Control for Capital Regions } & Remove Capital Regions \\
\hline Panel A: First Subnational Level & & \\
\hline Full Sample & $0.102^{* * *}$ & $0.104^{* * *}$ \\
& $(0.0258)$ & $(0.0356)$ \\
High-income Countries & $0.122^{*}$ & $0.143^{*}$ \\
& $(0.0720)$ & $(0.0842)$ \\
Developing Countries & $0.108^{* * *}$ & $0.112^{* * *}$ \\
& $(0.0349)$ & $(0.0385)$ \\
\hline Number of Countries & $69,35,34$ & $69,35,34$ \\
Number of Observations & $24958,11433,13525$ & $23798,10806,12992$ \\
\hline \hline & & \\
Panel B: Second Subnational Level & $0.104^{* *}$ \\
\hline Full Sample & $0.0983^{* *}$ & $(0.0412)$ \\
& $(0.0392)$ & 0.0832 \\
High-income Countries & 0.0759 & $(0.0735)$ \\
Number of Observations & $549857,234731,315126$ & $529090,221877,307213$ \\
\hline \hline
\end{tabular}

Notes: The outcome variables in all specifications is subnational level growth rate of lights per capita. The coefficients reported are the convergence coefficients (coefficients of the interaction term between the decentralization measure used and the distance measure). Column 1 is the analysis that controls for level 1 regions where country capitals are located and column 2 is the analysis excluding those level 1 regions. All regressions include country fixed effects and year fixed effects. Panel A presents analysis using first subnational level data and panel B presents analysis using second subnational level data. In both panels, row 1 uses all countries with requisite data, row 2 uses high-income countries with requisite data, and row 3 uses developing countries with requisite data. The standard errors, in parenthesis, are clustered at the country level. Number of Countries and Number of Observations indicate number of countries and number of observations for the full sample, the sample of high-income countries, and the sample of developing countries, respectively.

$* p<.1, * * p<.05, * * * p<.01$. 


\subsubsection{Leave-one-out Estimations}

In this section, I test if any one particular country drives my baseline estimates by running the baseline regression excluding one country at a time. Figures $3.3 \mathrm{a}$ and $3.3 \mathrm{~b}$ present the results using first and second subnational level data respectively. Since there are 69 countries in my sample, I run the experiment 69 times, yielding 69 leave-one-out convergence coefficients. I present these coefficients using a histogram, and I include the estimates from my baseline specifications for comparison. The horizontal axis of the histogram denotes the value of convergence coefficients and the vertical axis denotes the frequency for each of the coefficients. The vertical dashed line gives the convergence coefficient from the baseline model. The distribution of the convergence coefficients, using both first and second subnational level data, is concentrated near the baseline coefficient (0.112 using first subnational level data and 0.0985 using second subnational level data), with less than 0.02 deviation of all leave-one-out estimations from the baseline results. It suggests that removing any one country from the baseline analysis does not significantly change the coefficient. Hence, I conclude that any one particular country is not driving my baseline results.

\subsubsection{Additional Robustness Tests}

In this section, I run a series of additional tests to establish the robustness of my baseline results.

First, I estimate regional convergence using the data on decentralization from Hooghe et al. (2016) only, which also include data on borrowing autonomy of subnational government, but covers only 61 countries. Since the self-rule measure now consists of all five components, including borrowing autonomy, I call it self-rule 5.

Second, I run the analysis by collapsing the yearly data into four-year averages. Thus, each observation $X_{t}$ is a four-year average of the values of $X$ in the baseline model. Since 


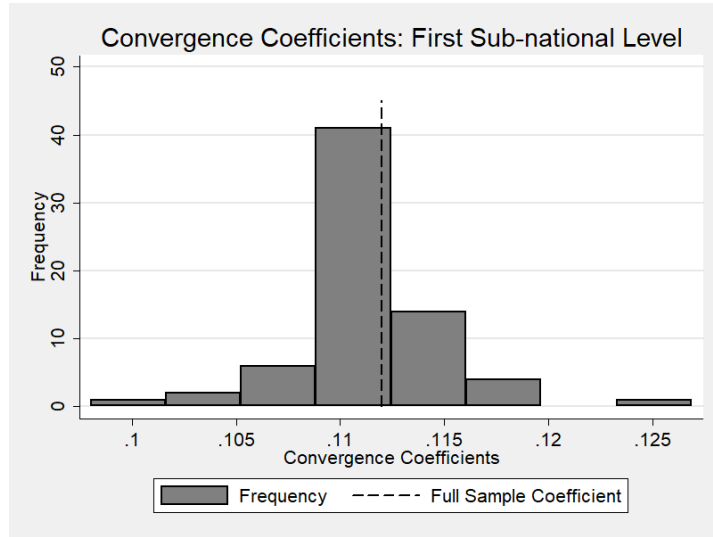

(a) First Subnational level

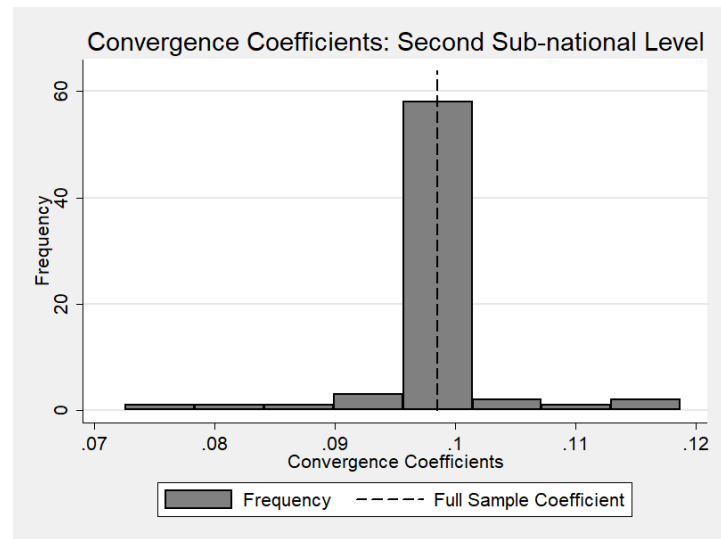

(b) Second Subnational level

Figure 3.3: Convergence Coefficients using Leave-one-out Estimators

Notes: The histogram presents the distribution of convergence coefficients from running 74 separate regressions, excluding one country at a time. The horizontal axis of the histogram denotes the value of the convergence coefficients and the vertical axis plots their frequency. The vertical dashed line gives the convergence coefficient from the baseline model.

my original night-time lights data covers the time span of 1992 to 2013, collapsing the data into four-year averages results in five time periods spanning 1992 to $2011 .^{33}$ There are two advantages of taking such averages. First, the convergence coefficients capture the longrun patterns of regional convergence, and second, it eliminates the impact of the business cycle on regional convergence. The obvious disadvantage is the loss of sample size, which is quite significant here as I am reduced to five time periods.

Third, I run the baseline regression on high-income countries and developing countries using alternative definitions of high-income countries. First, I classify countries as highincome countries and developing countries based on the World Bank's analytical classification using 1992 as the base year. Under this classification, a country is classified as a high-income country if its gross national income (GNI) per capita is greater than USD 7,620 in 1992, otherwise, it is classified as a developing country. Second, I classify a coun-

\footnotetext{
${ }^{33}$ Note that I have data on decentralization up to 2010, thus, I use a three-year average of self-rule for years 2008 to 2010, instead of limiting my sample period to 2007. Given that the aggregate self-rule index has low year-on-year changes, a three-year average and a four-year average should be very similar.
} 
try as a high-income country if it one of the members of the OECD, otherwise it is classified as a developing country.

Fourth, I run the baseline regression by trimming the data to remove top and bottom $0.1 \%$ based on regional growth rate. This helps remove any existing outliers that may influence my findings.

Fifth, I add some important control variables from the cross-country growth literature in my baseline specification. These variables are investment as a share of GDP, average years of schooling, trade as a share of GDP, and a dummy indicating whether a country is an oil producer or not. I use lagged values of all variables, except for the dummies for oil-producing countries.

Table 3.8 presents the results of these robustness tests. To save space, I only report the convergence coefficients of each test. Column 1 presents the convergence coefficients using self-rule 5 measure of decentralization instead of self-rule measure used in the baseline analysis. Column 2 presents results from analysis using four-year average data. Columns 3 and 4 present results from the analysis for high-income and developing countries using two alternative definitions of high-income countries. In columns 3, countries are classified as high-income based on the World Bank's classification in the year 1992 and in column 4, countries are classified as high-income if they are members of the OECD. Column 5 presents results from analysis using the trimmed data and column 6 presents results from analysis including additional controls mentioned above. Row 1 presents the analysis on the full sample of countries, row 2 on the sample of high-income countries, and row 3 on the sample of developing countries. Panel A presents the analysis using the first subnational level data, and panel B presents the analysis using second subnational level data. Each regression includes country fixed effects and year fixed effects.

The results support my findings from the baseline analysis. On the one hand, all of the convergence coefficients are positive and significant for the full sample and the sample of 
developing countries with one exception in the case of developing countries when using four-year averages of second subnational level data. ${ }^{34}$ On the other hand, all of the convergence coefficients for the high-income countries are insignificant at the conventional level with the exceptions of the coefficients from the analysis using four-year averages of first subnational level data and from the analysis using trimmed first subnational level data.

The robustness tests presented in this section support my findings in the baseline analysis. There is strong and robust evidence to support that the decentralization hinders regional convergence in developing countries, while results on the high-income countries are not robust. Hence, I cannot conclude with certainty that decentralization has a significant impact on regional convergence in the high-income countries. ${ }^{35}$

Table 3.8: Additional Robustness Tests of Within-Country Convergence

\begin{tabular}{|c|c|c|c|c|c|c|}
\hline & $\begin{array}{l}\text { Self-rule } 5 \\
\end{array}$ & $\begin{array}{l}\text { Four-year Average Data } \\
\end{array}$ & Income Group in 1992 & OECD vs Non-OECD & $\begin{array}{l}\text { Trimmed Data } \\
\end{array}$ & Additional Controls \\
\hline \multicolumn{7}{|c|}{ Panel A: First Subnational Level } \\
\hline Full Sample & $\begin{array}{l}0.110^{* * *} \\
(0.0248)\end{array}$ & $\begin{array}{c}0.0735^{* * *} \\
(0.0157)\end{array}$ & & & $\begin{array}{l}0.123^{* * *} \\
(0.0184)\end{array}$ & $\begin{array}{l}0.114^{* * *} \\
(0.0280)\end{array}$ \\
\hline High-income Countries & $\begin{array}{c}0.139 \\
(0.0856)\end{array}$ & $\begin{array}{l}0.0549^{*} \\
(0.0276)\end{array}$ & $\begin{array}{c}0.432 \\
(0.289)\end{array}$ & $\begin{array}{c}0.126 \\
(0.0772)\end{array}$ & $\begin{array}{l}0.0777^{* *} \\
(0.0294)\end{array}$ & $\begin{array}{c}0.127 \\
(0.0821)\end{array}$ \\
\hline Developing Countries & $\begin{array}{l}0.109^{* * *} \\
(0.0380)\end{array}$ & $\begin{array}{l}0.0631^{* *} \\
(0.0266)\end{array}$ & $\begin{array}{l}0.112^{* * *} \\
(0.0312)\end{array}$ & $\begin{array}{l}0.130^{* * *} \\
(0.0352)\end{array}$ & $\begin{array}{l}0.135^{* * *} \\
(0.0317)\end{array}$ & $\begin{array}{l}0.121^{* * *} \\
(0.0372)\end{array}$ \\
\hline Number of Countries & $61,35,26$ & $69,35,34$ & 23,46 & 32,37 & $69,35,34$ & $68,35,33$ \\
\hline Number of Observations & $23919,11433,12486$ & $6983,3205,3778$ & 7254,17704 & 10490,14468 & $24951,11431,13520$ & $24688,11244,13444$ \\
\hline \multicolumn{7}{|c|}{ Panel B: Second Subnational Level } \\
\hline Full Sample & $\begin{array}{l}0.0985^{* *} \\
(0.0487)\end{array}$ & $\begin{array}{l}0.0581^{*} \\
(0.0300)\end{array}$ & & & $\begin{array}{l}0.0833^{* *} \\
(0.0351)\end{array}$ & $\begin{array}{l}0.0918^{* *} \\
(0.0401)\end{array}$ \\
\hline High-income Countries & $\begin{array}{c}0.0827 \\
(0.0699)\end{array}$ & $\begin{array}{c}0.0750 \\
(0.0561)\end{array}$ & $\begin{array}{l}0.0909 \\
(0.110)\end{array}$ & $\begin{array}{c}0.0224 \\
(0.0468)\end{array}$ & $\begin{array}{c}0.0387 \\
(0.0499)\end{array}$ & $\begin{array}{l}0.00839 \\
(0.0390)\end{array}$ \\
\hline Developing Countries & $\begin{array}{l}0.117^{* *} \\
(0.0541)\end{array}$ & $\begin{array}{c}0.0446 \\
(0.0300)\end{array}$ & $\begin{array}{c}0.116^{* *} \\
(0.0446)\end{array}$ & $\begin{array}{l}0.163^{* * *} \\
(0.0522)\end{array}$ & $\begin{array}{l}0.107^{* *} \\
(0.0399)\end{array}$ & $\begin{array}{c}0.122^{* *} \\
(0.0448)\end{array}$ \\
\hline Number of Countries & $61,35,26$ & $69,35,34$ & 23,46 & 32,37 & $69,35,34$ & $68,35,33$ \\
\hline Number of Observations & $544146,234731,309415$ & $153498,65825,87673$ & 166248,383573 & 223142,326715 & $549042,234535,314507$ & $546686,232136,314550$ \\
\hline $\begin{array}{l}\text { Notes: The outcome variables } \\
\text { the decentralization measure us } \\
1992 \text { 's income classification to } \\
\text { column } 5 \text { is the analysis using } \\
\text { using first subnational level dat } \\
\text { data, and row } 3 \text { uses developin } \\
\text { countries and number of observ } \\
* p<1, * *\end{array}$ & $\begin{array}{l}\text { In all specifications is subnation } \\
\text { sed and the distance measure). } \\
\text { distinguish between high-incon } \\
\text { the trimmed data, and column } 6 \\
\text { a and panel B presents analysis } \\
\text { g countries with requisite data. } \\
\text { rations for the full sample, the sa } \\
01\end{array}$ & $\begin{array}{l}\text { evel growth rate of lights per } \\
\text { umn } 1 \text { is the analysis using } \\
\text { and developing countries, co } \\
\text { the analysis with additional c } \\
\text { ng second subnational level c } \\
\text { e standard errors, in parenth } \\
\text { le of high-income countries }\end{array}$ & $\begin{array}{l}\text { ta. The coefficients rep } \\
\text { ule } 5 \text { measure, column } \\
4 \text { is the analysis using } \\
\text { ls included. All regress } \\
\text { In both panels, row } 1 \text { use } \\
\text { are clustered at the cou } \\
\text { the sample of developin }\end{array}$ & $\begin{array}{l}\text { d are the convergence coe } \\
\text { she analysis using four-y } \\
\text { CD membership to disting } \\
\text { s include country fixed eff } \\
\text { Il countries with requisite } \\
\text { level. Number of Count } \\
\text { ountries, respectively. }\end{array}$ & $\begin{array}{l}\text { cients (coefficients of the interact } \\
\text { average data, column } 3 \text { is the an } \\
\text { h between high-income and deve } \\
\text { ts and year fixed effects. Panel A } \\
\text { a, row } 2 \text { uses high-income count } \\
\text { s and Number of Observations in }\end{array}$ & $\begin{array}{l}\text { ion term between } \\
\text { alysis using year } \\
\text { lloping countries, } \\
\text { presents analysis } \\
\text { res with requisite } \\
\text { dicate number of }\end{array}$ \\
\hline
\end{tabular}

\footnotetext{
${ }^{34}$ Note that for columns 3 and 4 , analysis on the full sample would be the same as in the baseline analysis, so they are not reported here.

${ }^{35}$ Out of 10 specifications for convergence analysis with self-rule measure, none of the coefficients are significant when second subnational level data are used and coefficients of only 5 specifications are significant at $10 \%$ level when first subnational level data are used for the sample of high-income countries. Hence, I cannot establish the robustness of the results for the sample of high-income countries.
} 


\subsection{Discussion on the Detrimental Effect of Decentraliza- tion in the Developing Countries}

There are various channels through which decentralization can hinder regional convergence in developing countries. Unfortunately, my data do not allow us to explore these mechanisms in detail. Thus, I review the decentralization literature and provide some possible explanations in this section. First, an effective intergovernmental transfer of resources to jurisdictions with lower fiscal capacities in important in a decentralized system, however, developing countries are less likely to have an effective equalization program that assist with public expenditures in poorer regions (Meltzer and Richard, 1981; Boadway and Flatters, 1982; Watson, 1986; Boadway et al., 2003; Boadway and Shah, 2007). Thus, it can lead to lower infrastructure spending in poorer regions of developing countries, which impedes their future growth. On top of that, Stein (1997) finds that average cost of providing public goods is higher under a decentralized system. Second, local governments in developing countries are more prone to elite capture than those of the high-income countries, hence, misappropriation of public funds by special interest groups are more likely in poor regions of the developing countries (Prud'Homme, 1995; Bardhan and Mookherjee, 2005). Third, poorer regions have a lower tax base than richer regions. Thus, their average tax rate would have to be higher to raise the same amount of revenue and provide comparable public goods. These factors can lead to both lower infrastructure spending and lower level of private investments in poor regions (Boadway, 1982; Prud'Homme, 1995; Boadway and Shah, 2007). Fourth, the composition of subnational government's spending is also important for the convergence process. If subnational governments of poorer regions are spending a relatively large amount in current spending and welfare program than in capital spending, then that can lead to less growth in the future, exacerbating the initial gap in income across regions (Davoodi and Zou, 1998). Fifth, human capital in developing 
countries is generally lower than that of the high-income countries. Hence, officials in local governments of developing countries are likely to be less skilled. So, a centralized system may be more beneficial where the central government can utilize the expertise of the few skilled government officials for policymaking (Prud'Homme, 1995). Sixth, the efficiency gains of decentralization may not materialize in developing countries as local governments may not be as responsive to the preferences of the residents. This can occur when residents do not elect local government officials or when the residents are unable to "vote with their feet" due to lack of resources.

\subsection{Conclusions}

In this paper, I attempt to understand how decentralization affects regional convergence using a global sample of countries. The theoretical prediction, as well as the empirical estimation in the literature, provides an ambiguous answer: decentralization can either cause convergence or divergence of subnational economies. Decentralization can improve economic growth by increasing the effectiveness and efficiency of the public sector, by fostering competition among regional governments, and by better matching resources and preferences of communities and governments. However, decentralization can also inhibit growth in more impoverished regions due to their limited state capacity, weaker endowments, and a higher incidence of elite capture, and due to the limited redistributive role of central government in a decentralized economy that can lead to an even larger disparity between richer and poorer regions.

I use data on night-time lights intensity at the regional level to proxy for local economic activity (or GDP) and Regional Authority Index's self-rule and its components to measure decentralization. The use of night-time lights data allows us to cover a large number of developing countries in my sample, which was not possible before. The use of self-rule and 
its components as measures of decentralization provides a broader measure of decentralization as it allows us to study a wide range of fiscal, political, and administrative authority of subnational regions.

Although my analysis fills an important gap in the literature, there are some limitations to my study. For instance, although night-time lights data allows us to cover a large number of developing countries, it is an imperfect proxy for regional income. I am also unable to fully explore the channels through which decentralization hinders convergence in developing countries, but not in developed countries. Does the link operate via the differential provision of public goods, via elite capture at the subnational level, or via less redistributive role of the central government?

I study within-country as well as within-first-subnational level convergence and find that decentralization hinders the convergence process in developing countries. For instance, I find that when the decentralization index of the country changes from the lowest possible value (i.e., 0) to the highest possible value (i.e., 1), the convergence rate of a region that is halfway to the country frontier slows down by about 8 percent. I find that decentralization hinders not only within-country convergence but also within-first-subnational region convergence. In fact, the convergence coefficients of within-first-subnational region analysis are larger than within-country convergence analysis. It suggests that the growth of first subnational level regions in developing countries is mostly driven by the growth of a few second subnational level regions within that first subnational level region. The findings on the sample of high-income countries are not robust, and hence, I refrain from drawing any conclusion on the impact of decentralization on high-income countries.

I also analyze the impact of changes in different components of decentralization such as fiscal autonomy, institutional depth, policy autonomy, and political representation on regional convergence. The sub-component analysis reinforces the findings from the analysis of the overall decentralization index that decentralization severely reduces the convergence 
process in developing countries. It also sheds light on the notion that the political and administrative dimensions of decentralization are also essential in explaining the impact of decentralization on regional convergence.

I conclude by noting that the methods and data used in this paper can be applied to study the impact of various phenomena such as structural reforms, democratic reforms, trade openness, and globalization on regional inequality and convergence. 


\section{Chapter 4}

\section{Active and Passive Policy Regimes in Economies with Government Debt}

Traditionally, inflation is mostly thought of as a monetary phenomena. Inflation in macroeconomics has mostly been modeled by focusing on monetary policy and abstracting away from fiscal policy. However, developments in past two decades, including the Global Financial Crisis, has compelled economists to study fiscal policy more closely. During the Global Financial Crisis, many economies reacted to sharply reduced short-term interest rates by implementing fiscal stimulus packages. Monetary authorities also engaged in nonconventional policies of purchasing long-term private and government assets. Economies moved away from fiscal austerity towards more joint policy regimes. Hence, it is essential to study a discretionary role of both fiscal and monetary authorities as the expectations regarding fiscal policies are equally important as those of monetary policies in determining equilibrium prices and quantities.

"Fiscal Theory" of price level calls for discretionary role for fiscal government to stabilize debt through surprise changes in inflation and bond prices. Proponents of fiscal theory explore policy issues through fiscal lenses and reach conclusions that contrast the findings 
of monetary policy approach. ${ }^{1}$ However, their analyses using reduced-form models suffer from similar shortcomings of the model used in the analysis of monetary policy using ad hoc policy rules. As Aruoba and Chugh (2010) noted, even when parameterized to make the model look similar to reduced-form models, implications can be very different when monetary frictions are modeled with earnest intent. ${ }^{2}$

To that end, I study monetary and fiscal policies in Lagos-Wright framework (Lagos and Wright, 2005) with private financial intermediaries that facilitate liquidity transformation in the spirit of Diamond and Dybvig (1983). In this setting, there's a role for currency and secured credit in the trade for consumption goods due to limited commitment and memory. Government bonds of short (one-period) and long (perpetuity) maturities are present as alternative store of value in the analysis. The government bonds of all maturities serve as pledgeable assets to acquire credit. I study two distinct policy regimes. First, I study a policy regime in which monetary authority actively changes money growth rate while fiscal authority passively adjusts nominal debt holding to keep money-to-debt ratio constant. Taxes adjust passively as well to balance the budget. Second, I study a regime in which fiscal authority actively changes nominal debt holdings and monetary authority passively adjusts money growth rate to keep the money-to-debt ratio constant. Studying different policy regimes allows me to study how different policy changes affect individuals' consumption opportunities differently, as well as difference in determination and evolution of inflation.

Reasons for including long-maturity bond in the analysis are three-folds. First, it allows me to explore a phenomenon described by Tobin (1963) as "monetary effect of the debt". In the context of debt management, the monetary effect of the debt arises from the maturity

\footnotetext{
${ }^{1}$ Leeper and Leith (2016) provides a good summary of fiscal theory of price level. Also see (Cochrane, 2001; Sims, 2013; Leeper and Zhou, 2013) for the argument for fiscal theory.

${ }^{2}$ See Williamson and Wright (2010) for discussion on the advantages of micro-founded search-based models over the reduced-form models.
} 
structure which outlasts the direct effect that is determined by the initial increase in deficit because it endures over the maturity horizon of the debt. Changes in maturity structure impacts the size and composition of household wealth that can affect the macroeconomic dynamics even if the total size of the debt is constant. On the other hand, Ricardian equivalence in the analysis of monetary policy using reduced form models imply that structure of debt is irrelevant. Hence, I can also analyze the monetary effect of the debt and Ricardian equivalence in this setup. Second, it allows me to study non-conventional policies that include forward guidance with promises about future policies. Third, long-maturity government bonds can alter the optimal government policies. A common policy recommendation in New Keynesian models with one-period government debt is to keep inflation constant, implying that monetary policy should not be used to stabilize debt (Schmitt-Grohé and Uribe, 2004). Sims (2013) questions the robustness of the result when long-maturity government bond is present. In the absence of long-maturity government bonds, only way to alter value of the debt in order to cushion fiscal shocks is through surprise inflation or deflation. However, value of the debt can be altered through sustained changes in nominal interest rates, with much smaller changes in inflation rate when the government can issue long-maturity bonds.

The findings of the paper are as follows. First, I find that the long-maturity government bonds are valued only when the pledgeability of the long-maturity bonds are less than that of the short-maturity bonds and the pledgeable assets are scarce, and hence, the consumption is inefficient. As Kocherlakota (2003) and Andolfatto (2011) point out, in presence of currency, government bonds don't serve risk-sharing purpose as both bonds and currency are risk-less assets in nominal terms. Hence, bonds need to be handicapped by making them illiquid if they are to serve any social purpose. Also, long-maturity bonds need to be handicapped further in order for it to be essential, which is achieved by having different pledgeability. 
Second, under active monetary policy regime, a permanent non-neutrality of money result arises from a monetary policy. Under equilibrium with scarce collateral, the monetary authority can improve individuals' welfare by increasing the money growth rate. Higher money growth means fiscal authority will have to increase the total nominal debt outstanding in this setting in order to keep the money-to-debt ratio constant. Hence, one time increase in money growth rate increases the total money stock of money and nominal debt permanently. Since the plegdeable assets are scarce in the equilibrium, an increase in government bonds lead to higher credit-backed consumption opportunities as the agents have more assets to use as collateral. However, there's a limit to how much the monetary authority can increase the money growth rate. Increasing the money growth rate decreases the nominal interest rates as the the supply of government bonds is larger. A zero lower bound on the short-term nominal interest rate implies that any monetary policy that leads to negative nominal interest rate is not feasible. In that case, fiscal authority can adjust total nominal debt by issuing long-maturity bonds instead. This is similar to monetary authority implementing the "Quantitative Easing" policy in spirit. ${ }^{3}$ This lowers the long-term interest rate instead, and hence, term premium, without affecting the short-term interest rate. Hence, presence of long-maturity government debt can be welfare improving. The findings on non-neutrality of money and the effect of Quantitative Easing type policy is similar to that of Gertler et al. (2013) and Williamson (2016).

The maturity structure of the government debt is relevant for the monetary policy in this setting. This finding is in contrary to the non-relevance of maturity structure for monetary policy in studies with reduced form models. ${ }^{4}$ It is not optimal to hold long-maturity government debt away from the zero lower bound in monetary policy regime however.

Third, under active fiscal regime, the fiscal authority can improve individuals' welfare

\footnotetext{
${ }^{3}$ Quantitative Easing policy is to the Central Bank purchase of long maturity government bonds

${ }^{4}$ See studies on fiscal theory. (Leeper and Leith, 2016; Cochrane, 2001; Sims, 2013; Leeper and Zhou, 2013)
} 
by increasing total government debt. This has a direct effect on the amount of pledgeable assets available for acquiring credit. Hence, credit backed consumptions increase. Similar to the active monetary regime, the fiscal authority is faced with zero lower bound on the short-term interest rate and hence cannot issue short-maturity bonds when faced with the constraint. Again, the long-maturity bonds help in this case as the policy makers can issue more long-maturity debt and effectively lower the term premium without affecting the short-term interest rate. One notable difference under this regime compared to the active monetary regime is the fact that the inflation is now driven by debt policy and it is nonmonotonic in the initial level of total debt. When the initial debt level is low, an increase in debt leads to lower inflation. However, as the initial level of debt rises, an increase in debt leads to higher inflation. Non-monotonic inflation dynamics implies that the currency based consumption evolve non-monotonously as well due to change in fiscal policy. Such non-monotonicity does not arise in monetary policy regime. This analysis supports the notion that fiscal policy can achieve desired inflation and macroeconomic outcomes. The finding also implies that when the level of debt increases, the fiscal authority has an incentive to inflate. This is a common finding in the fiscal theory of inflation. Also, the maturity structure of the debt matters. Allowing long-maturity government debt to change can result in higher welfare while lowering the effective zero lower bound. This finding reinforces the notion of the monetary effect of the debt. However, the finding that increasing inflation (at a feasible range) leads to improved welfare is in contrast to the policy recommendation of studies on fiscal theory of inflation that calls for constant inflation, especially in the presence of sticky prices.

The paper contributes to two different strands of literature on fiscal and monetary policy. First, it contributes to the fiscal theory of price level by studying the role of fiscal policy in determining inflation using a search-based approach where interest rates are de- 
termined through equilibrium rather than from an ad hoc policy rule. ${ }^{5}$ Second, the paper contributes to the literature on the role of maturity structure in monetary policy. Third, it contributes to the literature of unconventional forward guidance policies such as Quantitative Easing or fiscal government's issuance of long-maturity bonds, which effectively increases average maturity of outstanding government debt. Studying equilibrium under different policy regimes contributes to the literature by analyzing how the policies affect the economy differently under different regimes.

Rest of the paper is as follows. Section 2 lays out the environment and section 3 solves the decision problems of the individuals' and the banks. Section 4 analyzes the government policies under active monetary and active fiscal regime. Section 5 concludes the paper with a brief summary of the findings.

\subsection{Environment}

There are an infinite number of discrete time periods, indexed by $t=0,1,2, \ldots$. At each date $t \geq 0$, the period is divided into two subperiods, hereafter referred to as morning and afternoon. The commodity space consists of two different perishable, consumption goods. In the morning subperiod, there is a specialized good, or a DM good, that is produced and consumed. In the afternoon market, there is a general good, or a CM good, that is produced and consumed in a competitive (Walrasian) market. There is a continuum of measure two of infinitely-lived agents in this economy.

Heterogeneity exists in the model economy. Let one half of the agents be permanently assigned to be producers in the morning market and one half are permanently assigned to be consumers in the morning market. Producers are the only ones that have access to the

\footnotetext{
${ }^{5}$ The literature is very thin and includes only a handful of studies including Aruoba and Chugh (2010) and Martin (2011) which study joint policies. This is the first paper paper to study passive monetary regime in new monetarist model.
} 
technology that produces the specialized good. Producers cannot produce the specialized good, but derive utility from consuming the specialized good. All agents can produce and consume in the afternoon market. The CM good is produced using a technology that transforms labor into the consumption good at a constant rate. In addition, there are three stores of value. One is a divisible, intrinsically useless asset called fiat money. Let $M_{t}$ denote the quantity of money at date $t$. The value of fiat money is stated in terms of the numeraire. Let $\phi_{t}$ denote the date- $t$ rate at which the general goods is exchanged for one unit of money. The other two stores of value are government bonds of short (one-period) and long (perpetuity) maturity. A one-period bond is a promise to pay one unit of money in the afternoon market of period $t+1$ and sells at price $z_{t}^{s}$ in the afternoon market of period t. A long-maturity bond is a promise to pay one unit of money in every future afternoon market and sells at price $z_{t}^{l}$ in the afternoon market of period $t$.

Trading in the afternoon market occurs with a Walrasian auctioneer. In contrast, the morning market is characterized by bilateral matches. Each bilateral match is distinguished by allowing monitored or non-monitored exchanges. A non-monitored meeting means that there is no record-keeping, thus precluding the use of unsecured credit. Any nonmonitored trades will be executed using fiat money. In a monitored trade, no histories are known, ruling out private credit arrangements. However, inside money, i .e., claims on bank deposits, can be used as a means of payment. ${ }^{6}$ In other words, monitored trades are characterized by the existence of a technology that can verify the bank deposit exists and is sufficient to satisfy the terms of trade. ${ }^{7}$

To completely describe the actions in the economy, let $q$ be the quantity of the DM good produced and let $x$ be the net quantity of the CM good consumed. Here, $x<0$ means that the agent produces more of the CM good than she consumes. If the agent is a producer,

\footnotetext{
${ }^{6}$ Here, we are borrowing heavily from Berentsen et al. (2007) so that bank deposits can be used in exchange.

${ }^{7}$ See, for example, the communication protocol described in Williamson (2012).
} 
momentary utility is represented as $U^{p}(x, h)=x-h$. We assume that $h$ measures the disutility of labor associated with producing $q$ units of the CM good. Let the consumer's momentary utility function be represented by $U^{c}=x+u(q)$, where $u(q)$ measures the utility derived from consuming $q$ units of the specialized good. We assume the following: $u^{\prime}>0, u^{\prime \prime}<0, u(0)=0$.

The timing in the model economy unfolds as follows. In the beginning of the afternoon market, agents do not know the type of match (monitored or non-monitored) in the following morning market. They learn their type at the end of the afternoon market after consumption and production decisions have taken place. Formally, the producer-consumer pair learns that they are in a non-monitored meeting with probability $\alpha$ and in a monitored meeting with probability $1-\alpha$ in the following morning market. Consider first how exchange occurs in a non-monitored meeting. The consumer withdraws money from the bank to exchange with the producer. Alternatively, a monitored meeting is marked by the consumer offering a deposit claim to the producer. The monitoring process provides for the producer by allowing for collateral to serve as a post-trade assurance that settlement occurs. Thus, even with limited commitment and memory, the two parties are satisfied.

In this model economy, government bonds are the collateral. Following Williamson (2016), we assume that there are different pledgeability characteristics for the two types of government bonds. The assumption is equivalent to a setup in which the consumers/depositors can abscond with the fraction $\theta_{s}$ and $\theta_{l}$ of short and long-maturity bonds. Different pledgeability can be thought of as applying a haircut to the long-maturity bonds. ${ }^{8}$ In the afternoon market, agents produce, consume, receive any net proceeds from deposit account, and then trade the CM good, depositing money and goods into a bank. Banks in this setting arise endogenously to allocate assets efficiently to appropriate agents. The banks provide insurance

\footnotetext{
${ }^{8}$ Federal Reserve applies different haircuts to short-maturity and long-maturity government debt. For instance, Fed will lend $99 \%$ of the market value of bond with maturity less than 5 years and $96 \%$ of bonds with duration mote than 10 years.
} 
service similar to Diamond and Dybvig (1983). Any agents can operate a bank, and hence, is subject to the same limited commitment as an agent. After learning their type, agents in non-monitored meetings can withdraw money balances from the bank at the end of the afternoon market. A bank offers a state-contingent contract to the depositor to maximize the expected utility of the agent. Hence, banking arrangement essentially allocates money balances to the agents in the non-monitored meetings and government debts to the agents in the monitored meetings.

In addition to producers and consumers, there is a government in this economy that collects lump-sum taxes, issues debt and chooses the money growth rate. Government activities are represented by the government budget constraint. Formally,

$$
\begin{gathered}
\phi_{0}\left(M_{0}+z_{0}^{s} B_{0}^{s}+z_{0}^{l} B_{0}^{l}\right)-\tau_{0}=0 \\
\phi_{t}\left(M_{t}-M_{t-1}+z_{t}^{s} B_{t}^{s}-B_{t-1}^{s}+z_{t}^{l} B_{t}^{l}-\left(z_{t}^{l}+1\right) B_{t-1}^{l}\right)-\tau_{t}=0
\end{gathered}
$$

where $\tau_{t}$ is the lump-sum tax levied by the government. $\mathbf{M}_{t}, \mathbf{B}_{t}^{s}$ and $B_{t}^{l}$ represent nominal quantities of money, short-term (one period) and long-maturity (perpetuity) government debt at the end of the afternoon market in period $t$ respectively. $z_{t}^{s}$ and $z_{t}^{l}$ are the prices of short and long-maturity government debts respectively. I assume that the government has no assets or liabilities at the beginning of period 0 . The Government operates only in the afternoon market. 


\subsection{Decision Problems}

\subsubsection{The bank's problem}

We assume there is a continuum of measure of banks in this model economy. Any agent can operate a bank. The banks serve risk-sharing purpose among agents and provide liquidity as in Diamond and Dybvig (1983). A bank accepts deposits, offers deposit contracts to the agents, acquires government assets and provides cash and deposit claims to the agents. The deposit claims must be backed by collaterals as the banks have same limited commitment as an agent. Only available collateral are the government bonds. The collateral held by the banks have limited pledgeability, however. Banks can abscond fraction $\theta_{s}$ of holdings of one-period government bonds and fraction $\theta_{l}$ of long-maturity bonds in the next afternoon market. Following Champ et al. (1996), each bank seeks to maximize the expected utility of depositors. The bank's decision involves allocating resources between money holdings and government bonds. In equilibrium, a bank solves the following problem in the afternoon market of period $t$.

$$
\begin{gathered}
\max _{k, m, b_{s}, d, R} \alpha u\left(q_{t+1}\right)+(1-\alpha) u\left(q_{t+1}^{m}\right)-k_{t} \\
\text { s.t. } \\
k_{t}-\alpha m_{t}-z_{t}^{s} b_{t}^{s}-z_{t}^{l} b_{t}^{l}-(1-\alpha) \beta R_{t+1} d_{t}+\beta \frac{\phi_{t+1}}{\phi_{t}} b_{t}^{s}+\beta \frac{\phi_{t+1}}{\phi_{t}} b_{t}^{l}\left(1+z_{t+1}^{l}\right) \geq 0 \\
-(1-\alpha) R_{t+1} d_{t}+\frac{\phi_{t+1}}{\phi_{t}} b_{t}^{s}+\frac{\phi_{t+1}}{\phi_{t}} b_{t}^{l}\left(1+z_{t+1}^{l}\right) \geq \frac{\phi_{t+1}}{\phi_{t}}\left(\theta_{s} b_{t}^{s}+\theta_{l} b_{t}^{l}\left(1+z_{t+1}^{l}\right)\right) \\
m_{t} \geq 0, k_{t} \geq 0, b_{t}^{s} \geq 0, b_{t}^{l} \geq 0, d_{t} \geq 0
\end{gathered}
$$

$k_{t}$ is the quantity of goods deposited in the bank, $m_{t}$ is the amount of money a depositor can withdraw at the end of an afternoon market. $R_{t+1} d_{t}$ is quantity of claims to the specialized goods in the next afternoon market that the buyer can buy in the morning market in a mon- 
itored meeting. First constraint is the balance-sheet constraint that says the bank receives a non-negative net returns over the current and next afternoon market. Since the rate of return on deposit claims dominate rate of return on money in equilibrium, only buyers in nonmonitored meetings will withdraw money. Hence, $\alpha m_{t}$ is the total money withdrawn. Remainder of the deposits is used to buy government bonds and redeem on the deposit claims next period. The expression $-z_{t}^{s} b_{t}^{s}-z_{t}^{l} b_{t}^{l}-(1-\alpha) \beta R_{t+1} d_{t}+\beta \frac{\phi_{t+1}}{\phi_{t}} b_{t}^{s}+\beta \frac{\phi_{t+1}}{\phi_{t}} b_{t}^{l}\left(1+z_{t+1}^{l}\right)$ is the present value of the net liabilities of the bank, which cannot exceed the present value of remainder of the deposits $\left(k_{t}-\alpha m_{t}\right)$. The second constraint is the bank's incentive constraint and the third is the non-negative constraints. The bank's incentive constraint states that the bank's net payoff, if it pays all liabilities in next afternoon market, is at least as large as the payoff it would receive if it absconded with what it could retain from its asset portfolio. Rewriting the constraint, we get,

$$
-(1-\alpha) R_{t+1} d_{t}+\frac{\phi_{t+1}}{\phi_{t}} b_{t}^{s}\left(1-\theta_{s}\right)+\frac{\phi_{t+1}}{\phi_{t}} b_{t}^{l}\left(1+z_{t+1}^{l}\right)\left(1-\theta_{l}\right) \geq 0
$$

The intuition is as follows: deposits are made in the CM at date t. At the end of period $\mathrm{t}$, withdrawals are made by those in the non-monitored meeting. Rest of the deposits are held until date $t+1$. For those in monitored meetings, the value of principal and interest paid cannot exceed the value of short-term (nominal) bonds held by the bank. Note that the incentive constraint binds only when $R_{t+1}<\frac{1}{\beta}$ otherwise agents who operate the bank gain nothing by absconding.

Plugging in the solutions for quantities from morning market, bank's problem can be written as,

$$
\begin{gathered}
\max _{d_{t}, k_{t}, m_{t}, b_{t}^{s}, b_{t}^{l}}\left(-k_{t}+\alpha u\left(\frac{\beta \phi_{t+1} m_{t}}{\phi_{t}}\right)+(1-\alpha) u\left(\beta R_{t+1} d_{t}\right)\right) \\
\text { s.t. }
\end{gathered}
$$




$$
\begin{gathered}
k_{t}-\alpha m_{t}-z_{t}^{s} b_{t}^{s}-z_{t}^{l} b_{t}^{l}-(1-\alpha) \beta R_{t+1} d_{t}+\beta \frac{\phi_{t+1}}{\phi_{t}} b_{t}^{s}+\beta \frac{\phi_{t+1}}{\phi_{t}} b_{t}^{l}\left(1+z_{t+1}^{l}\right) \geq 0 \\
-(1-\alpha) R_{t+1} d_{t}+\frac{\phi_{t+1}}{\phi_{t}} b_{t}^{s}\left(1-\theta_{s}\right)+\frac{\phi_{t+1}}{\phi_{t}} b_{t}^{l}\left(1+z_{t+1}^{l}\right)\left(1-\theta_{l}\right) \geq 0 \\
m_{t} \geq 0, k_{t} \geq 0, b_{t}^{s} \geq 0, b_{t}^{l} \geq 0, d_{t} \geq 0
\end{gathered}
$$

The formulation of the bank's problem assumes that the terms of trade in the morning market are decided by a take-it-or-leave-it offer. A buyer in a non-monitored meeting receives $\frac{\beta \phi_{t+1}}{\phi_{t}}\left(m_{t}\right)$ amount of specialized goods for $m_{t}$ amount of money. A buyer in a monitored meeting receives $\beta R_{t+1} d_{t}$ amount of goods in exchange for claims to $R_{t+1} d_{t}$ deposits in afternoon market of period $t+1$. Note that the balance sheet constraint must bind as the objective function is increasing in $m$ and $d$ while left hand side of the constraint is decreasing. In equilibrium, return on money is generally dominated by return on deposits. This implies that the agents have no incentive to not deposit all the goods in the bank, i. e., $m_{t}^{a}=0$.

The bank's FOCs are:

$$
\begin{gathered}
\beta \frac{\phi_{t+1}}{\phi_{t}} u^{\prime}\left(\frac{\beta \phi_{t+1} m_{t}}{\phi_{t}}\right)-1=0 \\
\beta u^{\prime}\left(\beta R_{t+1} d_{t}\right)-\beta-\lambda_{t} \leq 0 \\
-z_{t}^{s}+\beta \frac{\phi_{t+1}}{\phi_{t}}+\lambda_{t} \frac{\phi_{t+1}}{\phi_{t}}\left(1-\theta_{s}\right) \leq 0 \\
-z_{t}^{l}+\beta \frac{\phi_{t+1}}{\phi_{t}}\left(1+z_{t+1}^{l}\right)+\lambda_{t} \frac{\phi_{t+1}}{\phi_{t}}\left(1-\theta_{l}\right)\left(1+z_{t+1}^{l}\right) \leq 0
\end{gathered}
$$

$\lambda_{t}$ is the lagrange multiplier associated with the bank's incentive constraint. From equation 4.13 , it is clear that the trade in monitored meeting is inefficient if the bank's incentive constraint binds. When the bank's incentive constraint does not bind, $\lambda_{t}=0$, returns on long and short-maturity bonds are the same. Hence, the long-maturity bonds do not provide 
marginal benefit over one-period bonds. We then focus on cases where the incentive constraint is binding. From equations 4.14 and 4.15 after substituting $\lambda_{t}=\beta u^{\prime}\left(\beta R_{t+1} d_{t}\right)-\beta$, nominal yields on bonds are,

$$
\begin{aligned}
& R_{t+1}^{s}=\frac{\phi_{t}}{\beta \phi_{t+1}\left(u^{\prime}\left(\beta R_{t+1} d_{t}\right)\left(1-\theta_{s}\right)+\theta_{s}\right)}-1 \\
& R_{t+1}^{l}=\frac{\phi_{t}}{\beta \phi_{t+1}\left(u^{\prime}\left(\beta R_{t+1} d_{t}\right)\left(1-\theta_{l}\right)+\theta_{l}\right)}-1
\end{aligned}
$$

The nominal term premium is then given by,

$$
R_{t+1}^{l}-R_{t+1}^{s}=\frac{\phi_{t}\left(u^{\prime}\left(\beta R_{t+1} d_{t}\right)-1\right)\left(\theta_{l}-\theta_{s}\right)}{\beta \phi_{t+1}\left(u^{\prime}\left(\beta R_{t+1} d_{t}\right)\left(1-\theta_{s}\right)+\theta_{s}\right)\left(u^{\prime}\left(\beta R_{t+1} d_{t}\right)\left(1-\theta_{l}\right)+\theta_{l}\right)}
$$

This implies that in order for term premium to be positive, we need $\theta_{l}>\theta_{s}$, that is, pledgeability of the long-maturity bonds are less than that of the short-maturity bonds, and $u^{\prime}\left(\beta R_{t+1} d_{t}\right)>1$, that is, the the trade in monitored meetings are inefficient. This means that these two conditions must satisfy in order for long-maturity bonds to be essential. In this case, the collateral is scarce in a sense that total value of collateral is not enough to support efficient trade in the monitored meetings. Also, similar to Kocherlakota (2003) and Andolfatto (2011) argument regarding handicapping one-period bonds relative to currency, long-maturity bonds need to be handicapped further in order for it to be essential, which is achieved by having different pledgeability. From this point on, I focus on this case only.

Binding incentive constraint implies that the bank must receive a payoff strictly greater than zero in the following afternoon market to keep itself from absconding. But binding equation 4.9 implies that the present value of the bank's payoff at period $t$ is zero. Hence, the bank acquires assets with value higher than that of the deposits. The difference is the bank capital that prevents the bank from absconding. In equilibrium, the bank does not 
abscond and the agents have incentive to deposit all their asset holdings in the bank.

\section{At Zero Lower Bound}

First, I look at the solution when monetary authority is facing zero lower bound on shortmaturity bonds, i. e. $z^{s}=1$. Combining FOCs and writing in terms of specialized goods, we get,

$$
-(1-\alpha) q_{t}^{m}\left(u^{\prime}\left(q_{t}^{m}\right)\left(1-\theta_{s}\right)+\theta_{s}\right)-\frac{z_{t}^{l} b_{t}^{l}\left(\theta_{l}-\theta_{s}\right)}{u^{\prime}\left(q_{t}^{m}\right)\left(1-\theta_{l}\right)+\theta_{l}}+\left(b_{t}^{s}+z_{t}^{l} b_{t}^{l}\right)\left(1-\theta_{s}\right)=0
$$

Rewriting,

$$
(1-\alpha) q_{t}^{m}\left(u^{\prime}\left(q_{t}^{*}\right)\left(1-\theta_{s}\right)+\theta_{s}\right)=-\frac{z_{t}^{l} b_{t}^{l}\left(\theta_{l}-\theta_{s}\right)}{u^{\prime}\left(q_{t}^{m}\right)\left(1-\theta_{l}\right)+\theta_{l}}+\left(b_{t}^{s}+z_{t}^{l} b_{t}^{l}\right)\left(1-\theta_{s}\right)
$$

Rewriting bond prices from FOCs in terms of specialized goods, we get,

$$
\begin{gathered}
1=z_{t}^{s}=\frac{u^{\prime}\left(q_{t}^{m}\right)\left(1-\theta_{s}\right)+\theta_{s}}{u^{\prime}\left(q_{t}\right)} \\
z_{t}^{l}=\frac{u^{\prime}\left(q_{t}^{m}\right)\left(1-\theta_{l}\right)+\theta_{l}}{u^{\prime}\left(q_{t}\right)-\left(u^{\prime}\left(q_{t}\right)\left(1-\theta_{l}\right)+\theta_{l}\right)}
\end{gathered}
$$

From equation 4.12, gross inflation rate is,

$$
\frac{\phi_{t}}{\phi_{t+1}}=\beta u^{\prime}\left(q_{t}\right)
$$

Quantities of specialized goods consumed solve equations 4.20, 4.21, 4.22 and 4.23. Note that any government policies that leads to an increase in $b_{t}^{s}$ is not feasible in this case as the price of short-term bonds cannot be below 1. In the next section, we'll discuss the equilibrium under two different policy regime. 


\section{Away From Zero Lower Bound}

Now consider the case where $z_{t}^{s}<1$. Combining FOCs and writing in terms of specialized goods, we get,

$$
\begin{gathered}
\frac{\phi_{t}}{\phi_{t+1}}=\beta u^{\prime}\left(q_{t}\right) \\
(1-\alpha) q_{t}^{m}\left(u^{\prime}\left(q_{t}^{m}\right)\left(1-\theta_{s}\right)+\theta_{s}\right)=-\frac{z_{t}^{l} b_{t}^{l}\left(\theta_{l}-\theta_{s}\right)}{u^{\prime}\left(q_{t}^{m}\right)\left(1-\theta_{l}\right)+\theta_{l}}+\left(z_{t}^{s} b_{t}^{s}+z_{t}^{l} b_{t}^{l}\right)\left(1-\theta_{s}\right)
\end{gathered}
$$

And bond prices are given by,

$$
\begin{gathered}
z_{t}^{s}=\frac{u^{\prime}\left(q_{t}^{m}\right)\left(1-\theta_{s}\right)+\theta_{s}}{u^{\prime}\left(q_{t}\right)}<1 \\
z_{t}^{l}=\frac{u^{\prime}\left(q_{t}^{m}\right)\left(1-\theta_{l}\right)+\theta_{l}}{u^{\prime}\left(q_{t}\right)-\left(u^{\prime}\left(q_{t}\right)\left(1-\theta_{l}\right)+\theta_{l}\right)}
\end{gathered}
$$

Quantities of specialized goods consumed solve equations 4.24, 4.25, 4.26 and 4.27. Expressing solutions in terms of goods are useful to study how government policy affects the quantities consumed, and hence, welfare of the agents.

\subsection{Government Policy}

First, I adopt a standard approach in the new monetarist literature, which is to assume that the fiscal authority is passive in a sense that policies are driven by the monetary authority and the fiscal authority passively adjusts debt holdings and levies taxes that supports the monetary authority's policies. Later, I consider the case where fiscal authority is active.

\subsubsection{Passive Fiscal Policy}

In this case, monetary authority implements policy that allows them to change money growth rate, while fiscal authority passively changes taxes and stock of government bonds 
to support the paths of the nominal money stock. I call this regime Monetary Policy Regime. Suppose that the total stock of money grow at a rate $\mu$ and the ratio of money to total nominal debt is constant, i. e.,

$$
M_{t}=\delta\left(M_{t}+z_{t}^{s} B_{t}^{s}+z_{t}^{l} B_{t}^{l}\right)
$$

This implies that the central bank chooses money growth rate and fiscal authority passively issues government debt to satisfy the above equation. From the government budget constraint, equation 4.2, taxes are passively determined by,

$$
\begin{gathered}
\tau_{0}=\phi_{0}\left(M_{0}+z_{0}^{s} B_{t}^{0}+z_{0}^{l} B_{0}^{l}\right) \\
\tau_{t}=\phi_{t} M_{t}\left(\frac{1}{\delta}-\frac{1}{\mu}-\frac{R_{t}^{s}(1-\delta)}{\delta \mu}\right)-\phi_{t}\left(R_{t}^{l}-R_{t}^{s}\right) z_{t-1}^{l} B_{t-1}^{l}
\end{gathered}
$$

In order to define equilibrium, we assume that the nominal value of outstanding longmaturity debt is a constant $A$, i. e., $z_{t}^{l} B_{t}^{l}=A$. In equilibrium, market clearing conditions below hold.

$$
\begin{gathered}
\phi_{t} M_{t}=\alpha m_{t} \\
\phi_{t} B_{t}^{s}=b_{t}^{s} \\
\phi_{t} B_{t}^{l}=b_{t}^{l}
\end{gathered}
$$

Then, given a monetary policy $(\mu)$, an equilibrium under passive fiscal policy consist of real quantities of money $m_{t}$ and government bonds $b_{t}^{s}$, and a tax $\tau_{t}$, such that the following equations hold

$$
\frac{\phi_{t+1}}{\phi_{t}}=\frac{1}{\mu}
$$


From equation 4.24

$$
\beta u^{\prime}\left(q_{t}\right)=\mu
$$

Equation 4.25 then becomes,

$$
(1-\alpha) q_{t}^{m}\left(u^{\prime}\left(q_{t}^{m}\right)\left(1-\theta_{s}\right)+\theta_{s}\right)+\frac{A\left(\theta_{l}-\theta_{s}\right)}{u^{\prime}\left(q_{t}^{m}\right)\left(1-\theta_{l}\right)+\theta_{l}}=\left(\frac{\alpha(1-\delta) q_{t} u^{\prime}\left(q_{t}\right)}{\delta}\right)\left(1-\theta_{s}\right)
$$

Taxes solve,

$$
\tau_{t}=\frac{\alpha \mu q_{t}}{\beta}\left(\frac{1}{\delta}-\frac{1}{\mu}-\frac{R_{t}^{s}(1-\delta)}{\delta \mu}\right)-\left(R_{t}^{l}-R_{t}^{s}\right) A
$$

where rates of return on government bonds solve,

$$
\begin{aligned}
& R_{t+1}^{s}=\frac{\mu}{\beta\left(u^{\prime}\left(q_{t}^{m}\right)\left(1-\theta_{s}\right)+\theta_{s}\right)}-1 \\
& R_{t+1}^{l}=\frac{\mu}{\beta\left(u^{\prime}\left(q_{t}^{m}\right)\left(1-\theta_{l}\right)+\theta_{l}\right)}-1
\end{aligned}
$$

The nominal term premium is then given by,

$$
R_{t+1}^{l}-R_{t+1}^{s}=\frac{\mu\left(u^{\prime}\left(q_{t}^{m}\right)-1\right)\left(\theta_{l}-\theta_{s}\right)}{\beta\left(u^{\prime}\left(q_{t}^{m}\right)\left(1-\theta_{s}\right)+\theta_{s}\right)\left(u^{\prime}\left(q_{t}^{m}\right)\left(1-\theta_{l}\right)+\theta_{l}\right)}
$$

Existence of equilibrium requires $0<\delta<1$ and $\mu \geq \beta$, i. e., nominal interest rates are non-negative. Given A, the bank's incentive constraint in equation 4.25 describes a locus in $\left(q, q^{m}\right)$ space. Also, the zero lower bound in equation 4.21 describes another locus in $\left(q, q^{m}\right)$ space. Both of these loci are depicted in left panel of Figure 4.1 for stationary equilibrium. The zero lower bound implies that the central bank cannot implement a policy that results in allocation below ZLB curve. Also note that $z_{t}^{s}$ is strictly decreasing in $q^{m}$ and strictly increasing in $q$, hence each point on the IC curve is associated with a unique 
short-term nominal interest rate.

Choice of $\mathrm{A}$ is important for the existence of equilibrium because if $\mathrm{A}$ is sufficiently large, feasible equilibrium does not exist. We assume that $\mathrm{A}$ is reasonable enough that the equilibrium is feasible and there exists set of choices for monetary authority that achieves feasible allocations.

Also, A, i. e., $z_{t}^{l} b_{t}^{l}$ in Equation 4.36 implies that the equilibrium quantities are dependent on the maturity structure of government debt. Change in $\mu$ affects equilibrium quantities. To adjust for a change in $\mu$, fiscal authority could adjust either the short-maturity or the long-maturity bonds to keep $\delta$ constant. It is relevant which maturity bond adjusts as the IC curve depends not only on $\mu$, but also on A. Right panel of Figure 4.1 shows the equilibrium when long-maturity bonds are not held constant. Curves IC1 represents the IC locus associated with higher level of long-maturity debt for same $\delta$. Hence, maturity structure does matter for monetary policy. Also, the figure shows that higher level of long-maturity debt is associated with lower IC curve, hence it is not optimal to increase long-maturity debt to support increase in $\mu$. Williamson (2016) shows that it is optimal to not hold any long-maturity debt in equilibrium and the findings here supports his finding away from zero lower bound in monetary policy regime.

Monetary policy in this setting is to alter $\mu$ in the feasible range. Equation 4.35 implies that $q_{t}$ is decreasing in $\mu$. Hence, an increase in $\mu$ decreases $q_{t}$. Now, since $-q^{m} \frac{u^{\prime \prime}}{u^{\prime}}<1$, the LHS of the equation 4.36 is increasing in $q_{t}^{m}$. Also, since $q u^{\prime}(q)$ is increasing in $\mu$, the RHS of equation 4.36 is increasing in $\mu$. Hence, an increase in $\mu$ decreases $q_{t}$ but increases $q_{t}^{m}$. This change in monetary policy is depicted in Figure 4.2 by the shift in IC curve to the left. Hence, new equilibrium moves to a point in the new IC curve where $q_{t}$ is lower but $q_{t}^{m}$ is higher.

The intuition is as follows. When the central bank increases the money growth rate, the amount of goods a unit of money can buy is lower, i. e., the money is worth less 


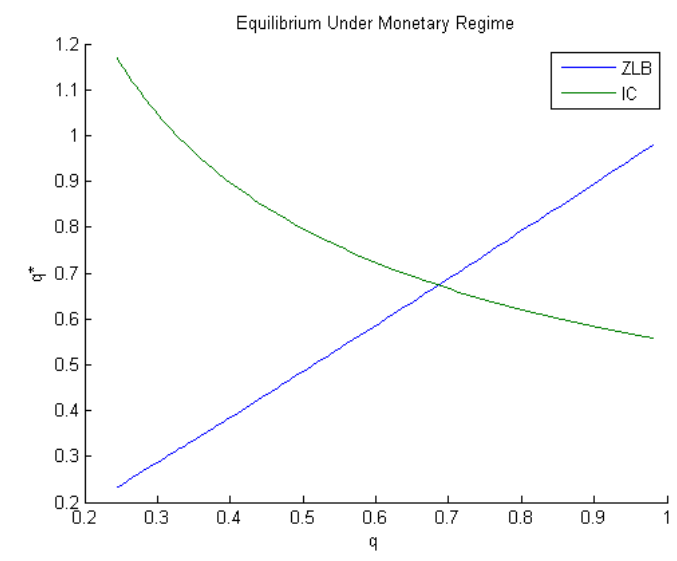

(a) Constant Nominal Value of Long-maturity Debt

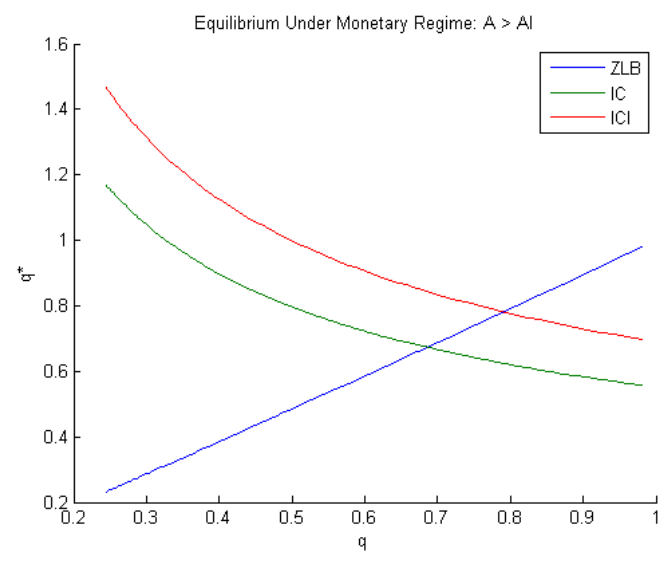

(b) Changing Long-maturity Debt

Figure 4.1: Equilibrium under Monetary Regime

than before. Hence, the price of the non-monitored good is higher and hence, the quantity consumed is lower. On the other hand, higher money growth means fiscal authority will have to increase the total nominal debt outstanding in order to keep money-to-debt ration, $\delta$, constant. Since, the bonds are scarce in the equilibrium, an increase in government bonds lead to higher amount of consumption in the monitored meetings as the agents have more assets to use as collateral. Whether the total welfare of agents improve with the government's action is indeterminate. If $(1-\alpha) u^{\prime}\left(q_{t}^{m}\right)>\alpha u^{\prime}\left(q_{t}\right)$, then increasing $\mu$ leads to higher total welfare. So in order to improve welfare, central bank can raise the money growth rate. Note that the nominal interest rates will then decline as the amount of bonds in the market will be higher. This can be an issue if the economy is facing zero lower bound on short-maturity bonds. Presence of long maturity bonds can be helpful in this scenario as the fiscal authority could issue more long-maturity bonds instead, a policy commonly known as Quantitative Easing (QE). This policy lowers the long-term interest rate, and hence, term premium, without affecting the short-term interest rate. Presence of long-maturity bonds presents the government with an additional policy tool where they can implement policies that changes long-maturity bond holdings instead of short-maturity bonds when short-term 
interest rate is constrained by zero lower bound. I show the relaxation of zero lower bound when long-maturity debt is used instead to support change in policy variable later in the text.

Note that a one time change in money growth rate changes the total money stock and nominal debt permanently as an increase in debt is necessary to keep $\delta$ constant. This changes the interest rates permanently and results in permanent change in consumption. In Figure 4.2, a one-time increase money growth rate shifts the IC curve permanently to the left. Hence, money is not neutral in this setting. Williamson (2016) finds similar non-neutrality of money in a similar setting with long-maturity government bonds. ${ }^{9}$ The difference here is that the shift in IC occurs even when short-maturity government debt holding is increased compared to Williamson (2016)'s setting where there is a shift in IC only when $\mathrm{QE}$ policy is implemented. The reason is that I allow the total government liability to increase irrelevant of whether short or long-maturity bonds increase, whereas Williamson (2016) does not.

\footnotetext{
${ }^{9}$ Similar setting refers to the channel system in Williamson (2016).
} 


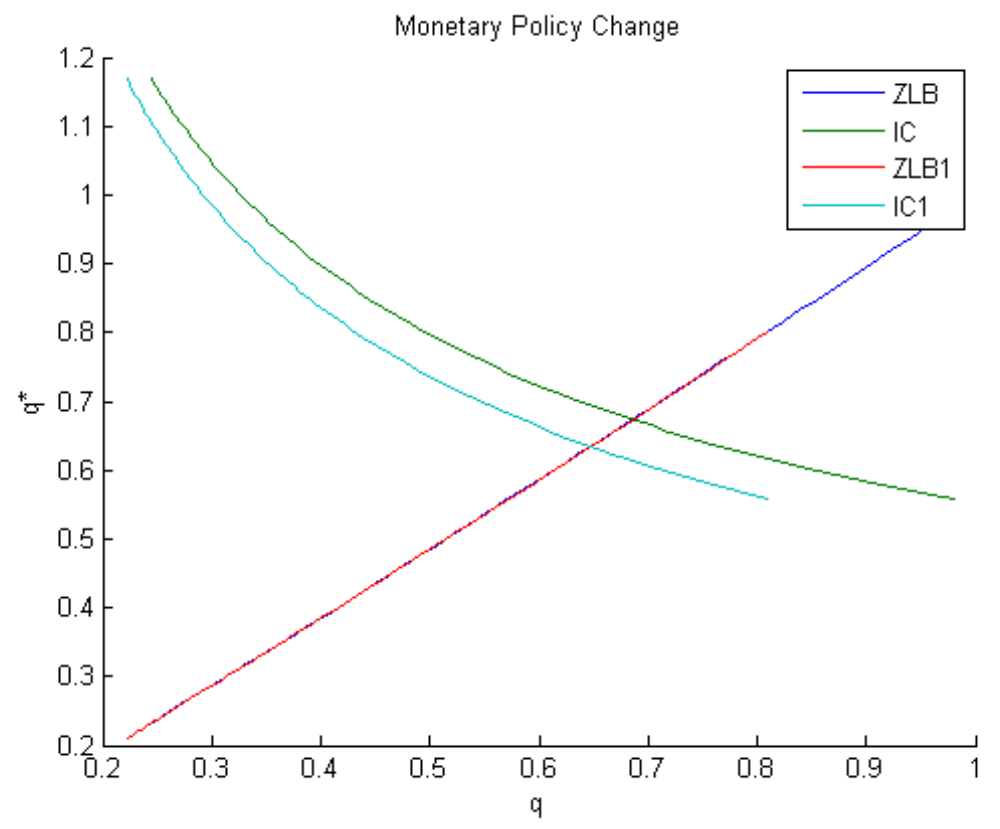

Figure 4.2: Equilibrium under Monetary Regime

\subsubsection{Active Fiscal Policy}

Fiscal theory of price level calls for a discretionary role for fiscal authority to stabilize debt using surprise changes in inflation and bond prices, as the expectations regarding fiscal policies are equally important as those of monetary policies in determining equilibrium prices and quantities. Hence in this section, I assume that the fiscal authority is active and monetary authority is passive. I call this Fiscal Policy Regime. Suppose that the fiscal authority changes the debt holdings and commits to levying taxes to balance the budget. Deficit is financed each period by issuing government debt and money. Also, assume that the monetary authority adjusts $\mu$ to satisfy equation 4.28 . This implies that $\mu$ cannot be set independently. Given $\delta$, last periods money holdings and fiscal authority's policy on nominal debt holdings, $\mu$ evolve passively as,

$$
\mu=\frac{\delta}{(1-\delta) M_{t-1}}\left(z_{t}^{s} B_{t}^{s}+z_{t}^{l} B_{t}^{l}\right)
$$


taxes are determined by,

$$
\begin{gathered}
\tau_{0}=\phi_{0}\left(M_{0}+z_{0}^{s} B_{t}^{0}+z_{0}^{l} B_{0}^{l}\right) \\
\tau_{t}=\phi_{t} M_{t}\left(\frac{1}{\delta}-\frac{1}{\mu}-\frac{R_{t}^{s}(1-\delta)}{\delta \mu}\right)-\phi_{t}\left(R_{t}^{l}-R_{t}^{s}\right) z_{t-1}^{l} B_{t-1}^{l}
\end{gathered}
$$

Given a fiscal policy $\left(B_{t}^{s}\right)$, an equilibrium under active fiscal policy consist of real quantities of money $m_{t}$ and a tax $\tau_{t}$, such that equations 4.34, 4.35, 4.25 (or equivalently, equation 4.36) hold, money growth rate evolve according to equation 4.41, interest rates are given by equations 4.38 and 4.39 . Taxes solve,

$$
\tau_{t}=\frac{\alpha \mu q_{t}}{\beta}\left(\frac{1}{\delta}-\frac{1}{\mu}-\frac{R_{t}^{s}(1-\delta)}{\delta \mu}\right)-\left(R_{t}^{l}-R_{t}^{s}\right) A
$$

Similar to the active monetary regime case, the bank's incentive constraint and zero lower bound describe loci in $\left(q, q^{m}\right)$ space. The stationary equilibria are depicted in Figure 4.3 for Fiscal Policy Regime. The zero lower bound implies that the fiscal authority cannot implement a policy that results in allocation below ZLB curve.

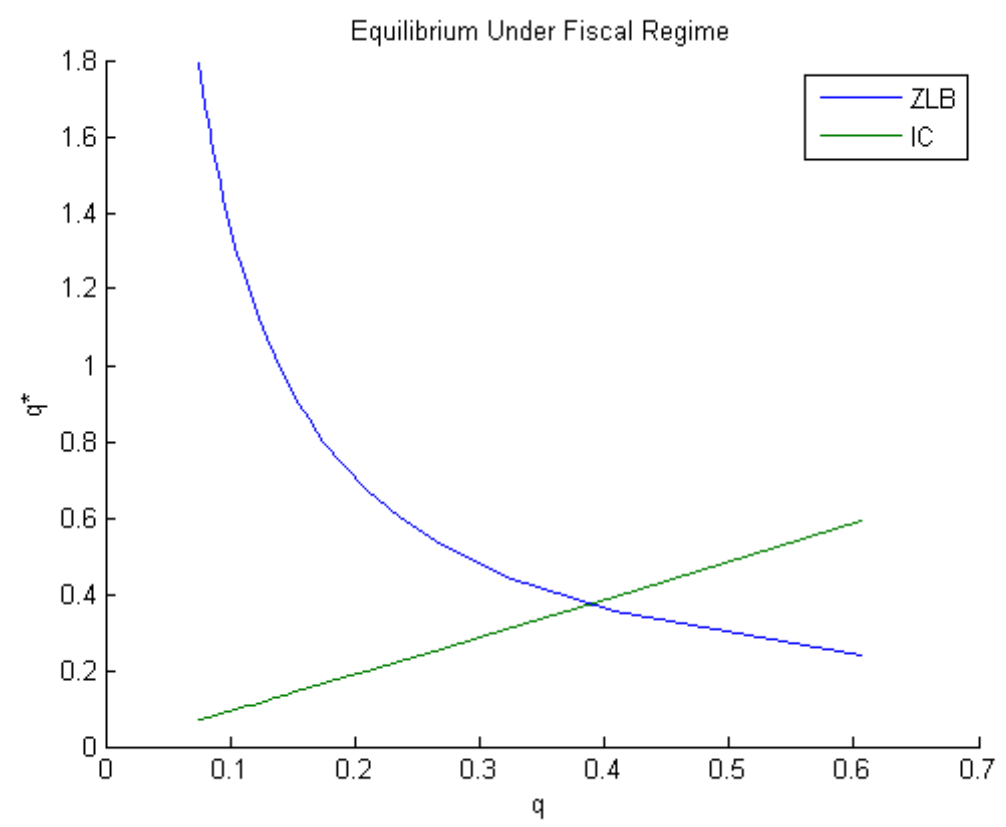

Figure 4.3: Equilibrium under Fiscal Regime 
Government policy is to alter $B_{t}^{s}$, assuming that $z_{t}^{l} B_{t}^{l}$ is still constant. Equivalently, fiscal authority instead alter taxes (or deficit) and allow debt holdings to adjust. This would achieve same results. Note that the nominal value of debt and money growth rate are nonlinear. In fact, they are non-monotonic. They decreasing initially when the quantity of debt issued is very small before increasing. We discuss this later in the section. For now, we focus on the case with sufficiently high value of initial debt. We analyze the impact of policy change numerically in Figure 4.4. An increase in $B_{t}^{s}$ does not shift either the IC curve or the ZLB curve. Change in equilibrium in this case is depicted by a movement along the curves. This is a major difference from the monetary policy regime. When fiscal authority increases $B_{t}^{s}$, there's a movement towards the left on the IC curve. Meaning, we move to a point with higher $q^{m}$ but a lower $q$.

The increase in non-monitored consumption is because of the fact that the bonds are scarce in the equilibrium and increase in supply of bonds implies more trading opportunities in monitored meetings. But since central bank has to increase money growth rate to keep $\delta$ constant, inflation rate will increase resulting on lower consumption in non-monitored meetings. So, any government intervention will help one group while hurting the other. This change is depicted in Figure 4.4 where the equilibrium moves to the left along the IC curve. Whether the total welfare of agents improve with the government's action is again indeterminate. If $(1-\alpha) u^{\prime}\left(q_{t}^{m}\right)>\alpha u^{\prime}\left(q_{t}\right)$, then increasing $B_{t}^{s}$ leads to higher total welfare. Note that the price of bonds cannot be lower than 1, so fiscal authority is constrained on how much short-maturity debt holdings they can increase. Again, presence of longmaturity bonds can help in this situation as fiscal authority can choose to issue more longmaturity bonds instead, effectively lowering the term premium without affecting the shortterm interest rate, when faced with zero lower bound on short-term interest rate. 


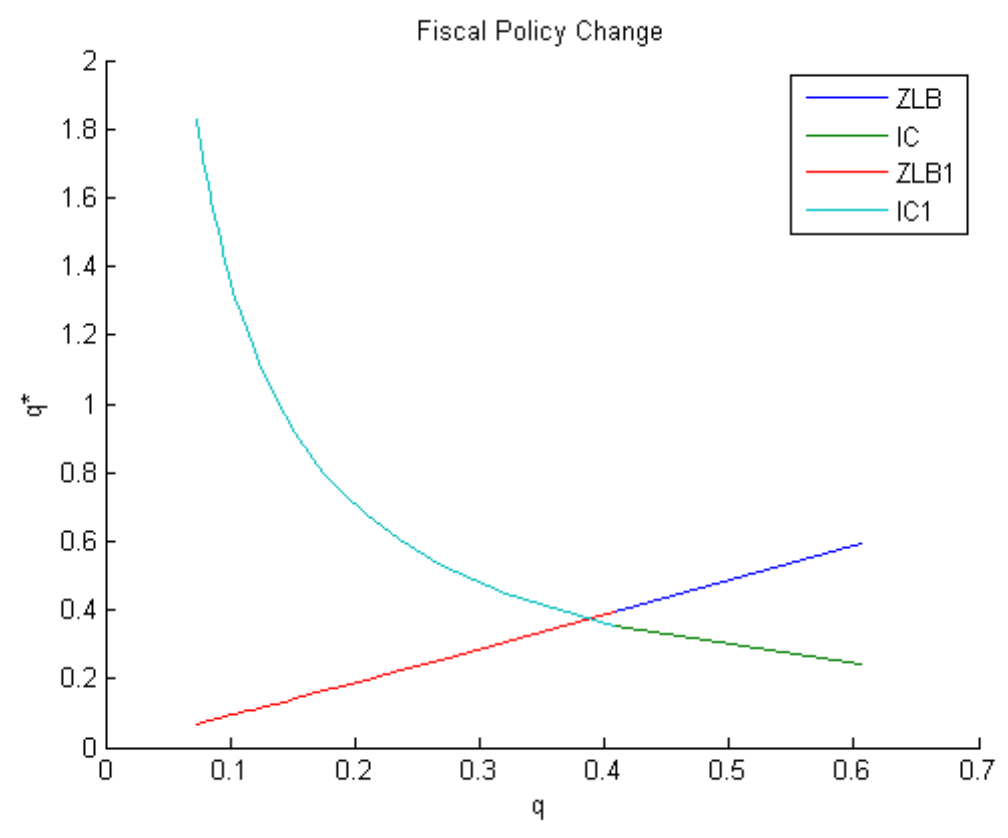

Figure 4.4: Equilibrium under Fiscal Regime

Alternatively, fiscal authority can alter long-maturity bonds instead. In this case, I fix the one-period bond holdings, $b_{t}^{s}$, and study the effect of an increase in long-maturity bond holdings, $B_{t}^{l}$. Figure 4.5 shows the effect of increasing $b_{t}^{l}$. The figure shows that there's a similar movement to the left in IC curve as in the case of changing $B_{t}^{s}$. It is not clear from the graph that whether changing long-maturity bonds leads to a lower zero lower bound compared to the policy of changing short maturity bonds, and whether the IC curves are different. Figure 4.6 graphs the IC curves from two policies, one with fixed long-maturity bonds and another with changing long-maturity bonds. ICs is the IC curve when the value of long-maturity debt is constant and ICl is the IC curve when it is allowed to change. Note that the shape of the IC curves are similar, however, for the same parameter values, allowing the long-maturity debt to change results in allocations towards the left part of the graph, which implies higher $q^{m}$ and lower $q$. If the assumption of $(1-\alpha) u^{\prime}\left(q_{t}^{m}\right)>\alpha u^{\prime}\left(q_{t}\right)$ true, then allowing long-maturity debt to change can result in allocations that yield high social welfare. This suggests that the maturity structure of the government debt matters. 
This finding lends support to the notion of the monetary effect of debt. Also, this finding differs from the monetary policy regime where increasing long-maturity debt would lead to lower social welfare.

Figure 4.7 compares the ZLBs under the two policies. Curve ZLBs is the ZLB under policy of changing short-maturity bonds and curve ZLBl is ZLB under policy of changing long-maturity bonds. The figure shows that the zero lower bound is lower in the case of the latter policy, and hence the policy expands the consumption opportunities. Hence, presence of long-maturity bonds aids fiscal authority to implement policies with more relaxed zero lower bound.

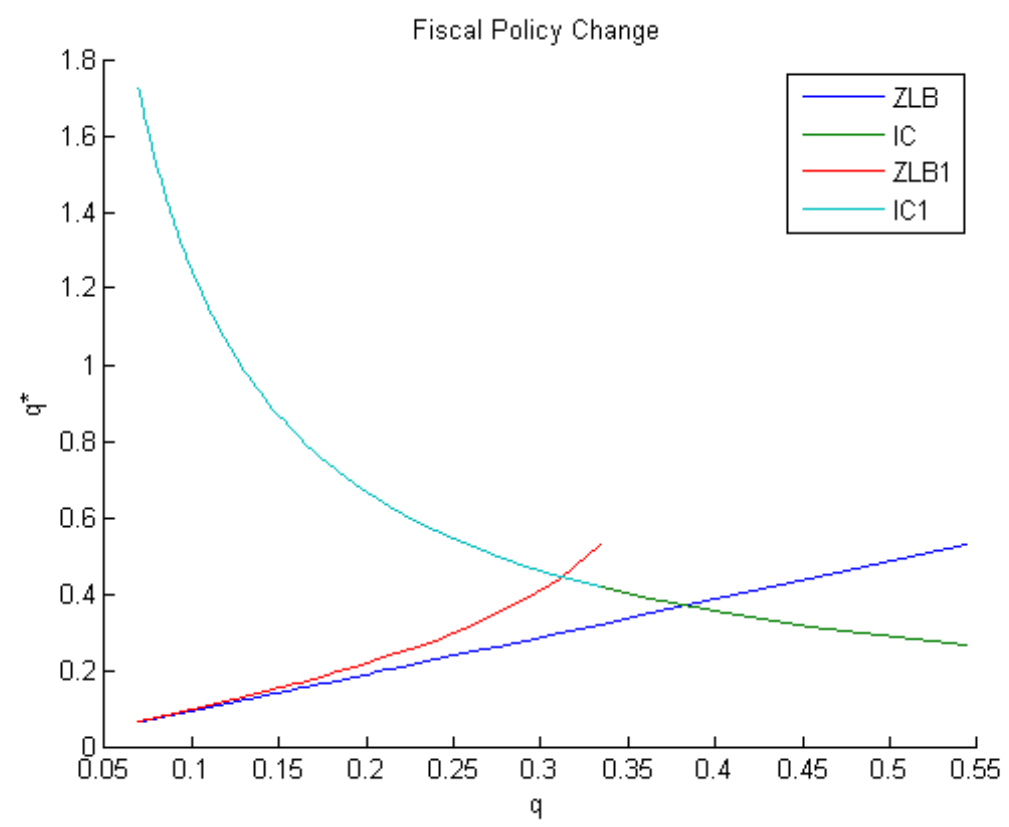

Figure 4.5: Equilibrium under Fiscal Regime 


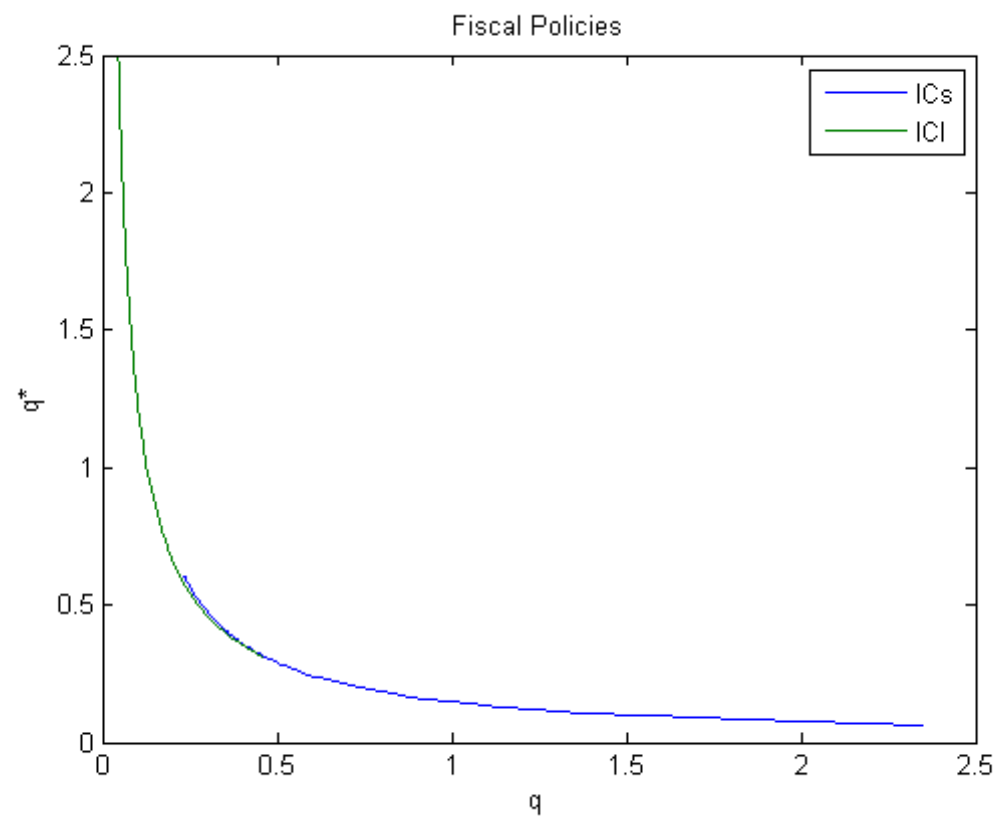

Figure 4.6: Equilibrium Under Fiscal Regime

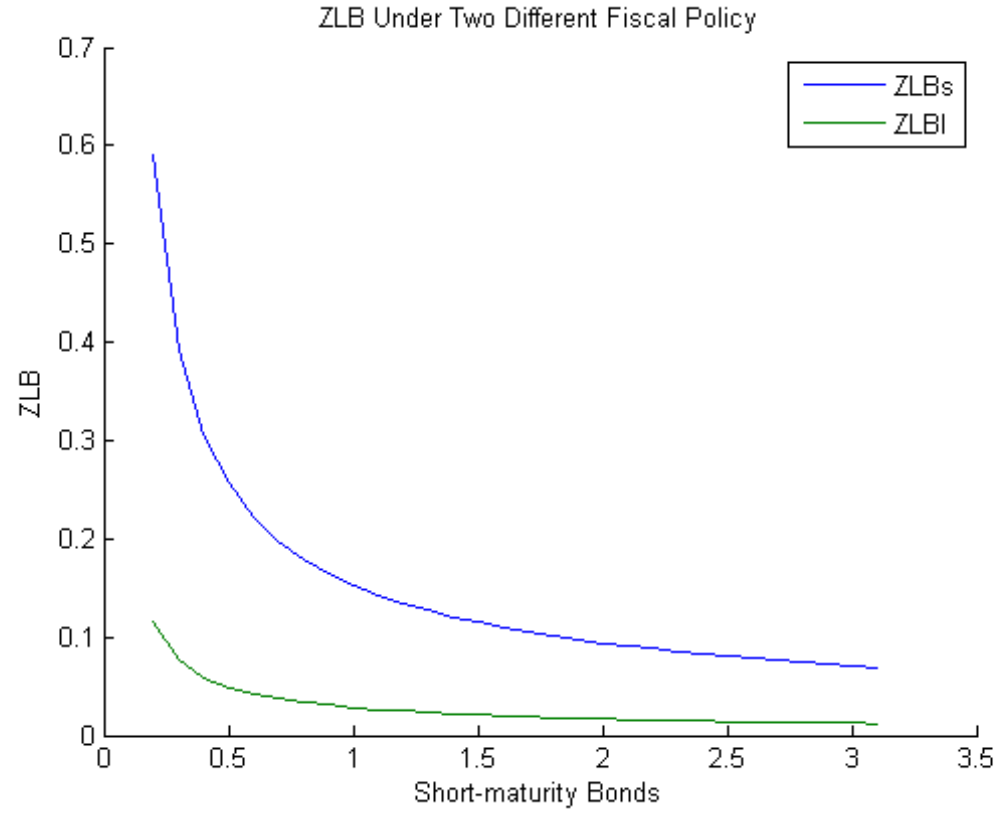

Figure 4.7: Zero Lower Bounds Under Fiscal Regime 


\subsubsection{Debt and Inflation}

Under Fiscal Regime, inflation is determined by the debt issuance policy of Fiscal authority. Rewriting Equation 4.41 using Equations 4.26 and 4.12, we get an expression for money growth rate given below.

$$
\mu=\frac{\delta}{(1-\delta) M_{t-1}}\left(\beta\left(\frac{u^{\prime}\left(q_{t}^{m}\right)\left(1-\theta_{s}\right)+\theta_{s}}{\mu}\right) B_{t}^{s}+A\right)
$$

Hence, $\mu$ is non-linear in $B^{s} .{ }^{10}$ Figure 4.8 shows the evolution of $\mu$ when Fiscal authority changes quantity of debt to the private sector. When the quantity of debt outstanding is very low, an issuance of debt by Fiscal authority reduces money growth rate. The money growth rate increases monotonously with an increase in debt when the initial quantity of debt is sufficiently large. This implies that an increase in quantity of debt when the initial debt holding is low results in increase in consumption in both monitored and non-monitored meetings. But when the initial debt holding is sufficiently large, an increase in debt will hurt agents in non-monitored meetings. The findings are consistent with the literature on Fiscal theory of inflation. In the absence of commitment, and increase in debt after certain level incentivizes government to inflate. Contrary to a common finding in studies on fiscal policies which calls for constant inflation rate, increasing money growth rate, and hence inflation, is welfare improving in this setting. ${ }^{11}$ Aruoba and Chugh (2010) in a setting where policy makers can commit to future policies and Martin (2011) in a setting under no commitment find that optimal policy is to implement positive inflation rate. The findings in this paper supports the finding. ${ }^{12}$

\footnotetext{
${ }^{10} \mathrm{WLOG}, \mathrm{I}$ look at the case with constant $z_{t}^{l} b_{t}^{l}$ only.

${ }^{11}$ This is true even when long-maturity debt is absent in this setting.

${ }^{12}$ This paper does not analyze optimal policies but the findings show that increasing inflation is welfare improving, hence Friedman rule cannot be optimal.
} 


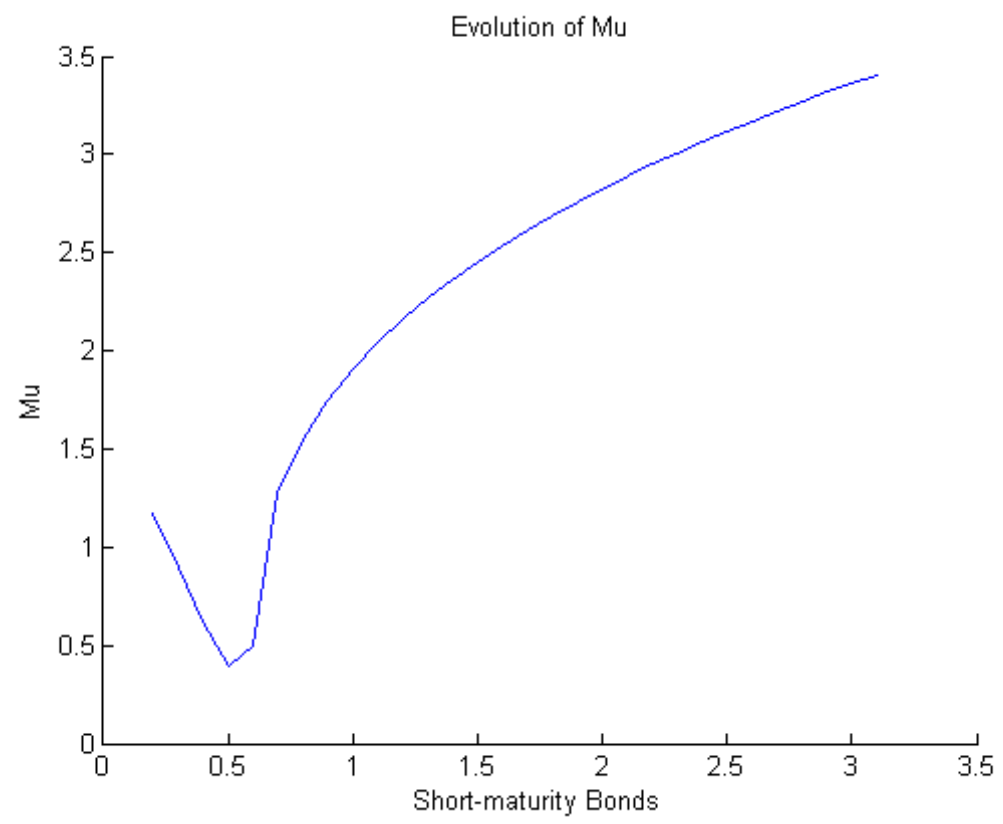

Figure 4.8: Evolution of Money Growth Rate

Studying equilibrium under different policy regimes is useful because it helps us understand how the policies affect the economy differently. Depending on which regime is active, the inflation dynamics can be different as shown in this section. Under monetary regime, inflation has monotonous effect in a sense that inflation reduces non-monitored trades monotonically while increasing monitored trades monotonically. On the other hand, under fiscal regime, changes in debt holdings drive the changes in quantities traded and there is a non-monotonous relationship between debt and inflation.

\subsection{Conclusion}

The purpose of this paper is to analyze fiscal and monetary policies in a micro-founded model that models real frictions that give rise to valued money. Incorporating long-maturity government bonds helps understand the role of maturity structure in different policy regimes (fiscal and monetary). The monetary effect of the debt can arise from the maturity structure 
which outlasts the direct effect over the maturity horizon of the debt. Changes in maturity structure impacts the size and composition of household wealth that can affect the macroeconomic dynamics even if the total size of the debt is constant. Moreover, having bonds of different maturity provides policy makers with flexibility to implement different policies that may be unconventional. Hence, it could lead to different outcome that may be welfare improving.

The model constructed in this paper provides insurance against liquidity needs in transaction. There is limited commitment and record-keeping, hence any credit based transaction must be collateralized with the government bonds. In order for term premium to exist, or the long-maturity bond to serve any social purpose, two conditions are neccessary. First, the pledgeability of the long-maturity bond must be lower than that of the short-maturity bond. Second, collateral must be scarce, i. e., the value of aggregate collateral (government bonds) is insufficient to support efficient credit-backed trades.

I study two different regimes, one where monetary authority is active and fiscal authority is passive (monetary policy regime), and one where monetary policy authority is passive and fiscal authority is active (fiscal policy regime). In both cases, presence of long-maturity bonds provides unconventional policy tools where policy makers can implement policies that involve long-maturity bonds instead of one-period bonds. This is useful because it allows the policy makers to change term premium without affecting short-term interest rate. It is particularly useful when the policy makers are faced with zero lower bound on short-term interest rate.

Policies that result in higher inflation, at a reasonable range, can be welfare improving in both regimes. The difference in two regimes is that the inflation evolves differently. Inflation evolves monotonously to policy changes in monetary policy regime, whereas it evolves non-monotonously in the fiscal policy regime. Also, the fiscal authority has an incentive to inflate when the initial level of debt is sufficiently high. Maturity structure 
of the government debt matter in both regime. However, monetary policy of increasing long-maturity government debt leads to lower welfare while the fiscal policy of issuing long-maturity debt can result in higher welfare.

Results reinforce the notion in fiscal theory of price level that fiscal policy can achieve desired inflation and output, and the notion of the monetary effect of the government debt. Result of relevance of maturity structure for monetary policy however is contrary to the results in studies that use reduced form models. Also, Friedman rule result in Ramsey models and in studies of fiscal theory is in contrast to the findings of the paper as moving away from Friedman rule is welfare improving when assets used as collaterals are scarce.

This paper represents a step towards understanding the fiscal and monetary policy when money is essential and the role of long-maturity government bonds. It would be useful to extend the analysis to study dynamics of moving from one stationary equilibrium to another. Additionally, it would be useful to study optimal policies under the two regimes as well as under a joint regime with and without ability to commit to the future policies. 


\section{Chapter 5}

\section{Conclusion}

In the dissertation, I present three essays in applied macroeconomics and monetary theory. First essay explores the existence of global financial cycles and examines the relationship between financial and macroeconomic sectors at a global scale. Second essay examines the role of decentralization on regional convergence using night-time satellite lights data as proxy for regional economic activities. Third essay analyzes active and passive fiscal and monetary policy regime in the presence of long and short-maturity government debt. I utilize the advances made in money search model to analyze the policy regimes.

First essay examines the time-varying linkages between the global financial and macroeconomic sectors. First, I examine the existence of global financial cycles. Second, I study if the financial sector is an important source of shocks for the global macroeconomic sector, and if there is time variation in the contribution of the financial shocks. I find evidence of quantitatively meaningful global cycles in credit and equity price. There is large degree of heterogeneity on the impact of the global factors across countries. The cycles are stronger in the years leading up to and following the crisis, including the house-price cycle. I do not find evidence of quantitatively meaningful joint global financial cycle encompassing all financial variables. I find that both the global and country-specific financial shocks 
matter in explaining fluctuations in the global cycles of macroeconomic variables. I also find evidence of time variation in the size and the transmission of the financial shocks, especially the equity-price and house-price shocks. There is evidence of increase in transmission of the financial shocks as well as increase in size of the shocks during financial crises, especially during the recent financial crisis. The contribution of the global and the US equity-price and house-price shocks increases significantly during the recent financial crisis.

Second essay attempts to understand how decentralization reform affects regional convergence using a global sample of countries. Proponents of decentralization argue that it improves economic growth by increasing government efficiency and accountability, while critics argue that it increases regional inequality as limited state capacity and weaker endowments in poorer regions inhibit their growth. The empirical evidence is mixed and is based mostly on developed countries, due to lack of sub-national level data. This chapter aims to fill that gap by analyzing the impact of decentralization on regional convergence using sub-national level data from a global sample of developed and developing countries. Iconstruct a panel of sub-national dataset from 1992 to 2013 by using intensity of nighttime lights captured by U.S. Air Force satellites to proxy for local economic performance. I combine lights data with a new database of fiscal, political, and administrative decentralization derived from actual laws that are institutionalized and circumscribed. The use of night-time lights data allows me to cover a large number of developing countries in my sample, which was not possible before. The use of the new decentralization data provides a broader measure of decentralization as it allows us to study a wide range of fiscal, political and administrative authority of sub-national regions. I study within-country as well as within first sub-national level convergence and find that decentralization hinders convergence. The impacts are larger for developing countries.

In third essay, I study monetary and fiscal policies in a setting where money is essential, 
and with private financial intermediaries that facilitate liquidity transformation. In this setting, there's a role for currency and secured credit in the trade for consumption goods due to limited commitment and memory. Government bonds of short (one-period) and long (perpetuity) maturities are present as alternative store of value in the analysis. The government bonds of all maturities serve as pledgeable assets to acquire credit. I study two distinct policy regimes. First, I study a policy regime in which monetary authority actively changes money growth rate while fiscal authority passively adjusts nominal debt holding to keep money-to-debt ratio constant. Taxes adjust passively as well to balance the budget. Second, I study a regime in which fiscal authority actively changes nominal debt holdings and monetary authority passively adjusts money growth rate to keep the money-to-debt ratio constant. Studying different policy regimes allows me to study how different policy changes affect individuals' consumption opportunities differently, as well as difference in determination and evolution of inflation.

I find that the pledgeability of the long-maturity bond must be lower than that of the short-maturity bond and the collateral must be scarce, i. e., the value of aggregate collateral (government bonds) is insufficient to support efficient credit-backed trades. In both fiscal and monetary policy regimes, presence of long-maturity bonds provides unconventional policy tools where policy makers can implement policies that involve long-maturity bonds instead of one-period bonds. This is useful because it allows the policy makers to change term premium without affecting short-term interest rate. It is particularly useful when the policy makers are faced with zero lower bound on short-term interest rate. Policies that result in higher inflation, at a reasonable range, can be welfare improving in both regimes. The difference in two regimes is that the inflation evolves differently. Inflation evolves monotonously to policy changes in monetary policy regime, whereas it evolves non-monotonously in the fiscal policy regime. Also, the fiscal authority has an incentive to inflate when the initial level of debt is sufficiently high. 
Results such as irrelevance of maturity structure for monetary policy away from zero lower bound reinforces the similar results in studies that use reduced form models. Friedman rule result in Ramsey models and in studies of fiscal theory however is in contrast to the findings of the paper as moving away from Friedman rule is welfare improving when assets used as collaterals are scarce. 


\section{Bibliography}

Angela Abbate, Sandra Eickmeier, Wolfgang Lemke, and Massimiliano Marcellino. The changing international transmission of financial shocks: evidence from a classical timevarying favar. Journal of Money, Credit and Banking, 48(4):573-601, 2016.

Tobias Adrian, Paolo Colla, and Hyun Song Shin. Which financial frictions? parsing the evidence from the financial crisis of 2007 to 2009. NBER Macroeconomics Annual, 27 (1):159-214, 2013.

Philippe Aghion, Peter Howitt, and David Mayer-Foulkes. The effect of financial development on convergence: Theory and evidence. The Quarterly Journal of Economics, 120 (1):173-222, 2005. doi: 10.1162/0033553053327515. URL http://qje.oxfordjournals. org/content/120/1/173.abstract.

Nobuo Akai and Masayo Sakata. Fiscal decentralization contributes to economic growth: Evidence from state-level cross-section data for the United States. Journal of Urban Economics, 52(1):93-108, 2002. ISSN 0094-1190. doi: 10.1016/S0094-1190(02)00018-9. URL http://www.sciencedirect.com/science/article/pii/S0094119002000189.

David Andolfatto. A note on the societal benefits of illiquid bonds. Canadian Journal of Economics/Revue canadienne d'économique, 44(1):133-147, 2011.

Calin Arcalean, Gerhard Glomm, Ioana Schiopu, and Jens Suedekum. Public budget composition, fiscal (de)centralization, and welfare. Canadian Journal of Economics/Revue canadienne d'économique, 43(3):832-859, 2010. doi: 10.1111/ j.1540-5982.2010.01597.x. URL https://onlinelibrary.wiley.com/doi/abs/10.1111/j. 1540-5982.2010.01597.x.

S Borağan Aruoba and Sanjay K Chugh. Optimal fiscal and monetary policy when money is essential. Journal of Economic Theory, 145(5):1618-1647, 2010.

Soumen Bagchi. Pricing and cost recovery of urban services: Issues in the context of decentralized urban governance in india. International Journal of Regulation and Governance, 3(2):103-134, 2003.

Pranab Bardhan. Decentralization of governance and development. The Journal of Economic Perspectives, 16(4):185-205, 2002. 
Pranab Bardhan and Dilip Mookherjee. Decentralizing antipoverty program delivery in developing countries. Journal of Public Economics, 89(4):675-704, April 2005. URL http://ideas.repec.org/a/eee/pubeco/v89y2005i4p675-704.html.

Thushyanthan Baskaran and Lars P. Feld. Fiscal decentralization and economic growth in oecd countries: Is there a relationship? Public Finance Review, 41(4):421-445, 2013. doi: 10.1177/1091142112463726. URL http://pfr.sagepub.com/content/41/4/421. abstract.

Aleksander Berentsen, Gabriele Camera, and Christopher Waller. Money, credit and banking. Journal of Economic theory, 135(1):171-195, 2007.

Ben S Bernanke, Mark Gertler, and Simon Gilchrist. The financial accelerator in a quantitative business cycle framework. Handbook of macroeconomics, 1:1341-1393, 1999.

R. Boadway and A. Shah. Intergovernmental Fiscal Transfers: Principles and Practice. The World Bank, Washington, DC, 2007.

R. W. Boadway. Public Sector Economics. Little, Brown, Boston, MA, 1982.

Robin Boadway and Frank Flatters. Efficiency and equalization payments in a federal system of government: A synthesis and extension of recent results. The Canadian Journal of Economics / Revue canadienne d'Economique, 15(4):613-633, 1982. ISSN 00084085, 15405982. URL http://www.jstor.org/stable/134918.

Robin Boadway, Katherine Cuff, and Maurice Marchand. Equalization and the decentralization of revenue-raising in a federation. Journal of Public Economic Theory, 5(2): 201-228, 2003. URL https://ideas.repec.org/p/cor/louvrp/1610.html.

Jaime Bonet. Fiscal decentralization and regional income disparities: Evidence from the colombian experience. The Annals of Regional Science, 40(3):661-676, 2006.

Claudio Borio. The financial cycle and macroeconomics: What have we learnt? Journal of Banking \& Finance, 45:182-198, 2014.

Shahid Javed Burki, Guillermo Perry, and William R Dillinger. Beyond the Center: Decentralizing the State. World Bank Publications, 1999.

Carlos Gil Canaleta, Pedro Pascual Arzoz, and Manuel Rapun Garate. Regional economic disparities and decentralisation. Urban Studies, 41(1):71-94, 2004. doi: 10.1080/0042098032000155696. URL https://doi.org/10.1080/0042098032000155696.

Charles T Carlstrom and Timothy S Fuerst. Agency costs, net worth, and business fluctuations: A computable general equilibrium analysis. The American Economic Review, pages 893-910, 1997. 
Karl E Case, John M Quigley, and Robert J Shiller. Comparing wealth effects: the stock market versus the housing market. Advances in macroeconomics, 5(1), 2005.

Karl E Case, John M Quigley, and Robert J Shiller. Wealth effects revisited 1978-2009. Technical report, National Bureau of Economic Research, 2011.

Ambrogio Cesa-Bianchi. Housing cycles and macroeconomic fluctuations: A global perspective. Journal of International Money and Finance, 37:215-238, 2013.

Ambrogio Cesa-Bianchi, Luis Felipe Cespedes, and Alessandro Rebucci. Global liquidity, house prices, and the macroeconomy: Evidence from advanced and emerging economies. Journal of Money, Credit and Banking, 47(S1):301-335, 2015.

Bruce Champ, Bruce D Smith, and Stephen D Williamson. Currency elasticity and banking panics: Theory and evidence. Canadian Journal of Economics, pages 828-864, 1996.

Natasha Xingyuan Che and Antonio Spilimbergo. Structural reforms and regional convergence. IMF Working Paper 12106, 2012.

Matteo Ciccarelli, Eva Ortega, and Maria Valderrama. Heterogeneity and cross-country spillovers in macroeconomic-financial linkages. 2012.

Stijn Claessens and Ayhan Kose. Asset prices and macroeconomic outcomes: a survey. BIS Working Paper No 676, 2017.

Stijn Claessens, M Ayhan Kose, and Marco E Terrones. What happens during recessions, crunches and busts? Economic Policy, 24(60):653-700, 2009.

Stijn Claessens, M Ayhan Kose, and Marco E Terrones. Financial cycles: what? how? when? 2010.

Stijn Claessens, Ayhan Kose, and Marco Terrones. How do business and financial cycles interact? Journal of International Economics, 87(1):178-190, 2012.

John H Cochrane. Long-term debt and optimal policy in the fiscal theory of the price level. Econometrica, 69(1):69-116, 2001.

Tim Cogley and Thomas Sargent. Drift and volatilities: monetary policies and outcomes in the post wwii u.s. Review of Economic Dynamics, 8(2):262-302, 2005.

Mario J Crucini, M Ayhan Kose, and Christopher Otrok. What are the driving forces of international business cycles? Review of Economic Dynamics, 14(1):156-175, 2011.

Troy Davig, Craig Hakkio, et al. What is the effect of financial stress on economic activity? Federal Reserve Bank of Kansas City, Economic Review, 95(2):35-62, 2010.

Hamid Davoodi and Heng-fu Zou. Fiscal decentralization and economic growth: A crosscountry study. Journal of Urban Economics, 43:244-257, 1998. 
M Del Negro and M Otrok. Dynamic factor models with time-varying parameters: measuring changes in international business cycles. University of Missouri, 2008.

Douglas W Diamond and Philip H Dybvig. Bank runs, deposit insurance, and liquidity. Journal of political economy, 91(3):401-419, 1983.

Dave Donaldson and Adam Storeygard. The view from above: Applications of satellite data in economics. Journal of Economic Perspectives, 30(4):171-98, November 2016. doi: 10.1257/jep.30.4.171. URL http://www.aeaweb.org/articles?id=10.1257/jep.30.4.171.

Robert D Ebel and Serdar Yilmaz. On the Measurement and Impact of Fiscal Decentralization, volume 2809. World Bank Publications, 2002.

Sandra Eickmeier and Tim Ng. How do credit supply shocks propagate internationally? a gvar approach. 2011.

Sandra Eickmeier, Wolfgang Lemke, and Massimiliano Giuseppe Marcellino. The changing international transmission of financial shocks: evidence from a classical time-varying favar. 2011.

Roberto Ezcurra and Pedro Pascual. Fiscal decentralization and regional disparities: Evidence from several european union countries. Environment and Planning A, 40(5): 1185-1201, 2008.

C. Simon Fan, Chen Lin, and Daniel Treisman. Political decentralization and corruption: Evidence from around the world. Journal of Public Economics, 93(12):14-34, 2009. ISSN 0047-2727. doi: 10.1016/j.jpubeco.2008.09.001. URL http://www.sciencedirect. com/science/article/pii/S0047272708001291.

Raymond Fisman and Roberta Gatti. Decentralization and corruption: Evidence across countries. Journal of Public Economics, 83(3):325-345, 2002. ISSN 0047-2727. doi: 10.1016/S0047-2727(00)00158-4. URL http://www.sciencedirect.com/science/article/ pii/S0047272700001584.

Luca Gambetti and Alberto Musso. Loan supply shocks and the business cycle. Journal of Applied Econometrics, 32(4):764-782, 2017.

C. Garman, S. Haggard, and E. Willis. Fiscal decentralization: A political theory with latin american cases. World Politics, 53(2):205-236, 2001.

John Geanakoplos. The leverage cycle. NBER macroeconomics annual, 24(1):1-66, 2010.

Norman Gemmell, Richard Kneller, and Ismael Sanz. Fiscal decentralization and economic growth: Spending versus revenue decentralization. Economic Inquiry, 51(4):1915-1931, 2013. ISSN 00952583. URL http://libproxy.tulane.edu: 2048/login?url=http://search.ebscohost.com/login.aspx?direct=true\&db=ecn\&AN= $1421220 \&$ site $=$ ehost-live $\&$ scope $=$ site . 
Mark Gertler, Peter Karadi, et al. Qe 1 vs. 2 vs. 3...: A framework for analyzing large-scale asset purchases as a monetary policy tool. international Journal of central Banking, 9 (1):5-53, 2013.

Luca Guerrieri and Matteo Iacoviello. Collateral constraints and macroeconomic asymmetries. Journal of Monetary Economics, 90:28-49, 2017.

Jongrim Ha, M Ayhan Kose, Christopher Otrok, and Eswar S Prasad. Global macrofinancial cycles and spillovers. In 18th Jacques Polak Annual Research Conference, International Monetary Fund, November, pages 2-3, 2017.

George W. Hammond and Mehmet S. Tosun. The impact of local decentralization on economic growth: Evidence from u.s. counties. Journal of Regional Science, 51(1): 47-64, 2011. doi: 10.1111/j.1467-9787.2010.00683.x. URL https://onlinelibrary.wiley. com/doi/abs/10.1111/j.1467-9787.2010.00683.x.

Jan Hatzius, Peter Hooper, Frederic S Mishkin, Kermit L Schoenholtz, and Mark W Watson. Financial conditions indexes: A fresh look after the financial crisis. Technical report, National Bureau of Economic Research, 2010.

Thomas Helbling, Raju Huidrom, M Ayhan Kose, and Christopher Otrok. Do credit shocks matter? a global perspective. European Economic Review, 55(3):340-353, 2011.

JV Henderson, A Storeygard, and DN Weil. Measuring economic growth from outer space. The American Economic Review, 102(2):994-1028, 2012.

Hal Hill. Globalization, inequality, and local-level dynamics: Indonesia and the philippines. Asian Economic Policy Review, 3(1):42-61, 2008.

Hideaki Hirata, M Ayhan Kose, Christopher Otrok, and Marco E Terrones. Global house price fluctuations: Synchronization and determinants. Technical report, National Bureau of Economic Research, 2012.

L. Hooghe, G. Marks, and A. H. Schakel. The Rise of Regional Authority: A Comparative Study of 42 Democracies. Routledge, New York, NY, 2010.

Liesbet Hooghe, Gary Marks, Arjan H Schakel, Sandra Chapman Osterkatz, Sara Niedzwiecki, and Sarah Shair-Rosenfield. Measuring Regional Authority: A Postfunctionalist Theory of Governance, volume 1. Oxford University Press, 2016.

K Hubrich and RJ Tetlow. Financial stress and economic dynamics: the transmission of crises. Journal of Monetary Economics, 70:100-115, 2015.

Matteo Iacoviello and Stefano Neri. Housing market spillovers: evidence from an estimated dsge model. American Economic Journal: Macroeconomics, 2(2):125-64, 2010. 
Òscar Jordà, Moritz Schularick, and Alan M Taylor. Macrofinancial history and the new business cycle facts. NBER Macroeconomics Annual, 31(1):213-263, 2017.

Breitung Jörg and Eickmeier Sandra. Analyzing international business and financial cycles using multi-level factor models: A comparison of alternative approaches. In Dynamic Factor Models, pages 177-214. Emerald Group Publishing Limited, 2016.

Alejandro Justiniano, Giorgio E Primiceri, and Andrea Tambalotti. Household leveraging and deleveraging. Review of Economic Dynamics, 18(1):3-20, 2015.

Sylvia Kaufmann and Maria Teresa Valderrama. The role of credit aggregates and asset prices in the transmission mechanism: A comparison between the euro area and the usa. The Manchester School, 78(4):345-377, 2010.

Nobuhiro Kiyotaki and John Moore. Credit cycles. Journal of political economy, 105(2): 211-248, 1997.

Narayana R Kocherlakota. Societal benefits of illiquid bonds. Journal of Economic Theory, 108(2):179-193, 2003.

Gary Koop and Dimitris Korobilis. A new index of financial conditions. European Economic Review, 71:101-116, 2014.

M Ayhan Kose, Christopher Otrok, and Charles H Whiteman. International business cycles: World, region, and country-specific factors. american economic review, 93(4):12161239, 2003.

M Ayhan Kose, Christopher Otrok, and Charles H Whiteman. Understanding the evolution of world business cycles. Journal of international Economics, 75(1):110-130, 2008.

M Ayhan Kose, Christopher Otrok, and Eswar Prasad. Global business cycles: convergence or decoupling? International Economic Review, 53(2):511-538, 2012.

Ricardo Lagos and Randall Wright. A unified framework for monetary theory and policy analysis. Journal of political Economy, 113(3):463-484, 2005.

Eric M Leeper and Campbell Leith. Understanding inflation as a joint monetary-fiscal phenomenon. Handbook of Macroeconomics, 2:2305-2415, 2016.

Eric M Leeper and Xuan Zhou. Inflation's role in optimal monetary-fiscal policy. Technical report, National Bureau of Economic Research, 2013.

Christian Lessmann. Fiscal decentralization and regional disparity: Evidence from crosssection and panel data. Environment and Planning A, 41(10):2455-2473, 2009. 
Christian Lessmann and Andre Seidel. Regional inequality, convergence, and its determinants - a view from outer space. European Economic Review, 92:110-132, 2017. ISSN 0014-2921. doi: 10.1016/j.euroecorev.2016.11.009. URL //www.sciencedirect. com/science/article/pii/S0014292116302215.

Yongzheng Liu, Jorge Martinez-Vazquez, and Alfred M. Wu. Fiscal decentralization, equalization, and intra-provincial inequality in china. International Tax and Public Finance, 24(2):248-281, Apr 2017. ISSN 1573-6970. doi: 10.1007/s10797-016-9416-1. URL https://doi.org/10.1007/s10797-016-9416-1.

David Lopez-Salido and Edward Nelson. Postwar financial crises and economic recoveries in the united states. Unpublished paper, May, 2010.

Fernando M Martin. On the joint determination of fiscal and monetary policy. Journal of Monetary Economics, 58(2):132-145, 2011.

Jorge Martinez-Vazquez, Santiago Lago-Peñas, and Agnese Sacchi. The Impact Of Fiscal Decentralization: A Survey. Journal of Economic Surveys, 31(4):1095-1129, September 2017. URL https://ideas.repec.org/a/bla/jecsur/v31y2017i4p1095-1129.html.

A. H. Meltzer and S. F. Richard. A rational theory of the size of government. Journal of Political Economy, 89(5):914-927, 1981.

Silvia Miranda-Agrippino and Hélene Rey. World asset markets and the global financial cycle. Technical report, National Bureau of Economic Research, 2015.

James M Nason and Ellis W Tallman. Business cycles and financial crises: The roles of credit supply and demand shocks. Macroeconomic Dynamics, 19(4):836-882, 2015.

Stephen Nickell. Biases in dynamic models with fixed effects. Econometrica, 49(6):14171426, 1981. ISSN 00129682, 14680262. URL http://www.jstor.org/stable/1911408.

Wallace E. Oates. Fiscal Decentralization and Economic Development. National Tax Journal, 46(2):237-43, June 1993. URL http://ideas.repec.org/a/ntj/journl/v46y1993ino. 2p237-43.html.

Esteban Prieto, Sandra Eickmeier, and Massimiliano Marcellino. Time variation in macrofinancial linkages. Journal of Applied Econometrics, 31(7):1215-1233, 2016.

Giorgio E Primiceri. Time varying structural vector autoregressions and monetary policy. The Review of Economic Studies, 72(3):821-852, 2005.

R. Prud'Homme. The dangers of decentralization. World Bank Research Observer, 10(2): 201-220, 1995.

D. T. Qian and B. R. Weingast. Federalism as a commitment to preserving market incentives. Journal of Economic Perspectives, 11(4):83-92, 1997. 
Danny Quah. Galton's fallacy and tests of the convergence hypothesis. The Scandinavian Journal of Economics, pages 427-443, 1993.

Danny T Quah. Empirics for growth and distribution: Stratification, polarization, and convergence clubs. Journal of Economic Growth, 2(1):27-59, 1997.

J. M. Quintana and M West. Time series analysis of compositional data. In J. M. Bernardo, M. H. DeGroot, D. V. Lindley, and A Smith, editors, Bayesian Statistics, volume 3. Oxford University Press, Oxford, 1988.

Andres Rodriguez-Pose and Roberto Ezcurra. Does decentralization matter for regional disparities? a cross-country analysis. Journal of Economic Geography, 10(5): 619-644, 2010. ISSN 14682702. URL http://libproxy.lib.ilstu.edu/login?url=http: //search.ebscohost.com/login.aspx?direct=true\&db=eoh\&AN=1136653\&site= ehost-live \&scope=site.

Stephanie Schmitt-Grohé and Martın Uribe. Optimal fiscal and monetary policy under imperfect competition. Journal of Macroeconomics, 26(2):183-209, 2004.

Christopher A Sims. Paper money. The American Economic Review, 103(2):563-584, 2013.

Russell S. Sobel, Nabamita Dutta, and Sanjukta Roy. Does fiscal decentralization result in a better business climate?. Applied Economics Letters, 20(1-3):84-91, 2013. ISSN 13504851. URL http://libproxy.tulane.edu:2048/login?url=http://search.ebscohost.com/ login.aspx direct $=$ true $\& \mathrm{db}=\mathrm{ecn} \& \mathrm{AN}=1360076 \&$ site $=$ ehost-live $\&$ scope $=$ site.

Jason Sorens. Does Fiscal Federalism Promote Regional Inequality? An Empirical Analysis of the OECD, 1980-2005. Regional Studies, 48(2):239-253, February 2014. URL http://ideas.repec.org/a/taf/regstd/v48y2014i2p239-253.html.

Jason P Sorens. Secession risk and fiscal federalism. Publius: The Journal of Federalism, 46(1):25-50, 2015.

E. Stein. Fiscal decentralization and government size in latin america. In K. Fukasaku and R. Hausmann, editors, Decentralization and Deficits in Latin America, IDB-OECD. Oxford University Press, Oxford, 1997.

James H Stock and Mark Watson. Dynamic factor models. Oxford handbook on economic forecasting, 2011.

James H Stock and Mark W Watson. Understanding changes in international business cycle dynamics. Journal of the European Economic Association, 3(5):968-1006, 2005.

James H Stock and Mark W Watson. Dynamic factor models, factor-augmented vector autoregressions, and structural vector autoregressions in macroeconomics. In Handbook of macroeconomics, volume 2, pages 415-525. Elsevier, 2016. 
Vito Tanzi. Fiscal federalism and decentralization: A review of some efficiency and macroeconomic aspects. In Paper Prepared for the World Bank's Annual Bank Conference on Development Economics. The World Bank, 1995.

C. Teibout. A pure theory of local expenditures. Journal of Political Economy, 64:416-424, 1956.

The World Bank. Decentralization: Rethinking government. World Development Report, 2000.

John Thornton. Fiscal decentralization and economic growth reconsidered. Journal of Urban Economics, 61(1):64-70, January 2007. URL http://ideas.repec.org/a/eee/juecon/ v61y2007i1p64-70.html.

James Tobin. An essay on the principles of debt management. Cowles Foundation for Research in Economics at Yale University, 1963.

William G. Watson. An estimate of the welfare gain from fiscal equalization. The Canadian Journal of Economics / Revue canadienne d'Economique, 19(2):298-308, 1986. ISSN 00084085, 15405982. URL http://www.jstor.org/stable/135286.

Barry R. Weingast. The economic role of political institutions: Market-preserving federalism and economic development. Journal of Law, Economics, \& Organization, 11(1): 1-31, 1995. ISSN 87566222, 14657341. URL http://www.jstor.org/stable/765068.

Stephen Williamson and Randall Wright. New monetarist economics: Models. In Handbook of Monetary Economics, volume 3, pages 25-96. Elsevier, 2010.

Stephen D Williamson. Liquidity, monetary policy, and the financial crisis: A new monetarist approach. The American Economic Review, 102(6):2570-2605, 2012.

Stephen D Williamson. Scarce collateral, the term premium, and quantitative easing. Journal of Economic Theory, 164:136-165, 2016.

Danyang Xie, Heng-fu Zou, and Hamid Davoodi. Fiscal Decentralization and Economic Growth in the United States. Journal of Urban Economics, 45(2):228-239, March 1999. URL http://ideas.repec.org/a/eee/juecon/v45y1999i2p228-239.html.

Tao Zhang and Heng-fu Zou. Fiscal decentralization, public spending, and economic growth in china. Journal of Public Economics, 67(2):221-240, February 1998. URL http://ideas.repec.org/a/eee/pubeco/v67y1998i2p221-240.html. 


\section{Appendix A}

\section{List of Countries Used in Chapter 2}

USA, Canada, Japan, Australia, UK, Belgium, Denmark, France, Germany, Italy, Netherlands, Norway, Sweden, Switzerland, Finland, Spain, Portugal 


\section{Appendix B}

\section{List of Countries Used in Chapter 3}

The following 69 countries are in my analysis

High Income: Argentina, Australia, Austria, Belgium, Canada, Chile, Croatia, Czech Republic, Denmark, Estonia, Finland, France, Germany, Greece, Hungary, Italy, Japan, Latvia, Lithuania, Netherlands, New Zealand, Norway, Poland, Portugal, Russia, Slovakia,

Slovenia, South Korea, Spain, Sweden, Switzerland, United Kingdom, United States, Uruguay, Venezuela

Upper Middle Income: Albania, Bosnia and Herzegovina, Botswana, Brazil, Bulgaria, Colombia, Costa Rica, Cuba, Dominican Republic, Ecuador, Malaysia, Mexico, Namibia, Panama, Paraguay, Peru, Romania, Serbia, South Africa, Thailand, Turkey

Lower Middle Income: Bolivia, El Salvador, Ghana, Guatemala, Honduras, Indonesia, Nicaragua, Philippines, Senegal, Zambia

Low Income: Haiti, Mali, Nepal 


\section{VITA}

I am a Ph.D. Candidate in Economics at the University of Missouri - Columbia. I started at the University of Missouri in fall 2014. I completed Bachelor of Science degree from University of Wisconsin - Superior in 2011 and Master of Arts degree fron Washington University in St. Louis in 2013. Prior to joining University of Missouri, I worked as a teacher in BASIS Flagstaff for a year. I have also worked as teaching assistant, research assistant, graduate instructor, tutor, mentor and office assistant over the years.

My research interests are monetary policy, applied macroeconomics and economic development. I am currently working on global financial cycles and macroeconomic linkages, role of decentralization on regional convergence, benefits of long-maturity bonds, and banking and liquidity in models with heterogeneous forecast. 